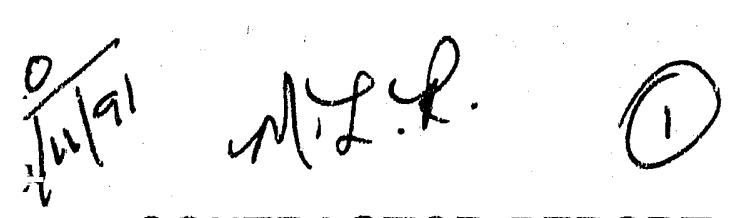

CONTRACTOR REPORT

SAND $90-7009$

Unlimited Release

UC -721

\title{
Consolidation, Permeability, and Strength of Crushed Salt/Bentonite Mixtures With Application to the WIPP
}

\section{Topical Report RSI-0357}

\section{Tom W. Pfeifle}

$\mathrm{RE} / \mathrm{SPEC}$ Inc.

PO Box 725

Rapid City, SD 57709

\footnotetext{
Irepared by Sandia National Laboratories Albuquerque, New Mexico 87185 and Livermore. California 94550 for the United States Department of Energy under Contract DE-ACD4-76DP00789
}

Printed January 1991 
Issued by Sandia National Laboratories, operated for the United States Department of Energy by Sandia Corporation.

NOTICE: This report was prepared as an account of work sponsored by an agency of the United States Government. Neither the United States Government nor any agency thereof, nor any of their employees, nor any of their contractors, subcontractors, or their employees, makes any warranty, express or implied, or assumes any iegal liability or responsibility for the accuracy, completeness, or usefulness of any information, apparatus, product, or process disclosed, or represents that its use would not infringe privately owned rights. Reference herein to any specific commercial product, process, or service by trade name, trademark, manufacturer, or otherwise, does not necessarily constitute or imply its endorsement, recommendation, or favoring hy the United States Government, any agency thereof or any of their contractors or subcontractors. The views and opinions expressed herein do not necessarily state or reflect those of the United States Government, any agency thereof or any of their contractors.

Printed in the United States of America. This report has been reproduced directly from the best available copy.

Available to DOE and DOE contractors from

Office of Scientific and Technical Information

PO Box 62

Clak Ridge, TN 37831

Prices available from (615) 576-8401, FTS 626-8401

Available to the public from

National Technical Information Service

US Department of Commerce

5285 Port Royal Rd

Springfield, VA 22161

NTIS price codes

Printed copy: A06

Microfiche copy: AO1 
SAND90-7009

Unlimited Release

Printed January 1991
SAND- $-90-7009$

DE91 007251

\title{
Consolidation, Permeability, and Strength of Crushed Salt/Bentonite Mixtures With Application to the WIPP
}

\author{
Tom W. Pfeifle \\ RE/SPEC Ine.
}

\begin{abstract}
Three tests were performed to measure the consolidation, permeability, and compressive strength of specimens prepared from bentonite/crushed salt mixtures. Each mixture comprised 30 percent bentonite and 70 percent crushed salt based on total dry weight. Brine was added to each mixture to adjust its water content to either 5 or 10 percent (nominal) of the total dry weight of the mixture. In the consolidation tests, each specimen was subjected to multiple stages of successively higher hydrostatic stress (pressure). During each stage, the pressure was maintained at a constant level and volumetric strain data were continuously logged. By using multiple stages, consolidation data were obtained at several pressures and the time required to consolidate the speciniens to full saturation was reduced. Once full saturation was achieved, each specimen was subjected to a final test stage in which the hydrostatic stress was reduced and a permeability test performed. Permeability was measured using the steady flow of brine and was found to range between $1 \times 10^{-17}$ and $5 \times 10^{-17} \mathrm{~m}^{2}$. After the final test stage, unconfined compressive strength was determined for each specimen and was found to range between 0.5 and 8.1 MPa. Two constitutive models were fitted to the consolidation data. One relatively simple model related volumetric strain to time while the other related instantaneous density to time, pressure, and initial density.
\end{abstract}

The content of this report was effective as of September 1989. This report was prepared by RE/SPEC Inc. under Contract 23-8484 with Sendia National Laboratories. 


\section{TABLE OF CONTENTS}

1.0 INTRODUCTION . . . . . . . . . . . . . . . . . . . . . . 1

1.1 BACKGROUND . . . . . . . . . . . . . . . . 1

1.2 APPROACH AND SCOPE $\ldots \ldots \ldots$. . . . . . . . . . 1

1.3 REPORT ORGANIZATION . . . . . . . . . . . . . 3

2.0 SPECIMENS . . . . . . . . . . . . . . . . . . 5

2.1 MATERIALS . . . . . . . . . . . . . . . . 5

2.2 PREPARATION . . . . . . . . . . . . . . . . . . . 7

2.2.1 Sample . . . . . . . . . . . . . . . . 7

2.2.2 Specimen . . . . . . . . . . . . . . . . 7

2.3 POST-TEST DISPOSITION . . . . . . . . . . . . . . . 9

3.0 TEST APPARATUS . . . . . . . . . . . . . . . . . . . 11

3.1 CONSOLIDATION . . . . . . . . . . . . . 11

3.1.1 Load Frame . . . . . . . . . . . . . . . . . . . . . 11

3.1.2 Instrumentation . . . . . . . . . . . . . . 11

3.1.3 Control . . . . . . . . . . . . . . . . . . . . . 13

3.2 PERMEABILITY . . . . . . . . . . . . . . . . . . . 13

3.3 STRENGTH . . . . . . . . . . . . . . . . . . . . 13

3.3.1 Load Frame . . . . . . . . . . . . . . . . . . . 13

3.3.2 Instrumentation and Control . . . . . . . . . . . . 16

3.4 CALIBRATION . . . . . . . . . . . . . . . 16

4.0 TEST PROCEDURES . . . . . . . . . . . . . . . . . . . 17

4.1 DENSITY . . . . . . . . . . . . . . . . . 17

4.2 CONDITIONING . . . . . . . . . . . . . . . 18

4.3 CONSOLIDATION . . . . . . . . . . . . . . . . 18

4.4 PERMEABILITY . . . . . . . . . . . . . . . . . . . 19

4.5 STRENGTH . . . . . . . . . . . . . . . 20

4.6 WATER DISTRIBUTION . . . . . . . . . . . . . . . 21 
5.0 TEST RESULTS . . . . . . . . . . . . . . . . . . . 23

5.1 CONSOLIDATION . . . . . . . . . . . 23

5.1.1 Volumetric Strain . . . . . . . . . . . . . . 23

5.1 .2 Density . . . . . . . . . . . . . . . . . . 27

5.2 PERMEABILITY . . . . . . . . . . . . . . . . 27

5.3 STRENGTH . . . . . . . . . . . . . . . . . 32

5.4 WATER CONTENT DISTRIBUTION ......... 33

6.0 MODEL FITTING . . . . . . . . . . . . . . . . . . . . . 37

6.1 LOG(t) MODEL . . . . . . . . . . . . . . . . . . . 37

6.2 DENSITY MODEL . . . . . . . . . . . . . . . . . 40

7.0 SUMMARY AND CONCLUSIONS . . . . . . . . . . 43

8.0 REFERENCES . . . . . . . . . . . . . . . . . 45

APPENDIX A. SUPPORTING DATA FOR CS1 . . . . . . . 47

APPENDIX B. SUPPORTING DATA FOR CS4 . . . . . . . 63

APPENDIX C, SUPPORTING DATA FOR CS3 . . . . . . 75 


\section{LIST OF TABLES}

1-1 Consolidation Test Conditions . . . . . . . . . . . . . . 2

2.1 Specimen Identification Numbers . . . . . . . . . . . . . 9

3-1 Calibration Results $(a)$. . . . . . . . . . . . . . . . 16

5-1 Summary of Creep Consolidation Tests . . . . . . . . . . . . . 28

5-2 Summary of Permeabilities and Strength . . . . . . . . . . . . . 33

5-3 Water Content Distribution . . . . . . . . . . . . . . . 36

6-1 Parameter Values for Volumetric Strain Model . . . . . . . . . . 38

6-2 Parameter Values for Density Model . . . . . . . . . . . . . . . 42 


\section{LIST OF FIGURES}

2-1 Grain Size Distribution Curves for WIPP Crushed Salt. . . . . . . 6

2-2 Jacketed Specimen. . . . . . . . . . . . . . . . . 8

3-1 Consolidation Machine Load Frame. . . . . . . . . . . . . . . . 12

3-2 Schematic of Brine Permeability Test Apparatus. . . . . . . . . . 14

3-3 Schematic of Four-Column Load Frame. . . . . . . . . . . . . . 15

5-1 Total Volumetric Strain as a Function of Time for CS1. . . . . . . 24

5-2 Total Volumetric Strain as a Function of Time for CS4. . . . . . . 25

5-3 Total Volumetric Strain as a Function of Time for CS3. . . . . . . 26

5-7 Axial Force-Displacement for Unconfined Compression Tests of WIPP Crushed Salt/Bentonite. . . . . . . . . . . . . . . . . 34 


\subsection{INTRODUCTION}

\subsection{BACKGROUND}

Crushed salt, mixed with bentonite to reduce permeability and to absorb radionuclides, is a primary candidate backfill material considered for use in the Waste Isolation Pilot Plant (WIPP) storage and access rooms. Crushed salt will be produced in large volumes during mining of the access and storage rooms and is compatible with the host rock. The permeability of the backfill is important because transport of soluble radionuclides by brine flow is of primary interest in determining the performance of the repository. Backfill permeability will likely decrease with time as the backfill consolidates under the load produced by the deformation of the surrounding intact host rock, as pore space is reduced and isolated, and as surface grain contacts are strengthened. Therefore, the mechanics of backfill consolidation and the variables that influence consolidation are of interest because of their expected relationship to permeability.

\subsection{APPROACH AND SCOPE}

Three consolidation tests were conducted under hydrostatic stresses between 3.45 and $14.0 \mathrm{MPa}$ at a temperature of $25^{\circ} \mathrm{C}$ using apparatus and specimens similar to those used by Holcomb and Hannum [1982], Pfeifle and Senseny [1985], and Stroup and Senseny [1987) to evaluate the influence of moisture on consolidation rate, permeability, and compressive strength of crushed salt/bentonite backfill. Volumetric strain was measured continuously during the consolidation phase of the tests to provide a complete history of consolidation.

The specimens used in the tests were prepared from watch samples of 70 percent crushed salt and 30 percent bentonite by dry weight. Brine was added to the batch samples to adjust the nominal water content to 5 or 10 percent of the total dry weight; i.e., the weight of water was subtracted from the total weight of the specimen. The equivalent nominal water content based on the total specimen weight (i.e., the weight of crushed salt, bentonite, and water) is then either 4.8 or 9.1 percent, respectively. Density was determined from the specimen mass and volume. The specimen volume was determined using a fluid displacement technique.

The conditions imposed during the tests were selected by Sandia National Laboratories Experimental Division, Albuquerque, New Mexico, as the tests proceeded. The objectives of the tests were (1) to measure the time-dependent consolidation of specimens at selected water contents; (2) to determine permeability of each specimen using the steady flow of brine technique once saturation was achieved; and (3) to estimate the strength of each consolidated specimen. To achieve these objectives, multiple stages of successively higher pressures were imposed during each test to acquire volumetric strain-time data at several pressures and also to reduce 
the overall time required to reach saturation by accelerating the rate of consolidation. Table 1-1 lists the prescribed conditions for each consolidation stage of the three tests. Once full saturation was achieved, each specimen was subjected to a final stage in which the hydrostatic stress was reduced and a permeability test performed. Table 1-1 also shows the condition for this stage. After the final stage, the unconfined compressive strength of each specirnen was determined by loading the specirnen in stroke (displacement) control at a constant rate $\left(0.002 \mathrm{~mm} \cdot \mathrm{s}^{-1}\right)$. The water content profile parallel to the specimen axis was then determined by sectioning the specimen at eight locations normal to its axis and performing water content determinations on the samples obtained.

Table 1-1. Consolidation Test Conditions

\begin{tabular}{|c|c|c|c|c|}
\hline \multirow{2}{*}{$\begin{array}{l}\text { Test } \\
\text { No. }\end{array}$} & \multicolumn{2}{|c|}{$\begin{array}{l}\text { Water } \\
\text { Content }\end{array}$} & \multirow{2}{*}{ Stage } & \multirow{2}{*}{$\begin{array}{l}\text { Hydrostatic } \\
\text { Stress } \\
\text { (MPa) }\end{array}$} \\
\hline & $\underset{\text { Wt. }^{(a)}(\%)}{\text { Dry }}$ & $\begin{array}{c}\text { Total } \\
\mathrm{wt}^{(b)}(\%)\end{array}$ & & \\
\hline \multirow{4}{*}{$\begin{array}{c}1 \\
(\mathrm{CS} 1)\end{array}$} & 5.30 & 5.03 & 1 & 3.45 \\
\hline & & & 2 & 7.00 \\
\hline & & & 3 & 14.00 \\
\hline & & & 4 & $7.00^{(c)}$ \\
\hline \multirow{3}{*}{$\begin{array}{c}2 \\
(\mathrm{CS} 4)\end{array}$} & 5.24 & 4.98 & 1 & 3.45 \\
\hline & . & & 2 & 14.00 \\
\hline & & & 3 & $0.50^{(c)}$ \\
\hline \multirow{4}{*}{$\begin{array}{c}3 \\
(\mathrm{CS} 3)\end{array}$} & 9.97 & 9.07 & 1 & 3.45 \\
\hline & & & 2 & 7.00 \\
\hline & & & 3 & 7.00 \\
\hline & & & 4 & $0.50^{(0)}$ \\
\hline
\end{tabular}

(a) Defined as the ratio expressed as a percentage of the weight (mass) of water in a given material to the weight (mass) of solid material particles.

(b) Defined as the ratio expressed as a percentage of the weight (mass) of water in a given material to the total weight (mass) of all materials including liquids and solids.

(c) Permeability test. 


\subsection{REPORT ORGANIZATION}

In addition to this introduction, the report comprises six chapters. Chapter 2 describes the specimens tested, and Chapter 3 describes the testing apparatus. Chapter 4 gives the test procedures, is followed by Chapter 5 which gives the test results, and Chapter 6 which gives model fitting parameters. The final chapter contains the conclusions. A list of cited references and three appendices conclude the report. 


\subsection{SPECIMENS}

\subsection{MATERIALS}

Two materials were combined to produce batch samples that were then used to prepare the individual test specimens. The samples comprised 70 percent by dry weight crushed salt and 30 percent by dry weight bentonite. After the materials were mixed, saturated brine was added to the samples to produce nominal water contents of from 5 to 10 percent of the total dry sample weight or 4.8 to 9.1 percent of the total sample weight (i.e., crushed salt, bentonite, and water).

The crushed salt used in the samples was provided by Sandia National Laboratories and was produced by a continuous miner during development of the WIPP test facility. The mine-run salt contains particles that range in size up to several centimeters and has the grain-size distribution shown in Figure 2-1.' Because the test specimens have a nominal diameter of only $100 \mathrm{~mm}$, the mine-run salt was sieved to remove particles larger than $9.5 \mathrm{~mm}$ to produce a specimen-diameter-tomaximum-particle-size diameter ratio of about 10. The larger particles were crushed using a flour mill and then returned to the sampies to ensure that impurities found only in the larger grains of the salt are preserved in each sample. The grain size distribution sbtained after crushing is also shown in Figure 2-1. The water content of the crushed salt was $0.24 \pm 0.03$ percent by dry weight as determined from three $1,00-\mathrm{g}$ samples dried for 2 days at $110^{\circ} \mathrm{C}$. This water content does not represent the as-mined water content because no special measures have been taken to preserve the water content either in shipping or during storage. Published values for the density of salt solids range from 1,900 to $2,200 \mathrm{~kg} \cdot \mathrm{m}^{-3}$. For this study, the assumed solid density of the salt is $2,120 \mathrm{~kg} \cdot \mathrm{m}^{-3}$.

The bentonite used in the samples was a granular MX-80 Volclay bentonite commercially available from the American Colloid Company of Belle Fourche, South Dakota, and is described in greater detail elsewhere [Pfeifle, 1986]. This product is identical to the material used in the backfill studies at the WIPP. The as-received water content $n$ f the bentonite was $8.71 \pm 0.40$ percent by dry weight as determined from the method described above. The assumed solid density of the bentonite is $2,700 \mathrm{~kg} \cdot \mathrm{m}^{-3}$.

The brine used to adjust the water content of the samples was a WIPP saltsaturated brine. The brine was prepared by adding crushed mine-run salt from the WIPP to a container of distilled water. Salt was added to the water, and the solution stirred until salt precipitated out of solution. The brine comprises 69 percent by weight of water and 31 percent by weight dissolved solids. 


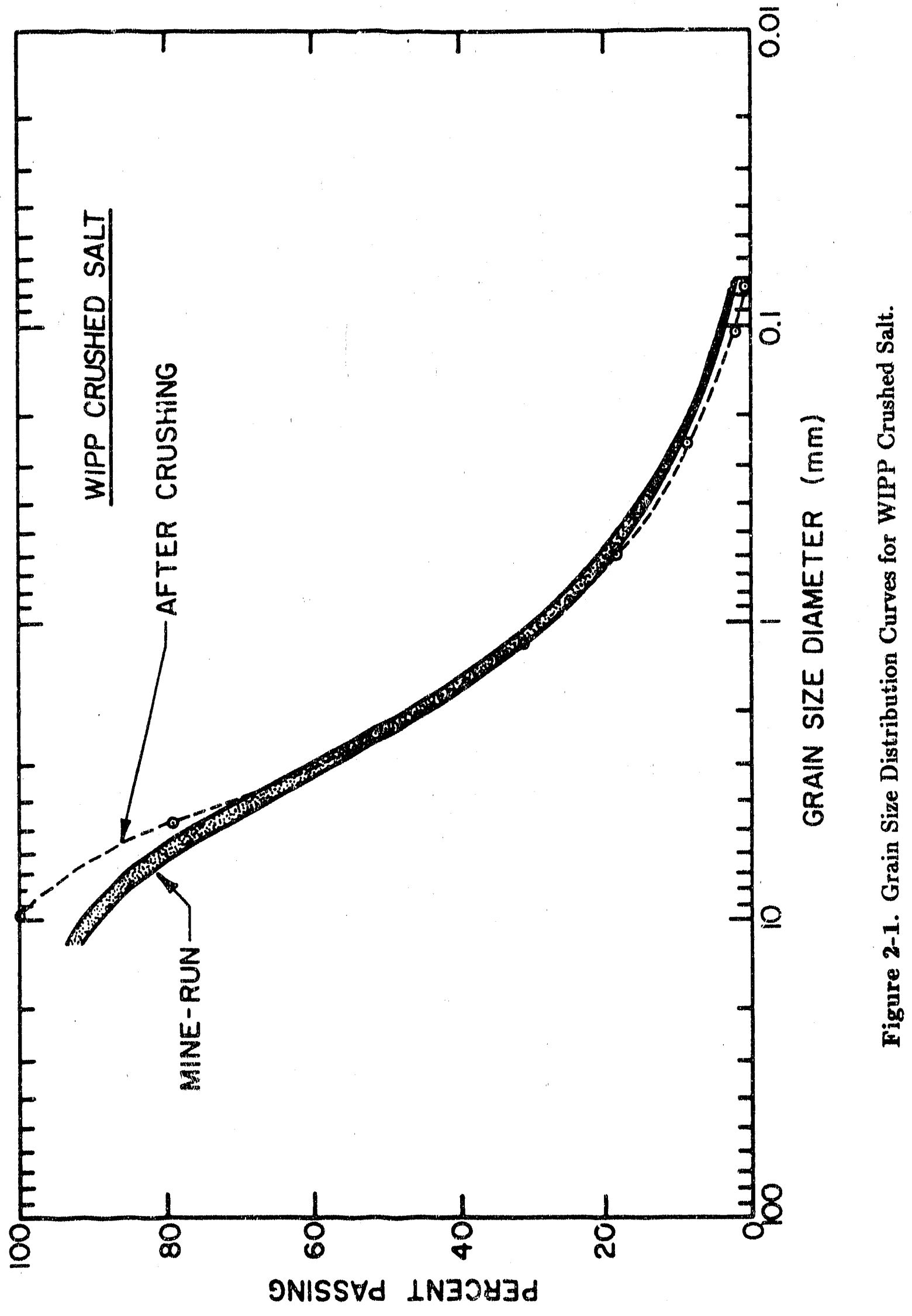




\subsection{PREPARATION}

\subsubsection{Sample}

Three separate sample batches comprising crushed salt, bentonite, and brine were prepared for use in fabricating the three test specimens used in this study. Shortly before each specimen was to be fabricated, a sample batch was prepared by first mixing the proper predetermined masss of "as-received" crushed salt and beisionite in large that container and then adding the correct raass of brine to the mixfure to yield the nominal water content ior the test. The description "asreceived" denotes materials that contsin both solids and some initia amou 2 t of water as described previously in Section 2.1. The mass of brine added to the mixture was adjusted to compensute for both the initial water content of the "asrecaived" materials and the water-to-dissolved solids ratio of the brine. This method produced sample batches comprising 70 percent by dry weight of crushed salt and 30 percent by dry weight of bentonite and yielded a ry mass of $3,000 \mathrm{~g}$ for each of the three sample batches. The theoretical solid density of the batches was 2,266 $\mathbf{k g} \cdot \mathrm{m}^{-\mathrm{s}}$.

The total or wet masses (including solids and water) among the sample batches varied depending on the nominal water content and, in all cases, exceeded the dry batch mass of $3,000 \mathrm{~g}$. Although the wet mass of the sample batches exceeded $3,000 \mathrm{~g}$, only approximately $2,500 \mathrm{~g}$ (wet) were required to fabricate each specimen. The larger sample batch provided sufficient material to determine the act'ral water content of each batch. Three water content determinations were made for each batch after the materials had been mixed thoroughly and before the specirnens were fabricated. These -eterminations were made using the procedure described previously and were averaged to provide the water content values shown in Table 1-1. The remainder of each sample batch was weighed and then temporarily stored in sealed containers to prevent moisture lass before the test specimens were fabricated. All mass deterninations were made using a Sartorius balance having a resolution of $0.01 \mathrm{~g}$.

\subsubsection{Specimem}

Specirnens were constructed as shown in Figure 2-2 using a 1.6-rnm-thick lead inner jacket to protect the outer Viton jacket, used to seal against the confining pressure oil. Scotchbrite was placed between each platen and the specimen to provide a high-permeability interface between the platen with its centrsl pore-fluid vent and the test specimen. Scotchbrite is a tradename for 3M's nylon-web pad impregnated with aluminum oxide and is used in industry as a cleaning and deburring pad for metals and ceramics. The cylindrical volume created by the jackets and platens was filled with the proper batch sample using five equal layers earh tamped lightly with a 3-mm-diameter rod to remove any trapped air voids. When the space was filled, the wet mass of the specimen was determined indirectly by weighing the amount 
RSI-078-84-10A

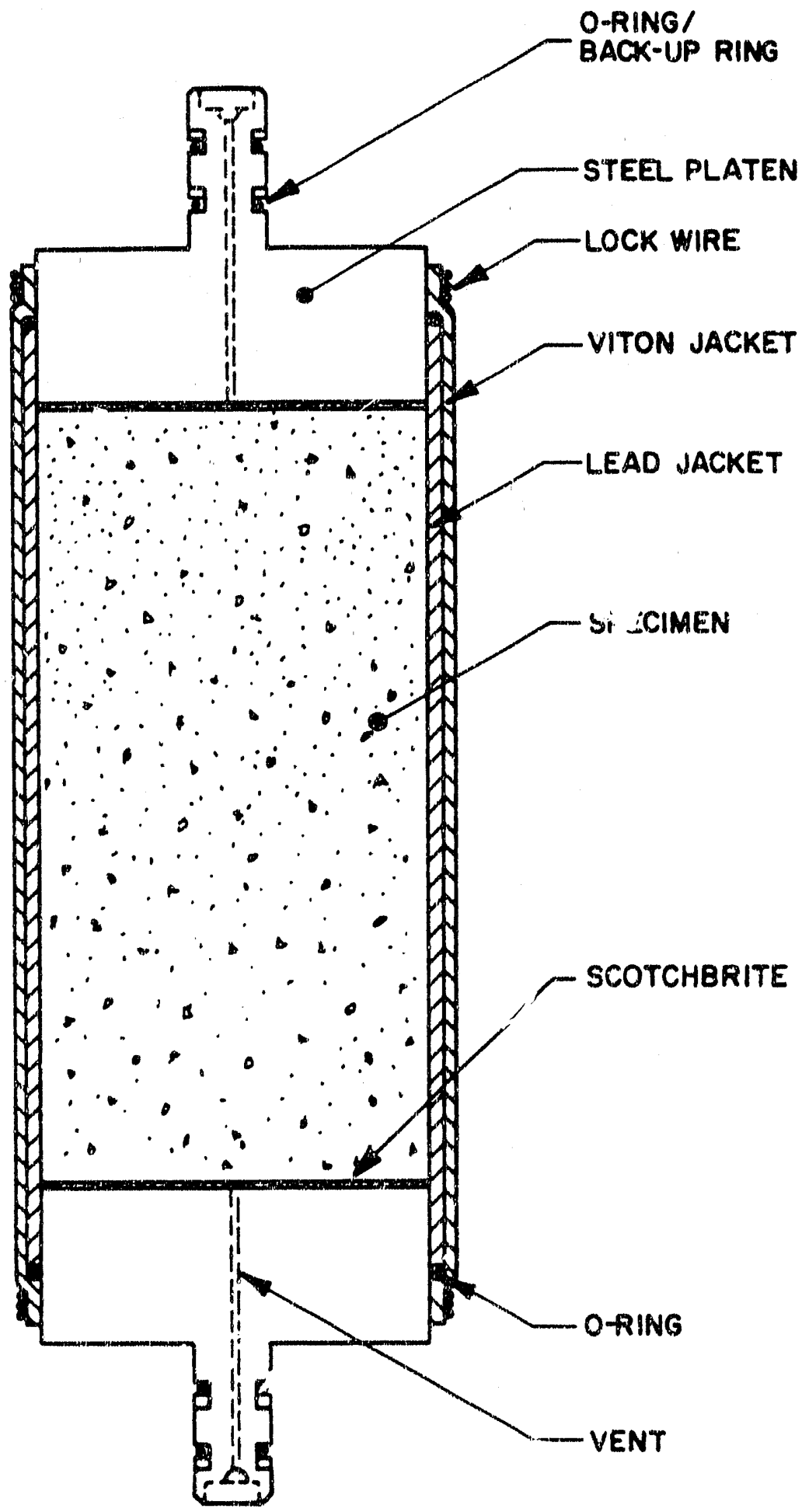

Figure 2-2. Jacketed Specimen. 
of the batch sample remaining in the original sample container using the Sartorius balance. This procedure allowed accurate determination of the starting mass and thus the density of the specimen.

Each specimen was assigned an identification number and logged into the RE/SPEC sample inventory. A typical identification number is as follows:

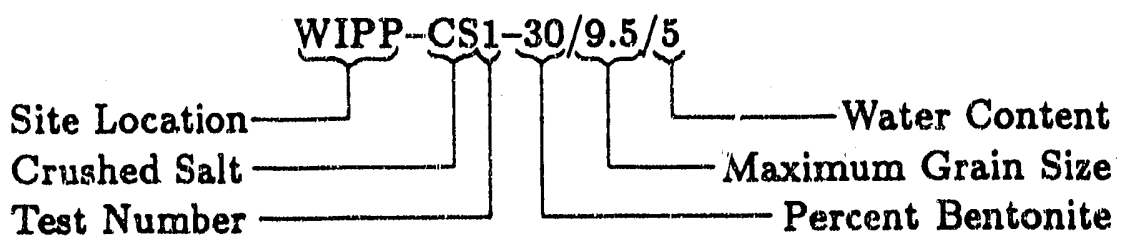

Abbreviated specimen numbers are used throughout the remainder of the report. Table 2-1 gives the correlation between complete and abbreviated identification numbers and the water contents for each specimen.

Table 2-1. Specimen Identification Numbers

\begin{tabular}{|c|c|c|c|}
\hline \multirow{2}{*}{ Complete } & \multirow{2}{*}{ Abbreviated } & \multicolumn{2}{|c|}{ Water Content } \\
\cline { 3 - 4 } & & Dry Wt. (\%) & Total Wt. (\%) \\
\hline \hline WIPP-CS1-30/9.5/5 & CS1 & $5.30 \pm 0.21$ & $5.03 \pm 0.19$ \\
WIPP-CS4-30/9.5/5 & CS4 & $5.24 \pm 0.73$ & $4.98 \pm 0.66$ \\
WIPP-CS3-30/9.5/10 & CS3 & $9.97 \pm 0.25$ & $9.07 \pm 0.21$ \\
\hline
\end{tabular}

\subsection{POST-TEST DISPOSITION}

As the tests were completed, specimens were sealed in plastic bags and returned to the RE/SPEC core storage facilities. Although each was a coherent mass of welded particles following the consolidation and permeability stages of the tests, the specimens were sectioned immediately after the unconfined compressive strength tests were performed to obtain eight samples for final water content determinations. Furthermore, each sample was broken into smaller aggregations before being placed into the drying ovens used for the water content determinations. Therefore, the specimens in storage comprise eight smaller aggregations of dried particles. 


\subsection{TEST APPARATUS}

\subsection{CONSOLIDATION}

\subsubsection{Load Frame}

Figure 3-1. presents a cross section ef a typical creep testing load frame with prominent components labeled for reference. They are nearly identical to those used by Holcomb and Hannum [1982] at Sandia National Laboratories. The machines use a single-ended, triaxial pressure vessel that accommodates a $100-\mathrm{mm}$-diameter cylindrical specimen having a length-to-diameter ratio of $L: D=2$ to 2.5. A linear actuator (hydraulic cylinder) bolted to the base of the load frame drives the loading piston, which applies axial compressive force to the specimen. Confining pressure is applied to the jacketed specimen by pressurizing the sealed vessel chamber with silicone oil. A dilatometer system maintains constant confining pressure and provides the volumetric measurement.

The testing machines can apply compressive axial loads up to $1.5 \mathrm{MN}$ and confining pressures up to $70 \mathrm{MPa}$. The heating system, including seals on the pressure vessel, can maintain specimen temperatures up to $200^{\circ} \mathrm{C}$.

A control panel houses the accumulators, hydraulic pumps, pressure intensifiers, transducer signal conditioners, temperature controllers, and confining pressure controllers for two adjacent test frames. The panels contain digital meters that display the output of the trarisducers. The temperature controller gives a digital output of the temperature. Mechanical pressure gages mounted in the panel give readings of the oil pressure in the hydraulic cylinder.

\subsubsection{Instrumentation}

Axial force is measured by a load cell in the load train outside the pressure vessel, while confining pressure is measured by a pressure transducer in the line between the intensifier and the pressure vessel. Temperature is measured by a thermocouple in the wall of the pressure vessel. The relationship between specimen temperature and that recorded by this thermocouple has been determined by calibration runs at several temperatures spanning the operating range. Two Linear Variable Differential Transformers (LVDTs) mounted outside the pressure vessel monitor displacement of the loading piston relative to the bottom of the pressure vessel. Volumetric deformation is measured using a dilatometer. With this technique, volumetric deformation is determined at fixed pressure by first measuring the volume of oil that the intensifier supplies to the pressure vessel and then compensating for the volume of oil displaced by the axial piston as measured by the LV/DTs. A rotary potentiometer or stroke transducer is mounted on the intensifier 


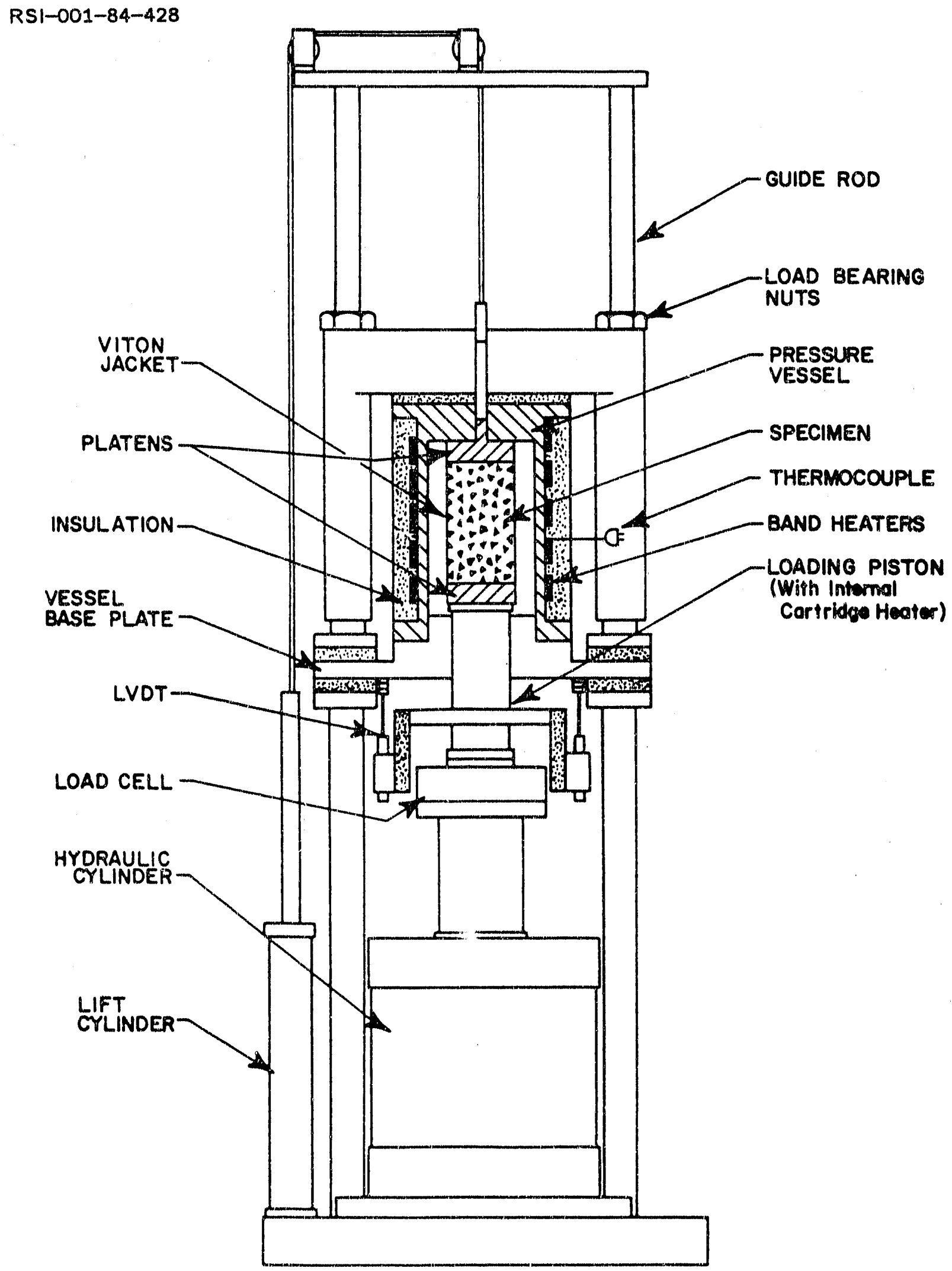

Figure 3-1. Consolidation Machine Load Frame. 
shaft to provide a signal proportional to the volume of oil supplied to the pressure vessel.

\subsubsection{Control}

Temperature is maintained with a manual set point controller that regisates power to the band heaters on the vessel. The thermocouple in the pressurf, vessel wall supplies the feedback signal. The specimen temperature is maintained cisnstant within $0.2^{\circ} \mathrm{C}$. Confining pressure is controlled by inputting the pressure tr $\iota n s d u c e r$ signal to a unit that contains two manual set points. These set points are adjusted to maintain the confining pressure constant within $20 \mathrm{kPa}$. The controller signals the intensifier to advance or retreat depending upon whether the lower or upper set point has been reached. A standby diesel generator provides electrical power to the test system during periods of commercial electrical power outages.

\subsection{PERMEABILITY}

Figure 3-2 shows a schematic of the apparatus used for the brine permeability measurements. In this apparatus, an accumulator is connected hydraulically to the specimen via stainless-steel tubing and the vent in the lower end platen. The accumulator is filled with brine and charged with nitrogen using a standard nitrogen bottle. The charge pressure (and therefore the pressure drop across the specimen) is regulated manually with a valve located on the nitrogen bottle and is measured using a diaphragm-type pressure transducer in the line between the nitrogen bottle and the accumulator. Brine flow through the specimen is captured and measured by a buret attached to the upper end platen of the specimen. Evaporation of water is controlled by placing a thin film of mineral oil on top of the brine column in the buret.

\subsection{STRENGTH}

\subsubsection{Load Frame}

Figure 3-3 shows a schematic of the four-column load frame used to perform the unconfined compressive strength tests. The frame and load actuator located in the base of the machine can apply $1 \mathrm{MN}$ of force to a specimen. The movable crosshead allows for a wide range of specimen lengths and a variety of tests.

A control console houses all signal conditioning for the transducers, as well as feedback and valve driver modules for the hydraulics. This console also interfaces with a DEC LSI-11/73 microprocessor to provide data acquisition and programmable control. 


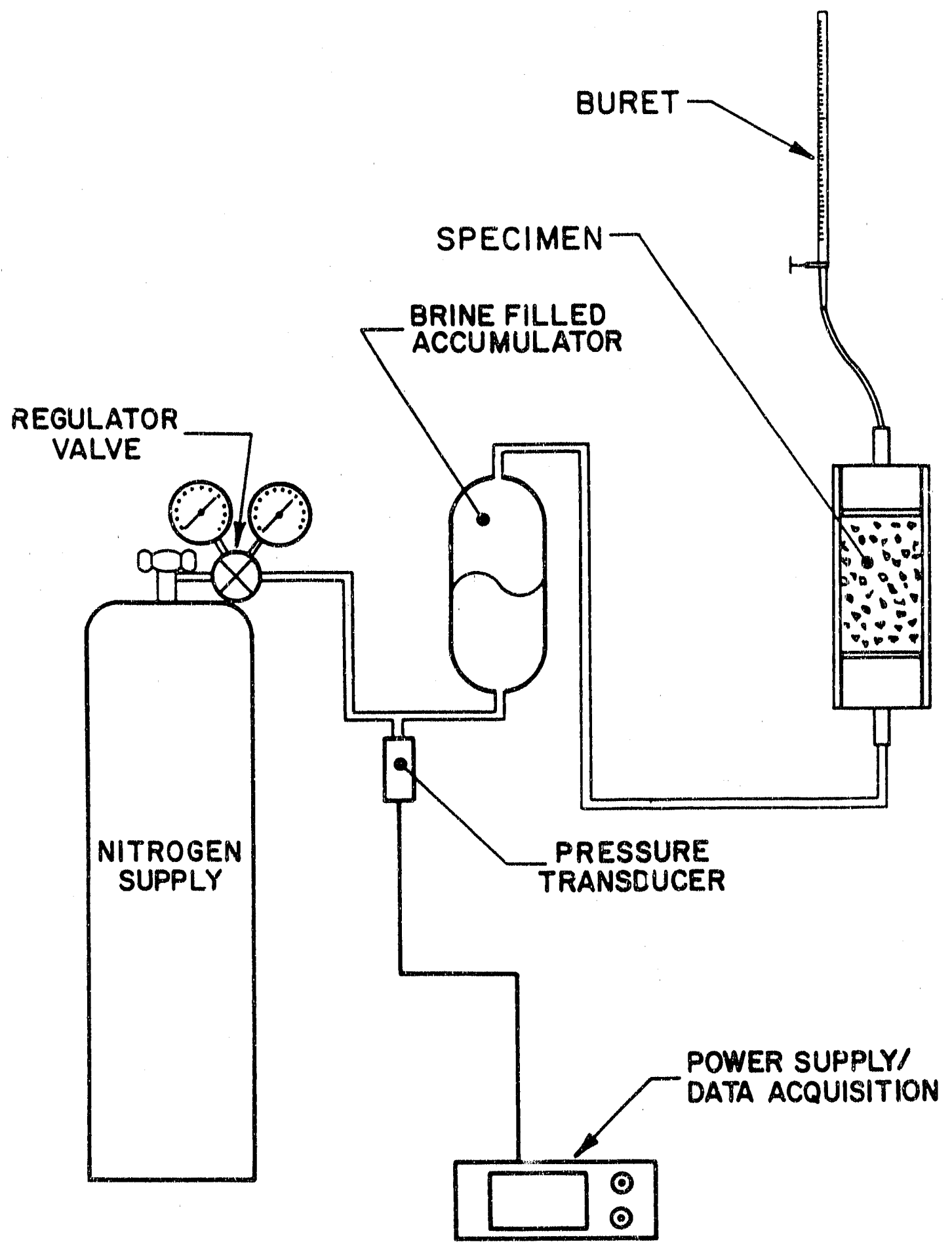

SCALE: NONE

Figure 3-2. Schematic of Brine Permeability Test Apparatus. 


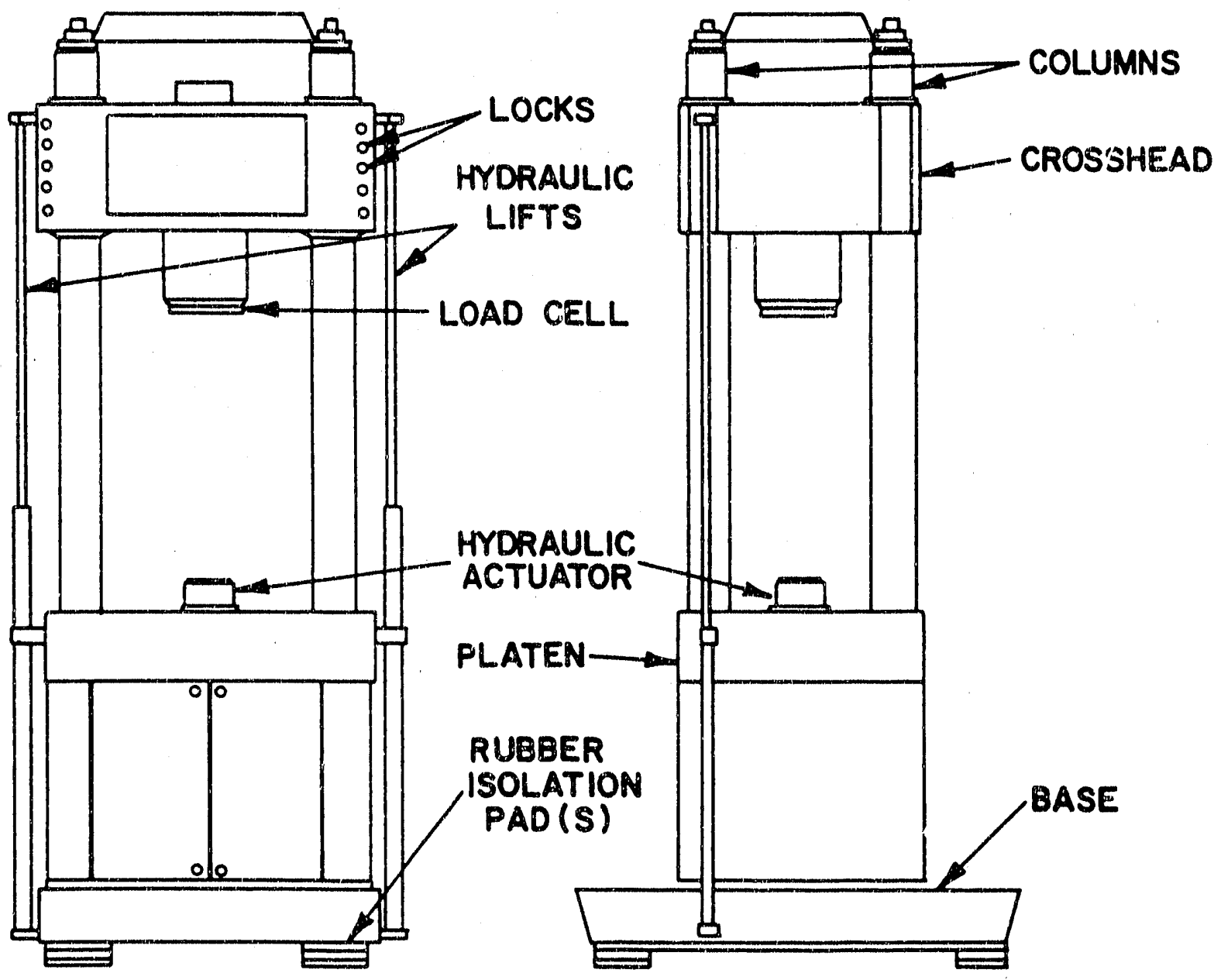

Figure 3-3. Schematic of Four-Column Load Fraxe. 


\subsubsection{Instrumentation and Control}

Two types of transducers were required for this effort: a load cell and an LVDT. The load cell is mounted on the movable crosshead and provides force measurements. The LVDT, located in the base-mounted actuator, proxides measurements of axial stroke or displacement and was also used as the control device for the constant stroke rate $t$ 'st. The ambient laboratory tr nperature during the tests was $20^{\circ} \pm 1^{\circ} \mathrm{C}$.

\subsection{CALIBRATION}

The transducers used to collect force, pressure, deformation, and temperature data were calibrated at RE/SPEC using standards traceable to the National Institute of Standards and Technology and documented procedures. Table 3-1 gives the range and resolution for these transducers. The accuracy of all transducers is 1 percent of reading, which includes both nonlinearity and repeatability. The burets used are Class A and have an accuracy of $>0.1 \mathrm{ml}$.

Table 3-1. Calibration Resultg ${ }^{(a)}$

\begin{tabular}{|c|c|c|}
\hline Measurement & Range & Resolution \\
\hline CONSOLIDATION & & \\
\hline $\begin{array}{l}\text { Axial Deformation ( } \mathrm{nm}) \\
\text { Lateral Strain }(\%) \\
\text { Axial Load }(\mathrm{MN}) \\
\text { Confining Pressure }(\mathrm{MPa}) \\
\text { Temperature }\left({ }^{\circ} \mathrm{C}\right)\end{array}$ & $\begin{array}{l}0 \text { to } 25.4 \\
0 \text { to } 3 \\
0 \text { to } 0.25 \\
0 \text { to } 3.45 \\
0 \text { to } 250\end{array}$ & $\begin{array}{l}0.0016^{(b)} \\
0.002^{(b)} \\
0.00003^{(b)} \\
0.0004^{(b)} \\
0.03^{(b)}\end{array}$ \\
\hline $\begin{array}{l}\text { PERMEABMLITY } \\
\text { Pressure }(\mathrm{kPa})\end{array}$ & 0 to 345 & $0.70^{(c)}$ \\
\hline $\begin{array}{l}\text { STRENGTH } \\
\text { Axial Deformation (mm) } \\
\text { Force (MN) }\end{array}$ & $\begin{array}{c}0 \text { to } 25.4 \\
0 \text { to } 0.1\end{array}$ & $\begin{array}{l}0.0016^{(b)} \\
0.00001^{(b)}\end{array}$ \\
\hline
\end{tabular}

(a) Accuracy: 1 percent of reading including nonlinearity and repeatability.

(b) 14-bit analog-to-digital converter.

(c) 4-1/2-digit panel meter. 


\subsection{TEST PROCEDURES}

\subsection{DENSITY}

A determination of specimen density was required bofore and after each stage of the tests. Density requires measurements of both mass and volume. Mass was measured $v$ ing a Sartorius balance as described in Section 2.2.2. Volume was determined using two techniques: (1) fluid (water) displacement and (2) indirect dimensional measurement. Volumetric measurements in both techniques were performed while the specimen was subjected to a vacuum of approximately $630 \mathrm{~mm}$ of mercury. The vacuum was used to remove air trapped between the jacketing materials and the specimen and at other component interfaces. The teraperature during the measurements was $20^{\circ} \pm 1^{\circ} \mathrm{C}$. The density of ea.th specimen at various stages during the tests is given later in Section 5.1.2, Tablo 5-1.

In the fluid displacement technique, the volume of the jacketed specimen was determined by measuring the wejght of water displaced when the specimen was submerged in a container equipped with an overflow spout and converting the weight to volume using the specific gravity of the fluid. The volume of the specimen was then determined by subtracting the volumes of the nonspecimen components from this displaced volume. The volumes of the platens, jr.ckets, O-rings, and lock-wire were determined from their mass and specific gravity. The vclume of the Scotchbrite depends on the applied vacuum and was, therefore, determined by using an aluminum cylinder of known dimensions in place of the crushed salt and bentonite specimen and submerging the evacuated specimen. The method yielded specimen volumes that were within 2 percent of their true volumes.

In the indirect measurement technique, specimen volume was determined from the length and diameter of the specimen assuming a right-circular, solid cylinder configuration. The diameter of the specimen was determined by first measuring the diameter of the jacketed specimen at six locations using a micrometer and then reducing the measurements by twice the lead and Viton jacket thicknesses. Similarly, the length of the specimen was determined by measuring the height of the jacketed specimen usinz a gage head and transfer standard and then subtracting the lengths of the end platens and the thickness of the Scotchbrite from this measured height. The thickness of the Scotchbrite depends on the applied vacuum and, therefore, was determined using an aluminum specimen of known dirnensions under vacuum. This technique yielded volumes within 2 percent of the fluid displacement technique even though the highly deformed specimens caused the jacketing to deform unevenly and produce large wrinkles. 


\subsection{CONDITIONING}

Because of the rapid consolidation expected during hydrostatic loading of the specirnens and the inability of the test system to measure volumetric displacements under nonconstant pressure, all specimens were conditioned before beginning each stage of the consolidation tests. The conditioning allowed measurement of the change in density during loading before the time-dependent consolidation started. The conditioning consisted of placing the specimen in the load frame, heating the specimen from ambient temperature $\left(20^{\circ} \mathrm{C}\right)$ to the test temperature of $25^{\circ} \mathrm{C}$, loading the specimen to the desired conditioning pressure, and then unloading the specimen immediately. The specimen was removed from the load frame, and its density was measured using both techniques described previcusly. For specimens CS1 and CS3, the conditioning pressures were the prescribed pressures of the following consolidation stage as given in Table 1-1. For Stage 1 of CS4, however, the conditioning pressure was $7 \mathrm{MPa}$ rather than the prescribed consolidation pressure of $3.45 \mathrm{MPa}$. The higher initial conditioning pressure was used to compact the specirnen to a higher initial density so that the time required to reach full saturation could be reduced. In subsequent stages of this test, the conditioning pressures were equal to the prescribed consolidation pressures given in Table 1-1.

The change in density during conditioning varied significantly depending on pressure, initial density, and perhaps water content. For example, Specimens CS1 and CS4 both started at about the same initial density and water content in Stage 1, but the density of CS1 (conditioning pressure of $3.45 \mathrm{MPa}$ ) increased by only 16 percent compared to a 23 percent increase for CS4 (conditioning pressure of $7 \mathrm{MPa}$ ). This difference is attributable to the higher pressure for CS4. The density of CS3 (conditioning pressure of $3.45 \mathrm{MPa}$ ) increased by 40 percent during Stage 1 conditioning; however, its initial density was as much as 11 percent lower than CS1 and CS4, and its water content of 10 percent was nearly twice that of the other two specimens.

In general, the conditioning procedure increased the density of the specimens at each stage; however, in some instances (e.g., CS3), the density actually decreased. This decrease was thought to be a result of specimen swelling and probably only occurred because of the delay in making the density measurements. For all specimens, the density decreased when the pressure was dropped to perform the permeability test.

\subsection{CONSOLIDATION}

The three consolidation tests were performed in stages. Before each stage was initiated, the specimen was conditioned as described above. After the density of the conditioned specim " a was determined, it was returned to the load frame, the pressure vessel lowered, and the loading piston advanced far enough to engage the top platen pressure seal, but not so far that the platen contacted the top of the 
pressure vessel. This positioning ensured that the specimen was not subjected to an axial stress difference imposed by the piston during consolidation. The supply line to the hydraulic cylinder was then closed so that the piston position was maintained. The pressure vessel was filled with silicone oil and heated to $25^{\circ} \mathrm{C}$. After temperature stabilization ( $\sim 24$ hours), the desired consolidation pressure for the stage was applied in approximately 30 seconds by pressurizing the oil with an air-driven pump. Data acquisition began when the prescribed pressure was reached and control of the pressure was given to the aut mmatic controller.

The lower platen vent was plugged during consolidation; however, the upper vent was equipped with a flexible tube containing a brine trap. The trap allowed air to escape but privented evaporation from the specimen during consolidation.

Depending on the amount of specimen consolidation, the piston could be advanced during the test to maintain the platen-vessel seal at the top of the vessel. The volumetric data collected by the potentiometer or stroke transducer were corrected to account for piston motion into or out of the pressure vessel since piston position is recorded using the LVDTs. The volumetric data were also corrected during data reduction so that the specimen volume at the end of the stage, as determined from the data collected continuously throughout the test, matched the specimen volume determined from the fluid displacement measurement made at the end of the stage.

The data acquisition computer was programmed to scan the data channels at 15-second intervals. Data were logged by the computer for each $0.02 \mathrm{~mm}$ of axial deformation or every hour if the axial deformation was less than $0.02 \mathrm{~mm}$ in a 1hour interval. Recorded data were written to disk by the acquisition computer and transmitted to a larger computer for analysis.

\subsection{PERMEABILITY \\ 1}

Once the specimen had consolidated so that it was fully saturated at the water content prescribed, a permeability test was performed. The theoretical saturated wet density of the specimen is calculated from simple volume-density relationships assuming complete interconnectivity of voids and using

$$
\rho_{\text {sat }}^{w}=\frac{G \rho_{w}(1+w)}{1+w G}
$$


where:

$$
\begin{aligned}
\rho_{\text {sat }}^{w} & =\text { Saturated wet density (having units } M L^{-3} \text { ) } \\
G & =\text { Specific gravity }{ }^{1} \text { of solids (unitless) } \\
\rho_{w} & =\text { Density of water (having units } M L^{-3} \text { ) } \\
w & =\text { Water content expressed as a fraction (unitless) }
\end{aligned}
$$

When the density of the specimen reached this theoretical density, the test stage was stopped, the pressure dropped, and the specimen removed to determine its density. The specimen was then returned to the same machine and a partially filled buret was connected to the outlet of the specimen using a flexible hose. The prescribed pressure was then applied to the specimen.

The prescribed hydrostatic pressure was to be $7 \mathrm{MPa}$; however, this pressure in some cases produced continued volumetric deformation which literally squeezed brine out of the specimen and confounded the flow data. In these cases, a pressure of $0.5 \mathrm{MPa}$ was imposed on the specimen. Once pressure was applied, the buret was subjected to a vacuum of about $630 \mathrm{~mm}$ of mercury for 12 to 24 hours to remove air from the hydraulic connections.

Permeability was determined by measuring the steady How rate of brine through the specimen and the pressure drop across the specimen under hydrostatic conditions. The pressure drop was maintained at $345 \mathrm{kPa}$ during the test. The flow rate was determined by monitoring the level of brine in the buret with time. The test was terminated when the flow rate was constant over several days or if flow could not be established after about 150 lays.

\subsection{STRENGTH}

After the permeability stage had been completed, an unconfined compressive strength test was performed on each specimen. Before the test was performed, however, the specimen was removed from the creep testing load frame, its density determined, and its Viton and lead jackets removed. The consolidation pressures, in all cases, were sufficient to deform the lead jacket into the surface voids of the specimens. When the jacket was removed, some salt grains remained embedded in the lead jacket. Although some grains were removed from the surfaces of the specimens and the specimen deformation was not entirely uniform over the length of the specimen, measurements of the average diameter and length of the specimens were made using a micrometer and gage head and transfer standard, respectively.

Each specimen was fitted with a loosely fitting plastic sleeve to prevent moisture loss and mounted in the four-column load frame. Pecause of the somewhat

\footnotetext{
${ }^{1}$ Spocific gravity, defined as the ratio of the mass of a unit volume of a material to the mass of the same volume of water at a given temperature, was calculated using the theoretical densities of salt and bentonite and assuming a density of water of $1,000 \mathrm{~kg} \mathrm{~m}^{-3}$. The specific gravity of the solids of a $70 / 30$ crushed salt/bentonite mixture is 2.266 .
} 
irregular shapes of the specimens, no direct contact deformation extensometers were attached to the specimens. Instead, only axial displacement of the load actuator was recorded. During each test, a small axial preload was applied manually to the test specimen and then a constant axial stroke (displacement) rate test was performed at ambient temperature $\left(20^{\circ} \pm 1^{\circ} \mathrm{C}\right)$. The LVDT tracking the displacement was also used as the feedback signal for control. The test proceeded at a nominal rate of $0.002 \mathrm{~mm} \cdot \mathrm{s}^{-1}$ (producing a nominal axial strain rate of $1 \times 10^{-5} \mathrm{~s}^{-1}$ ) until peak load was achieved, at which time the specimen was unloaded. Force and displacement data were recorded during loading. Peak load and the average specimen diameter were used to calculate the unconfined compressive strength.

\subsection{VIATER DISTRIBUTION}

The water distribution parallel to the specimen axis was determined for each specimen after the strength test was performed. Eight samples were obtained by sectioning each specimen with a hacksaw. Cuts were made perpendicular to the specimen axis and were spaced so as to yield samples of approximately the same mass. The samples were then broken up into smaller aggregations and dried in an oven at $110^{\circ} \mathrm{C}$ for 6 days. 


\subsection{TEST RESULTS}

\subsection{CONSOLIDATION}

During each test, the change in specimen volume was continuously measured using a dilatometer. From this data and the specimen mass and volume determined as described in Section 4.1, volumetric strain, density, and fractional density were determined. Elastic strains resulting from stress changes were assumed to be small compared to the inelastic strains and, therefore, were ignored in all analyses.

\subsubsection{Volumetric Strain}

The enginetring strain detinition was used to calculate volumetric strain, $\epsilon_{v}$, as *

$$
\epsilon_{v}=\frac{\Delta V}{V}
$$

where $\Delta V$ was the change in specimen volume and $V$ was either the original specimen volume, $V_{0}$, or the specimen volume at the beginning of a particular consolidation stage, $V_{\text {o. }}$ The choice of the specimen volume depended upon whether the total strains or the consolidation strains from a particular stage were required. Figures 5-1 to 5-3 give the total volumetric strains for Tests CS1, CS4, and CS3, respectively, and include both the conditioning and the consolidation strains. The durations of the tests (including permeability) ranged from 272 to 305 days. Appendices A, B, and $\mathrm{C}$ give the volumetric strain-time curves for only the consolidation periods of each stage of Tests CS1, CS4, and CS3, respectively.

During subsequent stages of a test, $t^{2} \&$ pressure was changed (Stages 2 and 3 of CS3 were performed at the same pressure and an explanation will be given in Section 5.2). The changes in pressure were implemented to acquire volumetric strain-time data at several pressures and also to reduce the time required to reach saturation; however, the maximum pressure allowable in the tests was $14 \mathrm{MPa}$ which represents the expected maximum pressure imposed on the backfill at the WIPP. In all tests, the pressure during the final stage of the test (permeability) was lower than the previous stage, either 0.5 or $7 \mathrm{MPa}$. The pressure in this final stage was to be $7 \mathrm{MPa}$ in all cases; however, this magnitude produced additional volume deformation that forced pore water out of the specimen and confounded the permeability measurements. As seen in Figures 5-1 through 5-3, little additional volumetric strain was measured during the final stage at the reduced pressures. In fact, the total volumetric strain decreased initially indicating that some swelling occurred immediately after the pressure was reduced. 


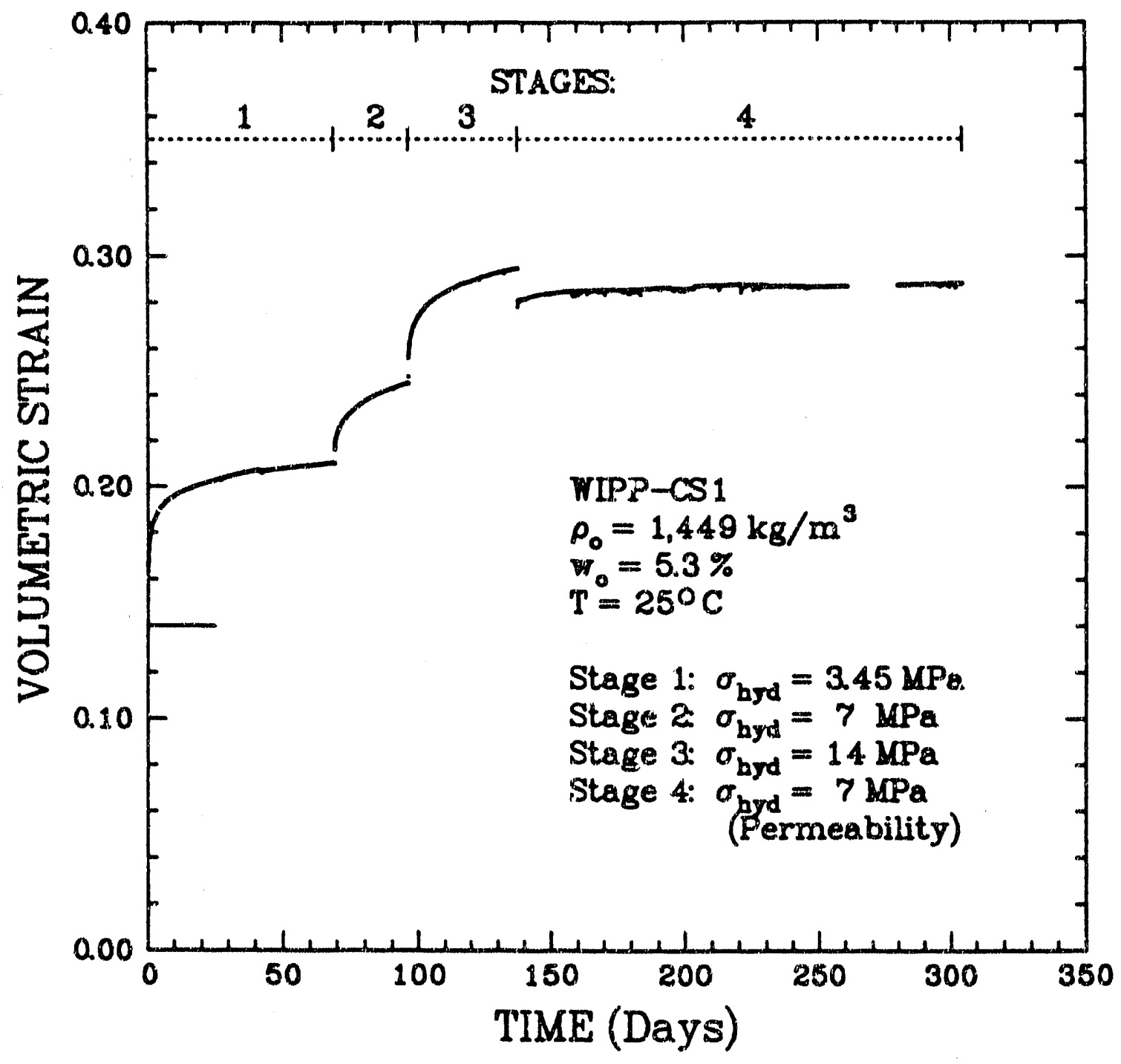

Figure 5-1. Total Volumetric Strain as a Function of Time for CS1. 


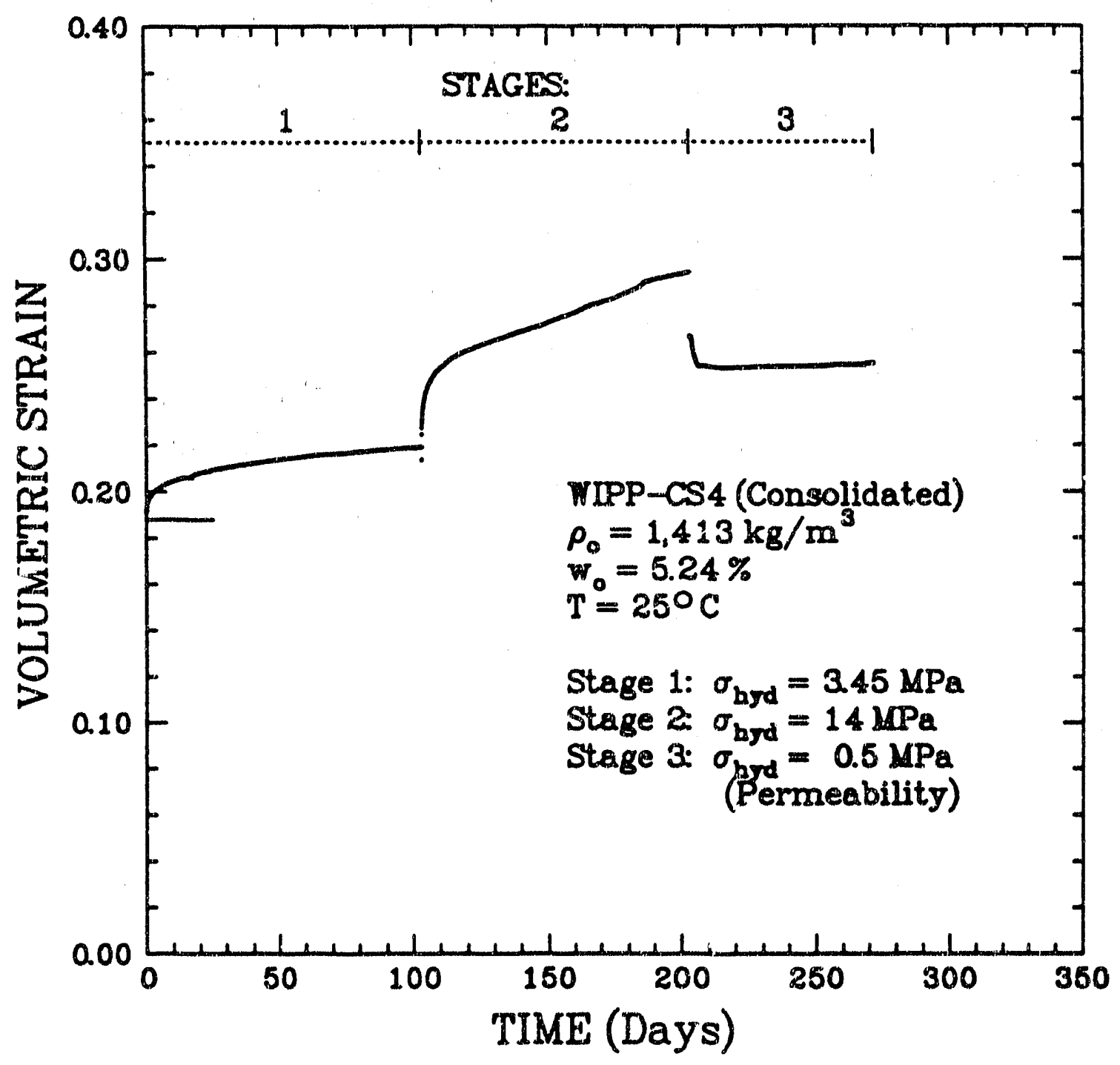

Figure 5-2. Total Volumetric Strain as a Function of Time for CS4. 


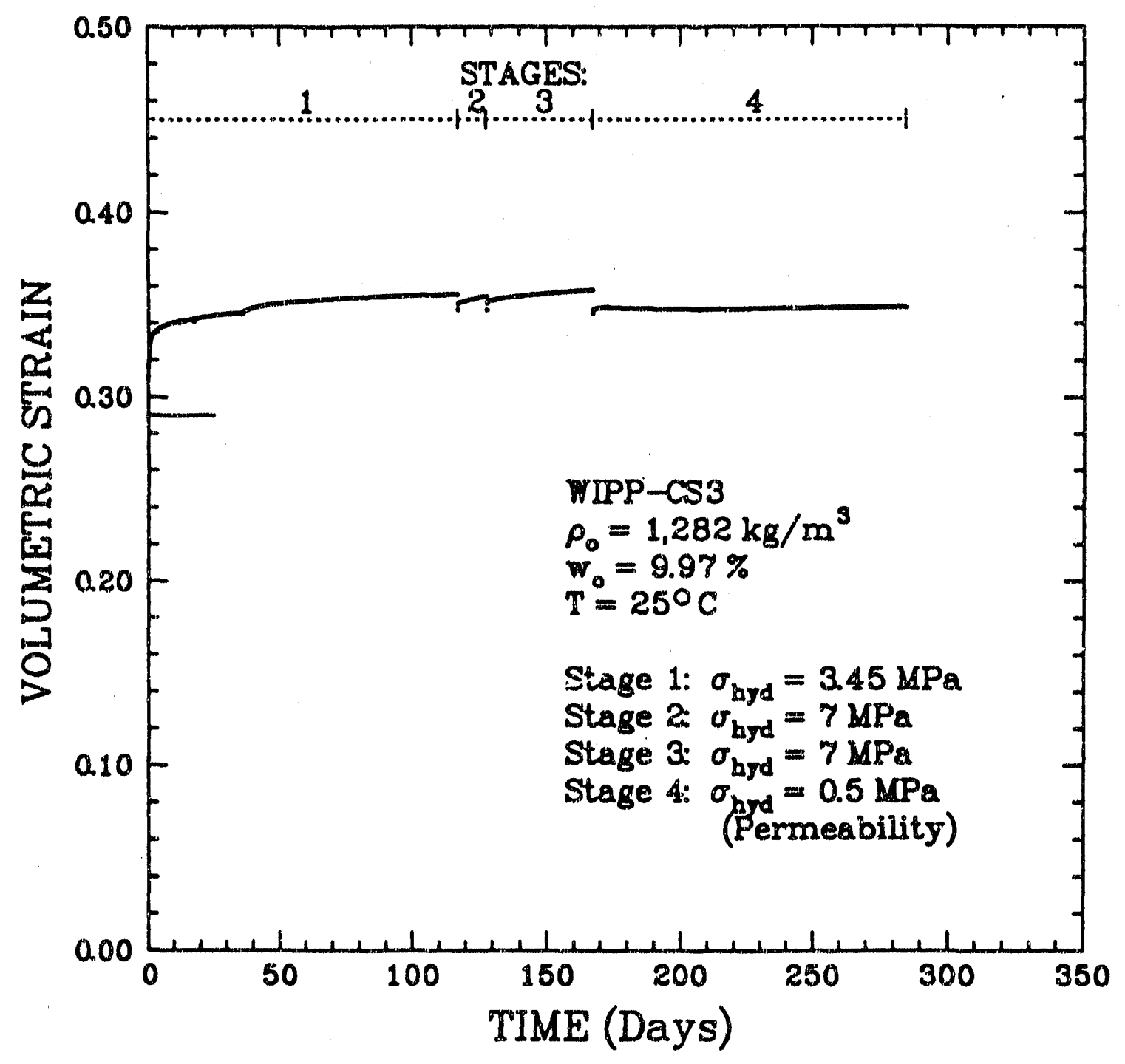

Figure 5-3. Total Volumetric Strain as a Function of Time for CS3. 


\subsubsection{Density}

Density was determined as a function of time to monitor the saturation level during the test and to provide data for model fitting and fractional density determinations. The wet density, $\rho^{w}$, was calculated from the wet mass, $\mathrm{M}^{w}$, and the volume as

$$
\rho^{w}=\frac{M^{w}}{V}
$$

This density was compared to the theoretical saturated density (Equation 4-1) to determine when the specimen reached full saturation. The dry density, $\rho^{d}$, was calculated as

$$
\rho^{d}=\frac{\rho^{w}}{1+w}
$$

where $w$ is the water content expressed as a fraction. For Test CS3, water was expelled from the specimen during Stages 2 and 3. Therefore, in calculating the dry density from Equation 5-3, c corrected water content was used. This corrected water content was calculated assuming that all volume changes occurring after saturation was reached resulted in the expulsion oi an identical volume of brine. Dry densitytime curves for each stage are given in the respective appendices for Tests CS1, CS4, and CS3. A summary of the density information is provided in Table 5-1. Density measurements performed at the end of each creep stage compared reasonably well, within 2 percent, with those deterrnined from the precreep density measurements and the volumetric strain data recorded by the dilatometer.

Fractional dry density-time curves for all stages of each test are given in Figures 5-4 through 5-6. Fractional density-time curves for each stage are also given in the appendices. Fractional density is calculated from the dry density as

$$
D=\frac{\rho^{d}}{\rho^{t h}}
$$

where $\rho^{\text {th }}$ is the theoretical solid density of the mixture equal to $2,266 \mathrm{~kg} \cdot \mathrm{m}^{-3}$. The fractional density information is also summarized in Table 5-1.

\subsection{PERMEABILITY}

Permeability tests using the steady flow rate of brine method, as described in Section 4.4, were performed on each specimen. The tests were to be performed on 


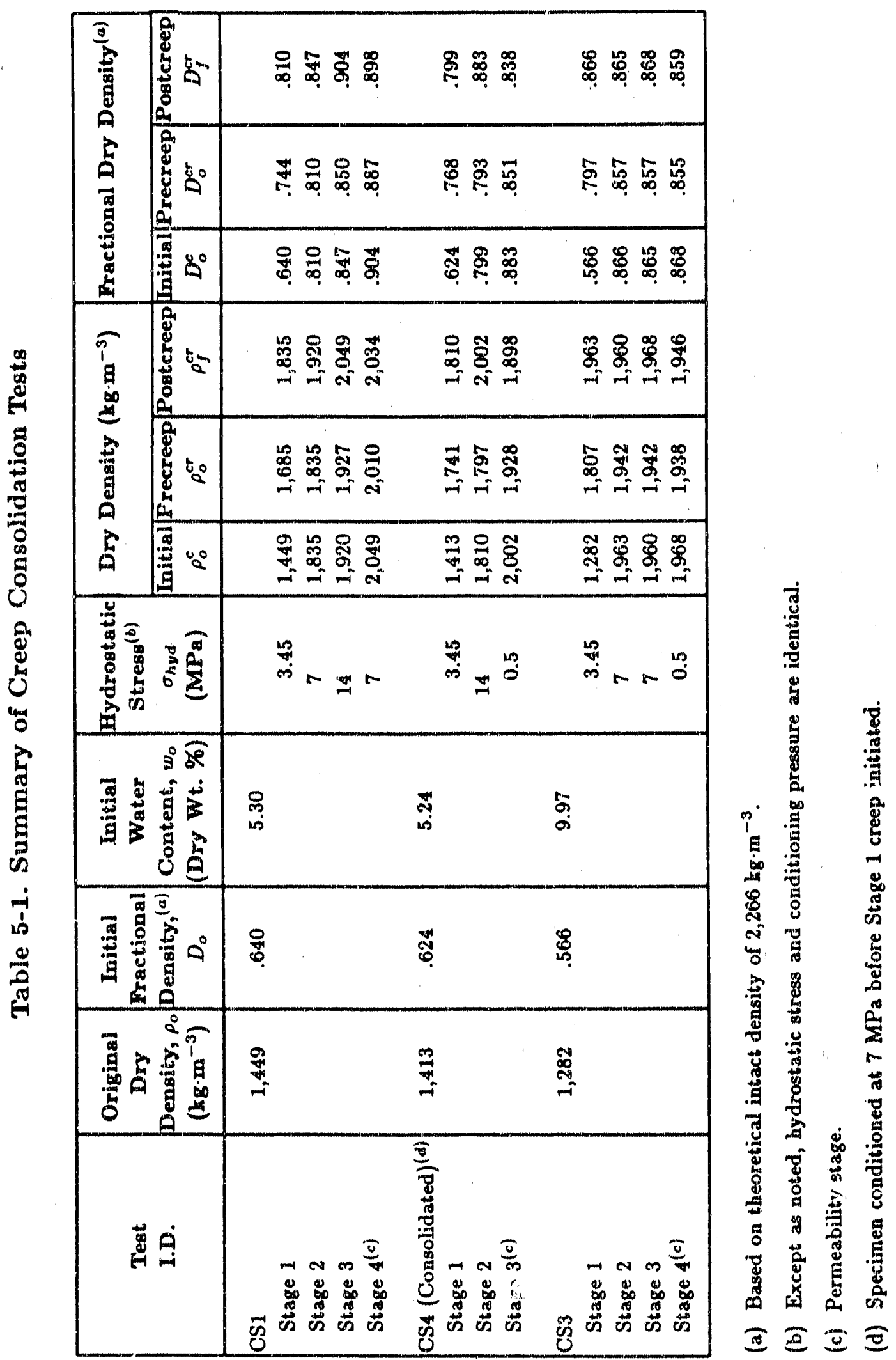




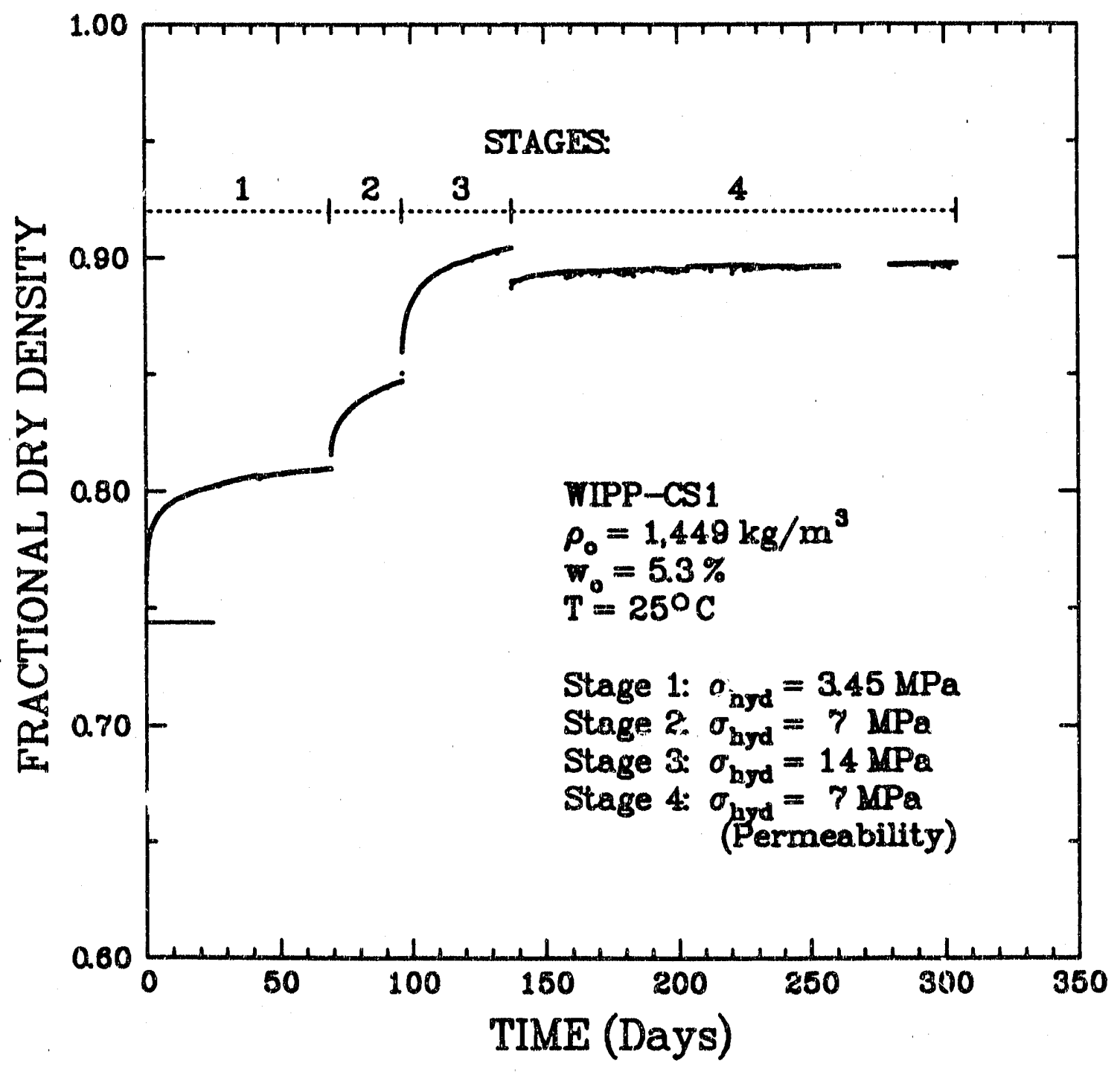

Fi, ure 5-4. Fractional Dry Density as a Function of Time for CS1. 


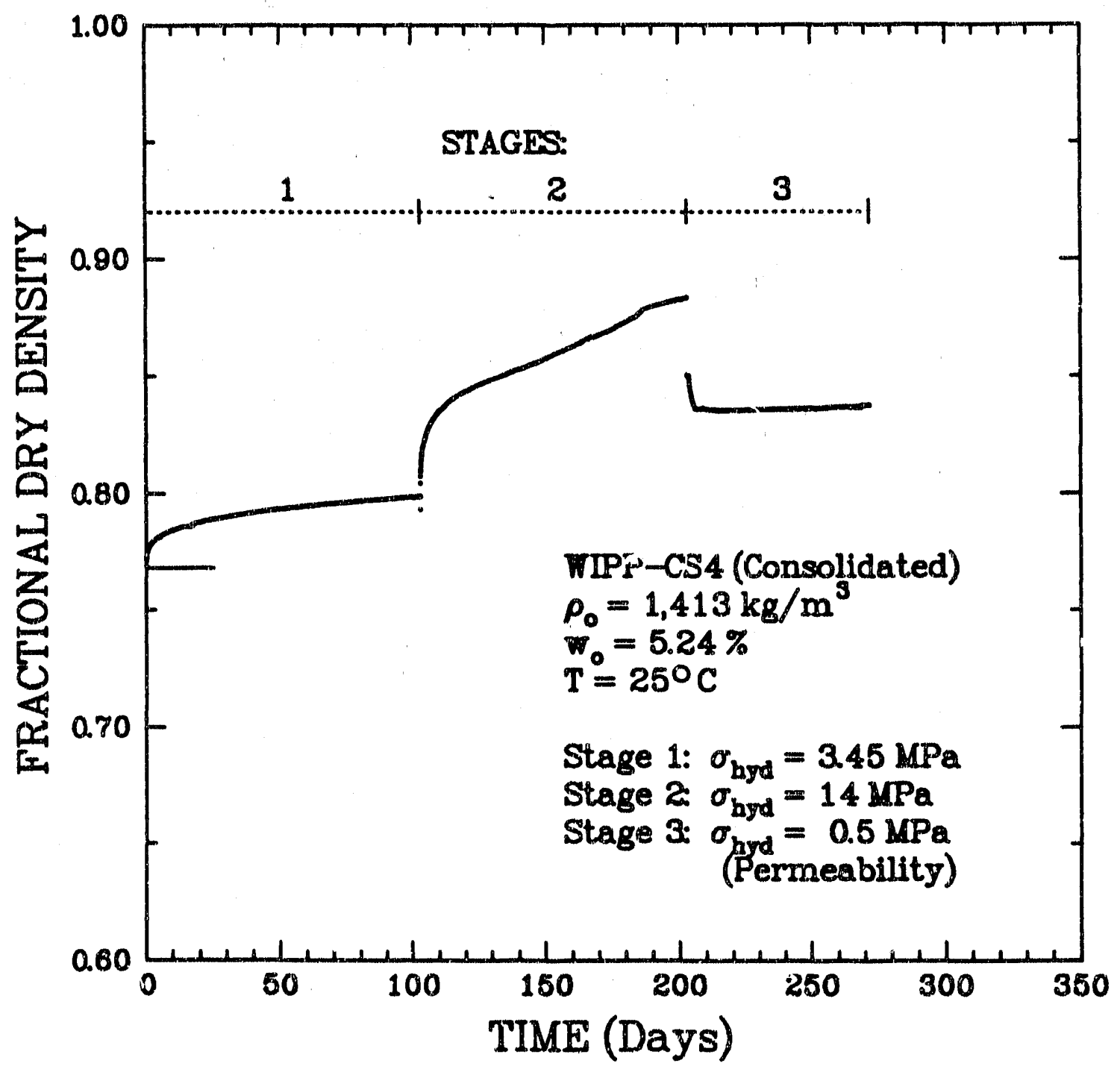

Figure 5-5. Fractional Dry Density as a Function of Time for CS4. 


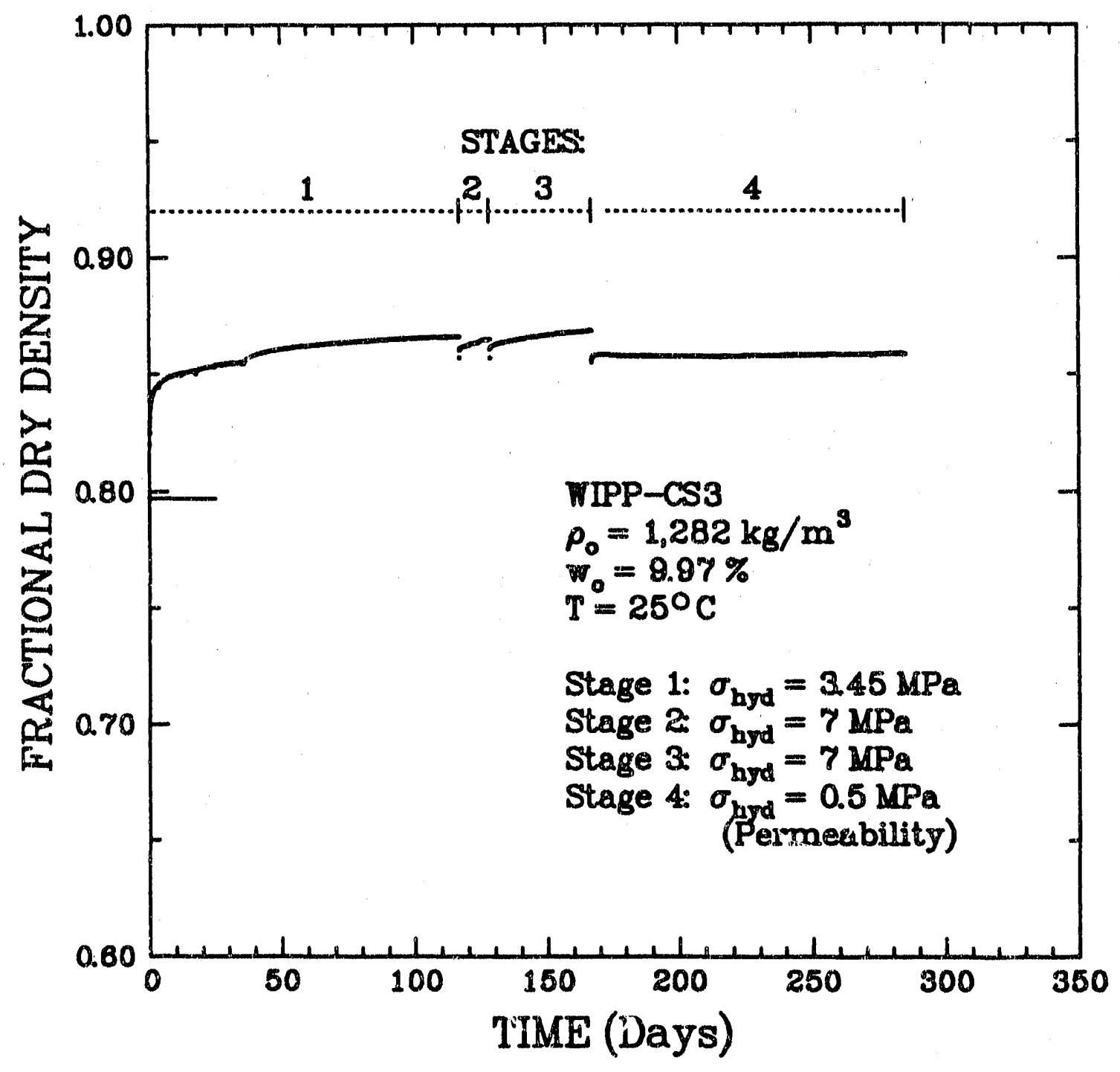

Figure 5-6. Fractional Dry Density as a Function of Time for CS3. 
saturated specimens at a confining pressure of $7 \mathrm{MPa}$ and a pressure drop across the specimen of $345 \mathrm{kPa}$.

In some cases, the prescribed conditions could not be imposed during the permeability test. For example in Test CS3 (nominal water content of 10 percent), the specimen reached its saturated density during the first stage of the consolidation test at a pressure of $3.45 \mathrm{MPa}$. In the second stage, the pressure was increased to $7 \mathrm{MPa}$ (the required confining pressure for the permeability test), but caused a rather large volume change so the permeability test was not performed. Once the volumetric strain rate had decreased in the second stage, a third stage at a pressure of $7 \mathrm{MPa}$ was initiated and the permeability test started. Again the volume deformations were too large, confounding the measurements of brine flow through the specimen as water was expelled from the pores. The permeability test was therefore performed at a confining pressure of $0.5 \mathrm{MPa}$, which was the pressure that was used during the permeability test for CS4. Also, the permeability test tor CS4 was initiated before the specimen reached full saturation. This specimen had been subjected to a consolidation pressure of $14 \mathrm{MPa}$ (the highest pressure allowed) for 100 days but only reached about 90 percent saturation at this time.

Permeability tests were continued until a constant flow rate of brine was established. Permeabilities were calculated from Darcy's law, i.e.,

$$
k=\frac{Q}{A} \cdot \frac{\mu L}{\Delta P}
$$

where:

$$
\begin{aligned}
k & =\text { Permeab:iity (having units } L^{2} \text { ) } \\
Q & =\text { Measured flow rate of brine (having units } L^{3} T^{-1} \text { ) } \\
A & =\text { Current area (having units } L^{2} \text { ) } \\
\mu & \left.=\text { Viscosity of brine (having units } M L^{-1} T^{-1}\right) \\
L & =\text { Current length (having units } L \text { ) } \\
\Delta P & =\text { Pressure drop across specimen (having units } M L^{-1} T^{-2} \text { ). }
\end{aligned}
$$

A viscosity of $1.26 \mathrm{cP}\left(1.26 \times 10^{-3} \mathrm{~kg} \cdot \mathrm{m}^{-1} \cdot \mathrm{s}^{-1}\right)$ was used for brine after Shor et al. [1981]. The pressure drop for all tests was $345 \mathrm{kPa}$. Table 5-2 gives the permeabilities of each specimen as calculated using Equation 5-5. Flow through the specimen in Tesi CS1 could not be established even after 167 days. For the durations of the permeability stages imposed, the smallest permeability value that could be determined under these conditions is about $1 \times 10^{-21} \mathrm{~m}^{2}$.

\subsection{STRENGTH}

The strength of the three specimens was determined from unconfined c ompression tests performed at a constant stroke (displacement) rate of $0.002 \mathrm{~mm} \cdot \mathrm{s}^{-1}$. 
Table 5-2. Summary of Permeabilities and Strength

\begin{tabular}{|c|c|c|c|c|}
\hline $\begin{array}{c}\text { Specimen } \\
\text { I.D. }\end{array}$ & $\begin{array}{c}\text { Water } \\
\text { Content } \\
\text { Dry Wt.' (\%) }\end{array}$ & $\begin{array}{c}\text { Density } \\
\left(\mathrm{kg} \mathrm{m}^{-3}\right)\end{array}$ & $\begin{array}{c}\text { Permeability } \\
\left(\mathrm{m}^{2} \times \mathbf{1 0}^{-17}\right)\end{array}$ & $\begin{array}{c}\text { Unconfined } \\
\text { Strength } \\
(\mathrm{MPa})\end{array}$ \\
\hline CS1 & 5.30 & 2,034 & $0.0^{(a)}$ & 8.1 \\
CS4 & 5.24 & 1,898 & 4.9 & 0.5 \\
CS3 & 9.97 & 1,946 & 1.3 & 1.1 \\
\hline
\end{tabular}

(a) No flow established after 167 days.

Figure 5-7 gives the axial force-displacement curves for each specimen. The unconfined strength was calculated from

$$
q_{u}=\frac{F_{\text {ult }}}{A}
$$

where $F_{\text {ult }}$ is the peak or ultimate force sustained by the specimen and $A$ is the area of the specimen. Table 5-2 gives the calculated values of the unconfined compressive strength for each specimen. The strengths ranged from 0.5 to $8.1 \mathrm{MPa}$ and are ordered with respect to dry density.

\subsection{WATER CONTENT DISTRIBUTION}

The distribution of water content was determined using the method described in Section 4.6. Table 5-3 gives the water contents for the eight samples obtained for each specimen. The sample numbers are ordered with Sample 1 obtained from the bottom of the specimen and Sample 8 from the top of the specimen. The weighted mean water content, $w_{\text {mean }}$, for each specimen is also shown and is calculated as

$$
w_{\text {mean }}=\frac{\Sigma M^{d}{ }_{i} w_{i}}{M^{d}{ }_{\text {tot }}}
$$

where:

$$
\begin{aligned}
M^{d} & =\text { Dry density of the } i^{\text {th }} \text { sample } \\
w_{i} & =\text { Water content of the } i^{\text {th }} \text { sample expressed as a fraction } \\
M^{d}{ }_{\text {tot }} & =\text { Total dry mass. }
\end{aligned}
$$




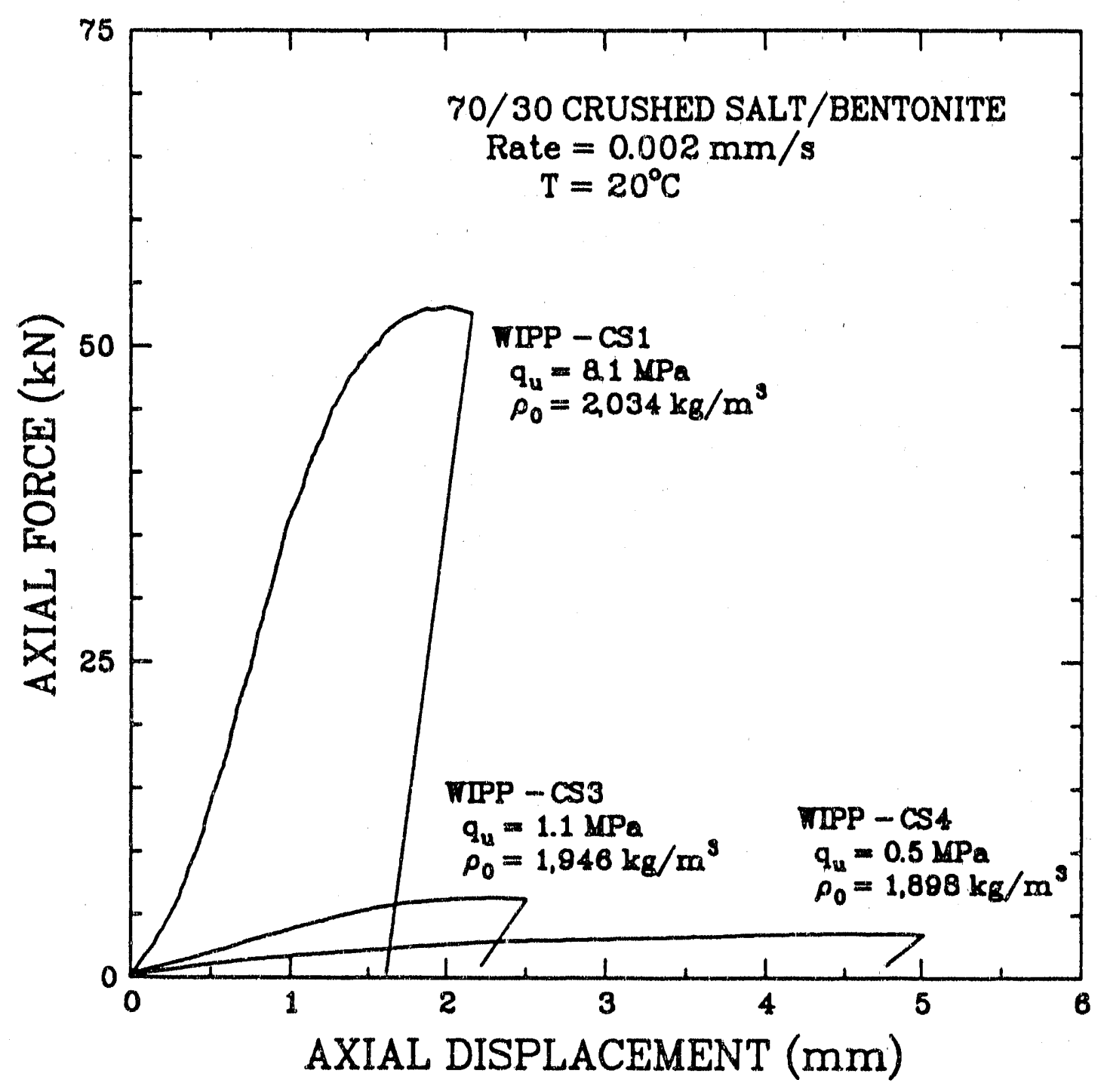

Figure 5-\%. Axial Force-Displacernent for Unconfined Compression Tests of WIPP Crushed Salt/Bentonite. 
The weighted mean water content for CS1 was approximately equal to the initial water content for the specimen ( 5.35 perent compared to 5.30 percent). The weighted mean water content for CS4 was much higher than the initial water content, i.e., 9.39 percent compared to 5.24 percent. This increase was probably a result of starting the permeability test before the specimen had reached full saturation. For CS3, the weighted mean water content was lower than the initial water content (8.92 percent compared to 9.97 percent); however, brine was expelled from this specimen during the consolidation stages and the drop in water content was expected. The water content distribution was generally uniform throughout the specimen except at the ends of the specimen where it was somewhat higher. 
Table 5-3. Water Content Distribution

\begin{tabular}{|c|c|c|c|c|}
\hline $\begin{array}{l}\text { Specimen } \\
\text { I.D. }\end{array}$ & $\begin{array}{c}\text { Initial } \\
\text { Water } \\
\text { Content }(\%)\end{array}$ & $\begin{array}{c}\text { Sample } \\
\text { No. }\end{array}$ & $\begin{array}{c}\text { Dry } \\
\text { Mass } \\
(\mathbf{g})\end{array}$ & $\begin{array}{c}\text { Water } \\
\text { Content } \\
\text { Dry Wt. (\%) }\end{array}$ \\
\hline CS1 & 5.30 & $\begin{array}{c}1 \\
2 \\
3 \\
4 \\
5 \\
6 \\
7 \\
8 \\
\operatorname{Mean}^{(a)}\end{array}$ & $\begin{array}{l}296.68 \\
294.21 \\
290.37 \\
261.38 \\
277.53 \\
308.70 \\
290.92 \\
277.06\end{array}$ & $\begin{array}{l}4.89 \\
4.88 \\
4.59 \\
4.81 \\
4.98 \\
5.78 \\
6.04 \\
6.86 \\
5.35\end{array}$ \\
\hline CS4 & 5.24 & $\begin{array}{c}1 \\
2 \\
3 \\
4 \\
5 \\
6 \\
7 \\
8 \\
\text { Meann }^{(a)}\end{array}$ & $\begin{array}{l}382.73 \\
240.39 \\
262.07 \\
301.05 \\
323.75 \\
343.32 \\
203.10 \\
269.22\end{array}$ & $\begin{array}{r}9.75 \\
7.36 \\
7.60 \\
8.56 \\
8.29 \\
9.90 \\
14.12 \\
10.44 \\
9.39\end{array}$ \\
\hline CS3 & 9.97 & $\begin{array}{c}1 \\
2 \\
3 \\
4 \\
5 \\
6 \\
7 \\
8 \\
\operatorname{Mean}^{(a)}\end{array}$ & $\begin{array}{l}237.30 \\
198.89 \\
2 ? 7.70 \\
20: .30 \\
198.04 \\
231.08 \\
200.37 \\
230.70\end{array}$ & $\begin{array}{r}10.75 \\
8.83 \\
8.91 \\
8.63 \\
8.52 \\
8.30 \\
8.09 \\
9.01 \\
8.92\end{array}$ \\
\hline
\end{tabular}

(a) Weighted mean calculated using dry mass as weights. 


\subsection{MODEL. FITTING}

Two empirical consolidation models were fitted to the volumetric strain and dry density data of Section 5.1. The $\log (t)$ model proposed by Holcomb and Hannum [1982] was fitted to the volumetric strain data. A model used by Sjaardema and Krieg [1987] was fitted to the dry density data. The fitting procedures and model parameters determined from the procedures are given below.

\subsection{LOG(t) MODEL}

The $\log (t)$ model was fitted to the engineering volumetric strains measured during each wage (except the permeability stage) of the consolidation tests and is defined as

$$
\epsilon_{v}=a \cdot \log _{10}(t)+b
$$

where $a$ is the slope or rate parameter determined from a least squares fit of the volumetric strain- $\log _{10}(t)$ data, $t$ is time in seconds, and $b$ is a fitting parameter. Values of $a$ and $b$ determined from fits to individual stages are given in Table 6-1. Curves of volumetric strain- $\log _{10}(t)$ are given in the appendices for each stage of CS1, CS4, and CS3. These curves are shown to be nonlinear at early times. Therefore, fits were also made to truncated data sets in which early time data were removed. The cutoff lime was arbitrarily selected as 100,000 seconds. Values of a and $b$ from the truncated data sets were about twice those determined from all the data and are also given in Table 6-1. Volumetric strains predicted by Equation 6-1 and the parameters determined from the truncated data sets are plotted on the volumetric strain-time curves given in the appendices.

Although Equation 6-1 is not valid at $t=0$ and fits short-term strain data poorly, the rate parameter may be used to study the influence of pressure and water content on the consolidation rate of crushed salt and crushed salt/bentonite. In the present study, the rate pararneter is constant (about 0.02) within the uncertainty of the data and is not affected by pressure or water content; however, the densities at the beginning of the stages are not constant. Therefore, comparisons of the rate parameter at different conditions of pressure and water content may be misleading. The low values of the rate parameter for Stages 2 and 3 of CS3 are prob_bly caused by a change in the rate controlling mechanism of consolidation for saturated materials compared to unsaturated materials.

Figure 6-1 plots the rate paraneter as a function of water content for this study and also for other studies [Holcomb and Hannurn, 1982; Holcomb and Shields, 1987; Pfeille and Senseny, 1985; Stroup and Senseny, 1987) of both crushed salt and crushed salt/bentonite mixtures. The rate parameter falls into two distinct regions 
Table 0-1. Parameter Values for Volumetric Strain Model

\begin{tabular}{|c|c|c|c|c|c|c|}
\hline \multirow{3}{*}{$\begin{array}{l}\text { Test } \\
\text { I.D. }\end{array}$} & \multirow{3}{*}{$\begin{array}{c}\text { Water } \\
\text { Content } \\
\text { Dry Wt. } \\
(\%)\end{array}$} & \multirow{3}{*}{$\begin{array}{c}\text { Hydrostatic } \\
\text { Stress } \\
\sigma_{\text {hyd }} \\
(\mathbf{M P a})\end{array}$} & \multicolumn{4}{|c|}{ Parameter Values $^{(a)}$} \\
\hline & & & \multicolumn{2}{|c|}{ All Data } & \multicolumn{2}{|c|}{ Truncated Data ${ }^{(b}$} \\
\hline & & & a & b & a & b \\
\hline $\mathrm{CS} 1$ & 5.3 & & & & & \\
\hline Stage 1 & & 3.45 & 0.0155 & -.0249 & 0.0203 & -.0555 \\
\hline Stage 2 & & 7 & 0.0100 & -.0246 & 0.0214 & -.0926 \\
\hline Stage 3 & & 14 & $0.015 \AA$ & -.0421 & 0.0259 & -.1081 \\
\hline $\mathrm{CS}_{4}{ }^{(c)}$ & 5.24 & & & & & \\
\hline Stage 1 & & 3.45 & 0.0118 & -.0471 & 0.0161 & -.0751 \\
\hline Stage 2 & & 14 & 0.0287 & -.1105 & 0.0407 & -.1887 \\
\hline CS3 & 9.97 & & & & & \\
\hline Stage 1 & & 3.45 & 0.0165 & -.0256 & 0.0203 & -.0502 \\
\hline Stage 2 & & 7 & 0.0016 & +.0003 & 0.0056 & -.0228 \\
\hline Stage 3 & & 7 & 0.0035 & -.0087 & 0.0068 & -.0290 \\
\hline
\end{tabular}

(a) $\epsilon_{v}=a \log t+b$

(b) Fits to data with $t>100,000$ seconds.

(c) Specimen consolidated to $7 \mathrm{MPa}$ before Stage 1 creep initiated. 


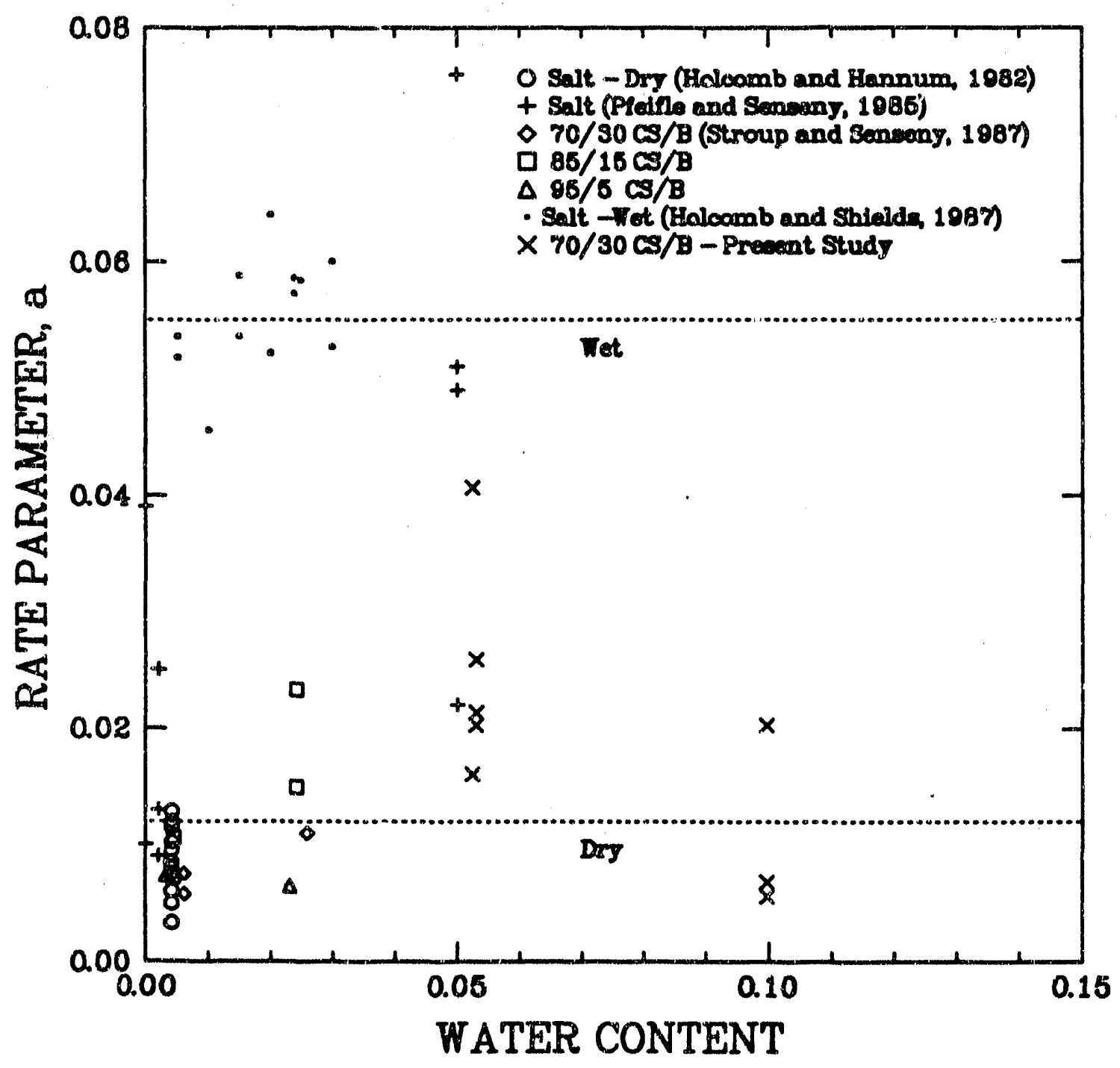

Figure 6-1. Consolidation Rate Parameter, a, as a Function of Water Content. 
of the plot, a wet region and a dry region. In the wet region, the rate parameter is approximately constant at 0.055 and the data shown are exclusively from tests of wet specimens (water contents greater than 0.005 ) of crushed salt. In the dry region, the rate parameter also appears to be constant (within the scatter) but at a significantly lower level of $\mathbf{0 . 0 1 2}$, and the data shown are from tests of both dry specimens of crushed salt and wet specimens of crushed salt/bentonite mixtures. This plot implies that the increase in the rate of consolidation experienced by wet crushed salt specirrens is absent when as little as 5 percent by dry weight of bentonite is added to the mixture. It then follows that the water that accelerates consolidation in specimens composed entirely of crushed salt is adsorbed by the bentonite in mixed specimens and, therefore, is not available to influence the consolidation rate. Obviously if the water content is high compared to the bentonite content, the rate parameter determined from tests of mixed specimens should approach that determined from wet specimens composed entirely of crushed salt. However, for water contents of 10 percent or less and a bentonite content of 30 percent, the values of the rate parameter are similar to those shown in the dry region of Figure 6-1.

\subsection{DENSITY MODEL}

In their analyses of backfilled shaft and drift configurations of the WIPP, Sjaardema and Krieg [1987] proposed an empirical consolidation model of the form

$$
\dot{\rho}=B_{0}\left[e^{B_{1} P}-1\right] e^{\Lambda \rho}
$$

where:

$$
\begin{aligned}
\dot{\rho} & =\text { Time rate of change of density } \\
\rho & =\text { Current density } \\
P & =\text { Applied pressure } \\
B_{0}, B_{1}, A & =\text { Fitting parameters. }
\end{aligned}
$$

In the present study, Equation 6-2 was integrated to express density as a function of time for use in fitting the dry density-time data of Section 5.1.2. Therefore, the model used in the fitting procedure was

$$
\rho=-\frac{1}{A} \ln \left[e^{-A \rho_{0}}-A \cdot B_{0}\left[e^{B_{1} P}-1\right] t\right]
$$

where:

$$
\begin{aligned}
\rho_{0} & =\text { Initial density }\left(\mathrm{kg} \cdot \mathrm{m}^{-3}\right) \\
P & =\text { Applied pressure }(\mathrm{MPa}) \\
t & =\text { Time }(\mathrm{s})
\end{aligned}
$$


Because Equation 6-3 is nonlinear in its parameters, a numerical procedure for solving simultarieous nonlinear equations was employed to minimize the sum-ofsquared error defined as

$$
S=\sum_{i=1}^{n}\left(\rho_{i}-\hat{\rho}_{i}\right)^{2}
$$

where:

$$
\begin{aligned}
& n=\text { Total number of measurements in the database } \\
& \rho_{i}=\text { Measured density at } i \\
& \hat{\rho}_{i}=\text { Predicted density at } i \text { from Equation 6-3. }
\end{aligned}
$$

In solving the nonlinear equations that arise from minimizing $S$, linear approximations to the equations were used. In this method, initial estimates of the unknown parameters were used to evaluate the coefficients in the linearized system of equations. The system of equations was solved to obtain new estimates of the parameters, and the process repeated until $S$ was minimized and the parameter values did not change by a prescribed amount. The numerical procedure employed in solving the equations was the Gauss/Newton method [Hartley, 1961].

Unlike the $\log (t)$ model, the density model was fit to each test rather than each stage of each test. Therefore, only three databases were fit rather than the eight used in the $\log (t)$ model. This approach was used so that the model parameters would be sensitive to the change both in pressure and initial density, as well as time. The parameters determined from the fits to each test could be compased to determine if a water content effect existed. Because the original databases contained large numbers of measurements $(>5,000)$, new databases were derived before the fitting procedure was employed. The new databases included 100 measurements (equally spaced in time) from each stage and, therefore, comprised 300, 200, and 300 measurements, respectively, for CS1, CS4, and CS3 (no measurements from the permeability stages were included in the databases). Table 6-2 gives the parameter values determined from the fits. With the exception of the rather low value of $B_{1}$ for CS3, the parameters determined for each test are nearly equal. The low value of $B_{1}$ may be a water content effect but probably resulted from fitting the noodel to a database containing consolidation measurements of a fully saturated specimen (i.e., Stages 2 and 3).

Using the parameters shown in Table 6-2, predictions of density as a function of time were made and are shown on the measured density-time plots given in the appendices. Predictions of fractional density were also made by dividing the predicted densities by the theoretical solid density of the mixture. These predictions are given in the appendices as well. 
Table 6-2. Parameter Values for Density Model

\begin{tabular}{|l|c|c|c|c|c|}
\hline \multirow{2}{*}{$\begin{array}{l}\text { Test } \\
\text { I.D. }\end{array}$} & $\begin{array}{c}\text { Water } \\
\text { Content } \\
\text { Dry Wt. (\%) }\end{array}$ & $\begin{array}{c}\text { Hydrostatic } \\
\text { Pressure } \\
(\mathrm{MPa})\end{array}$ & \multicolumn{3}{|c|}{ Parameter Values $(a)$} \\
\cline { 3 - 6 }
\end{tabular}
(a) $\rho=-\frac{1}{A} \ln \left\{e^{-A \rho o}-A B_{0}\left[e^{B_{1} P}-1\right] t\right\}$
(b) Specimen consolidated to $7 \mathrm{MPa}$ before Stage 1 creep initiated. 


\subsection{SUMMARY AND CONCLUSIONS}

Three consolidation tests were performed on specimens of 70 percent crushed salt by dry weight and 30 percent bentonite by dry weight. The specimens were prepared at nominal water contents of 5 or 10 percent based on total dry weight. Each test comprised several stages in which various hydrostatic stress or pressure levels were applied. The pressures ranged from 3.45 to $14 \mathrm{MPa}$. Pressures were maintained until the specimens reached full saturation at which time permeability tests were performed using the constant rate of flow of brine technique. Strength and water content distribution were determined for each specimen.

Two of the three specimens reached full saturation at times less than about 150 days at pressure; however, the third srecimen did not reach saturation even after 200 days at pressure. $A \log (t)$ model was fitted to the volumetric strain data to study the effect of pressure and water content on the consolidation rate parameter, a. Although the water content ranged from 5 to 10 percent and the pressure from 3.45 to $14 \mathrm{MPa}$, the rate parameter determined from the fits was essentially constant. This result should be used cautiously, however, because the initial densities for each stage were not constant. A density model proposed by Sjaardema and Krieg [1987] was fitted to the dry density data. The parameter values determined from these fits include pressure-sensitivity but changed little when the water content was changed.

Constant rate of flow tests showed that the permeability of saturated specimens of crushed salt/bentonite ranged from $1.3 \times 10^{-17} \mathrm{~m}^{2}$ to $4.9 \times 10^{-17} \mathrm{~m}^{2}$. In one test, no flow could be established even after 167 days. The specimen in this test had the highest density of the three tested.

Constant displacement rate unconfined compressive strengths of the three specimens ranged from 0.5 to $8.1 \mathrm{MPa}$. These strengths were correlat ad to density; i.e., higher strengths were measured at higher densities. The water content distribution was approximately uniform throughuut the specimen with the exception of slightly higher water contents near the ends of the specimens. 


\subsection{REFERENCES}

Hartley, H. O., 1961. "The Modified Gauss-Newton Method for Fitting of Nonlinear Regression Functions by Least Squares," Technometrics, Vol. 3, pp. 269-280.

Holcomb, D. J., and D. W. Hannum, 1982. Consolidation of Crushed Salt Backfill Under Conditions Appropriate to the WIPP Facility, SAND82-0630, Sandia National Laboratories, Albuquerque, NM.

Holcomb, D. J., and M. Shields, 1987. Hydrostatic Creep Consolidation of Crushed Salt With Added Water, SAND87-1990, Sandia National Laboratories, Albuquerque, NM.

Pfeifle, T. W., 1986. Backfill Material Specifications and Requirements for the WIPP Simulated DHLW and TRU Waste Technology Experiments, SAND85-7209, prepared by RE/SPEC Inc., Rapid City, SD, for Sandia National Laboratories, Albuquerque, NM.

Pfeifle, T. W., and P. E. Senseny, 1985. Permeability and Consolidation of Crushed Salt From the WIPP Site, prepared by RE/SPEC Inc., Rapid City, SD, RSI-0278, for Sandia National Laboratories, Albuquerque, NM.

Shor, A. J., C. F. Baes, Jr., and C. M. Canonico, 1981. Consolidation and Permeability of Salt in Brine, ORNL-5774, Oak Ridge National Laboratory, Oak Ridge, TN.

Sjaardema, G. D., and R. D. Krieg, 1987. A Constitutive Model for the Consolidation of WIPP Crushed Salt and Its Use in Analyses of Backfilled Shaft and Drift Configurations, SAND87-1977, Sandia National Laboratories, Albuquerque, NM.

Stroup, D. E., and P. E. Senseny, 1987. Influence of Bentonite Content on Consolidation and Permeability of Crushed Salt From the WIPP, prepared by RE/SPEC Inc., Rapid City, SD, RSI-0309, for Sandia National Laboratories, Albuquerque, NM. 


\section{APPENDIX A}

SUPPORTING DATA FOR CS1 


\section{APPENDIX A \\ LIST OF FIGURES}

A-1 Measured and Predicted Volumetric Strains as Functions of Time for CS1 Stage 1. . . . . . . . . . . . . . . . . . . . .

A-2 Measured and Predicted Volumetric Strains as Functions of Time for CS1 Stage 2. . . . . . . . . . . . . . . . . . . . . . . .

A-3 Measured and Predicted Volumetric Strains as Functions of Time for CS1 Stage 3. . . . . . . . . . . . . . . . . . . 53

A-4 Volumetric Strain as a Function of Log Time for CS1 Stage 1. . . . 54

A-5 Volumetric Strain as a Function of Log Time for CS1 Stage 2. . . . 55

A-6 Volumetric Strain as a Function of Log Time for CS1', Stage 3. . . . 56

A-7 Measured and Predicted Dry Densities as Functions of Time for CS1 Stage 1. . . . . . . . . . . . . . . . . . . . . . . . 57

A-8 Measured and Predicted Dry Densities as Functions of Time for CS1 Stage 2. . . . . . . . . . . . . . . . . . . . . . . 58

A-9 Measured and Predicted Dry Densities as Functions of Time for CS1 Stage 3. . . . . . . . . . . . . . . . . . . . . . . 59

A-10 Measured and Predicted Fractional Densities as Functions of Time for CS1 Stage 1. . . . . . . . . . . . . . . . . . . . . . . . . 60

A-11 Measured and Yredicted Fractional Densities as Functions of Time for CS1 Stage 2. . . . . . . . . . . . . . . .

A-12 Measured and Predicted Fractional Densities as Functions of Time for CS1 Stage 3. . . . . . . . . . . . . . . . . 


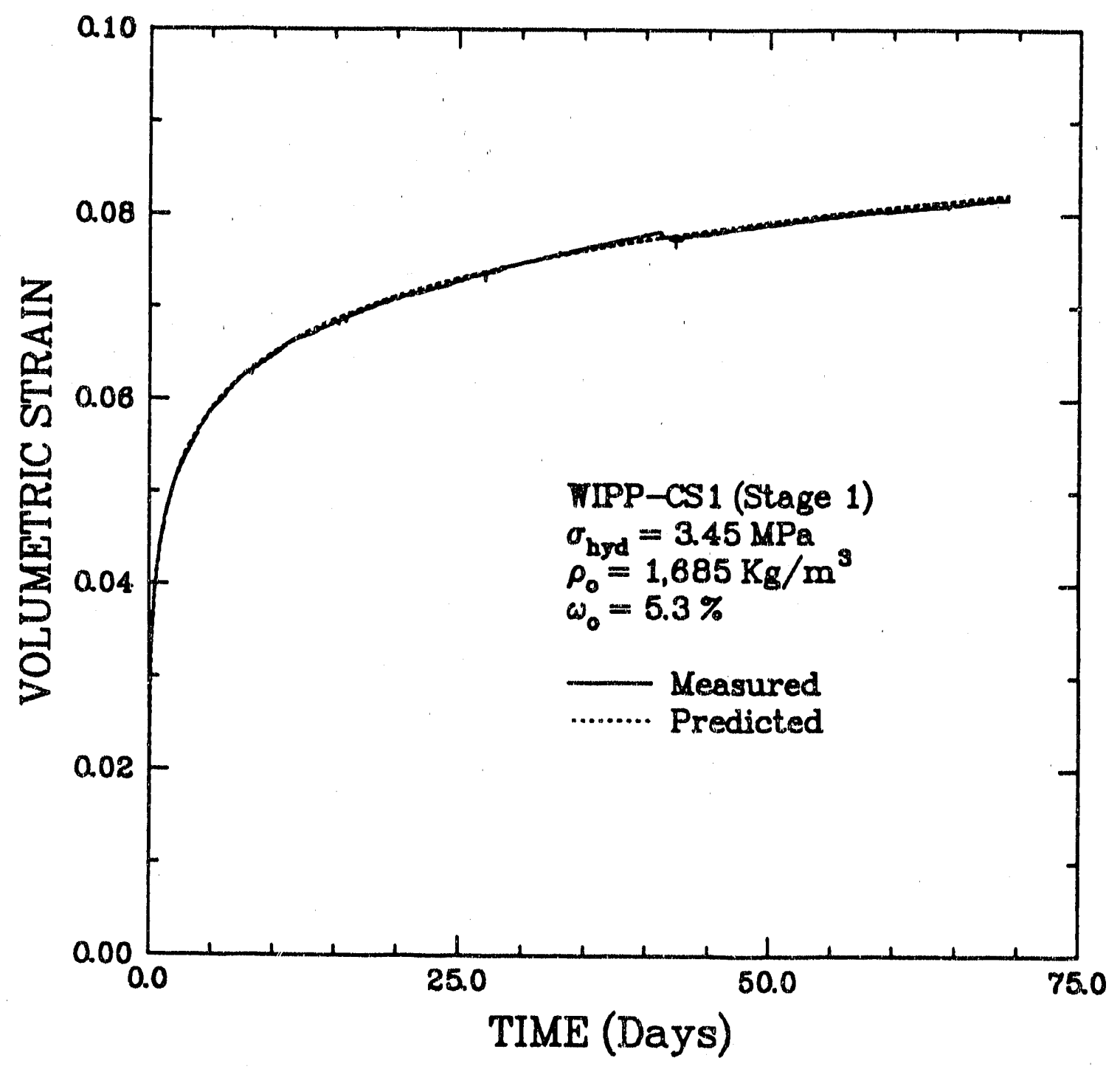

Figure A-1. Measured and Predicted Volumetric Strains as Functions of Time for CS1 Stage 1. 


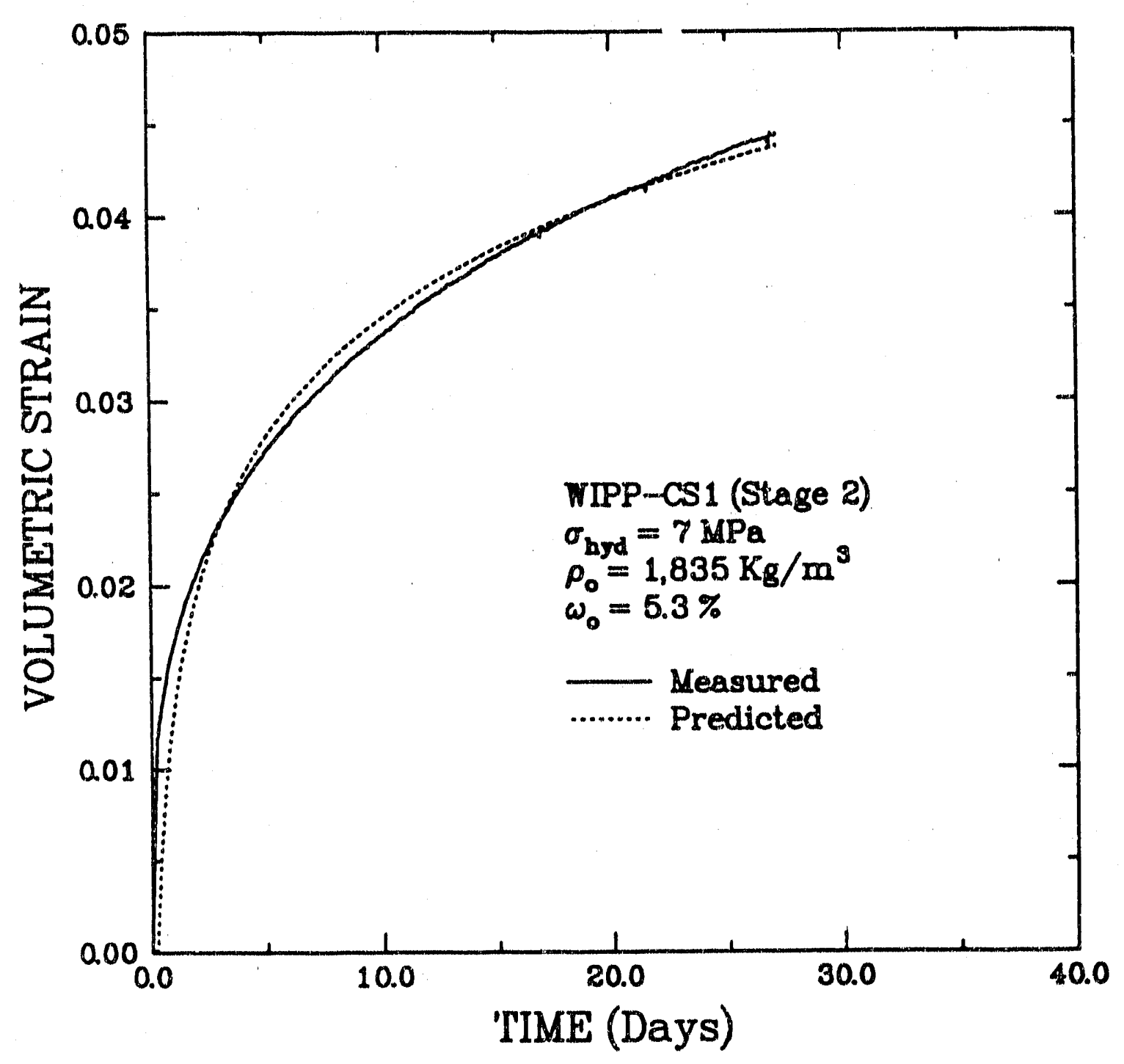

Figure A-2. Measured and Predicted Volumetric Strains as Functions of Time for CS1 Stage 2. 


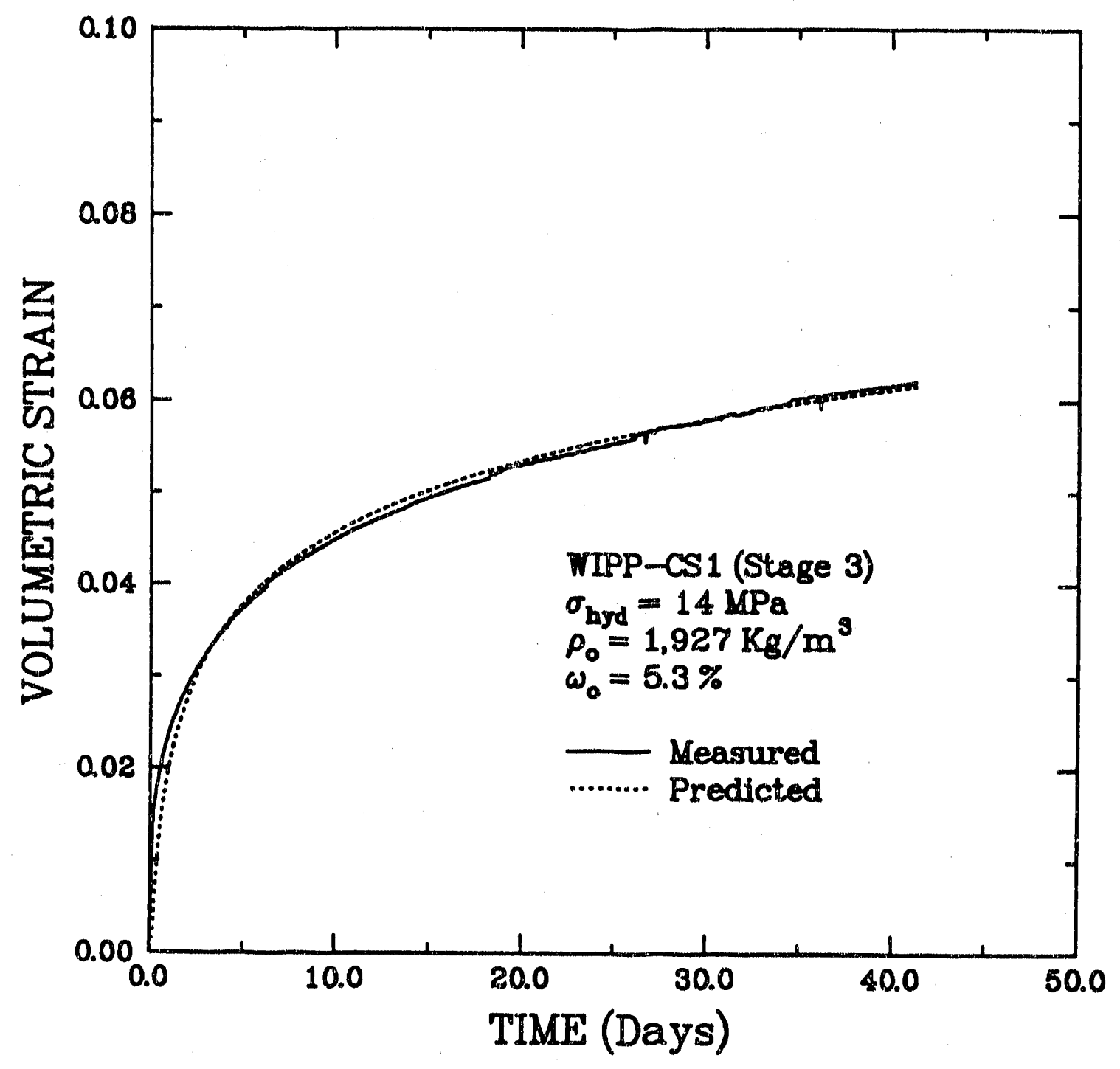

Figure A-3. Measured and Predicted Volumetric Strains as Functions of Time for CS1 Stage 3. 


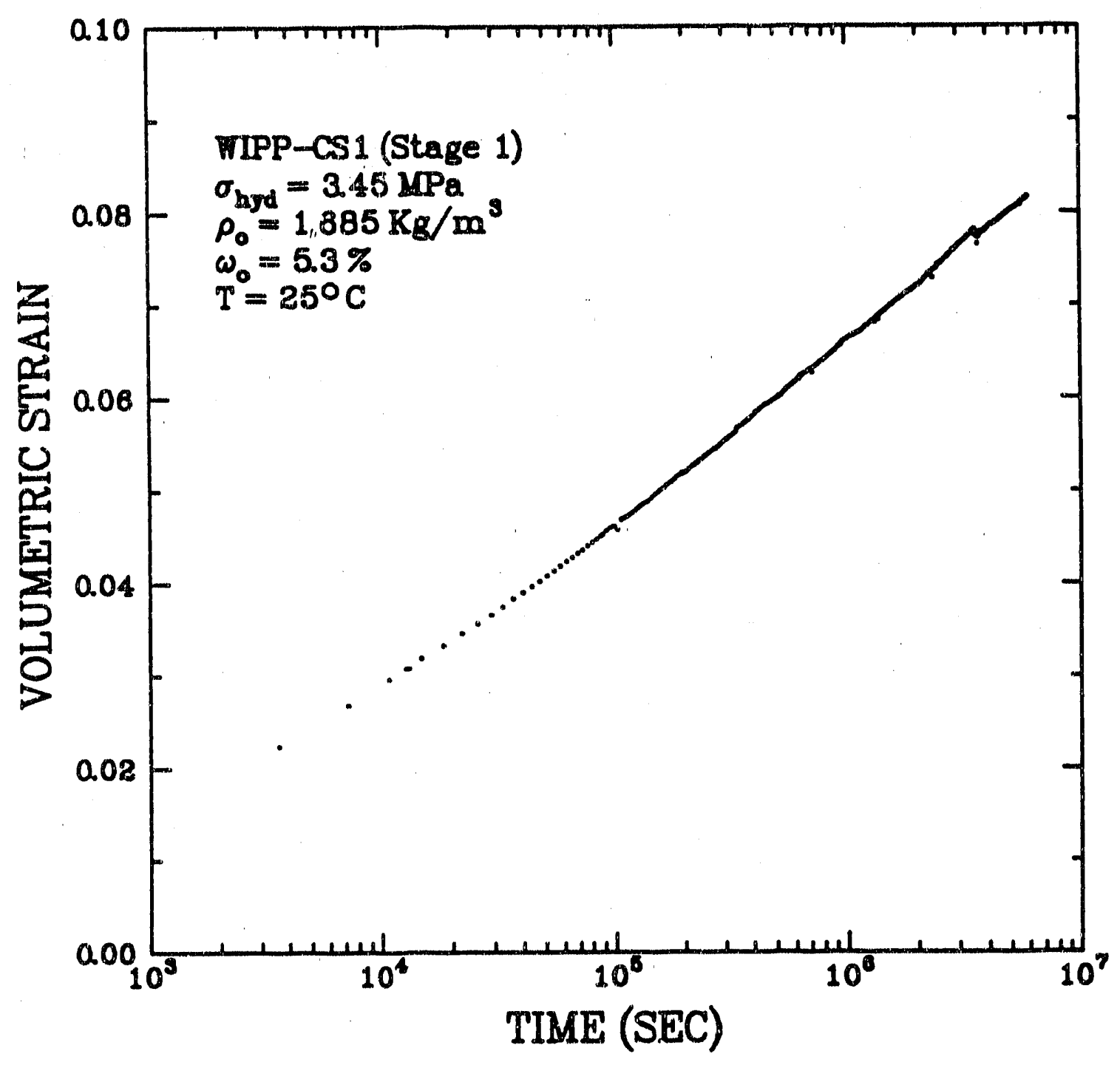

Figure A-4. Volumetric Strain as a Function of Log Time for CS1 Stage 1. 


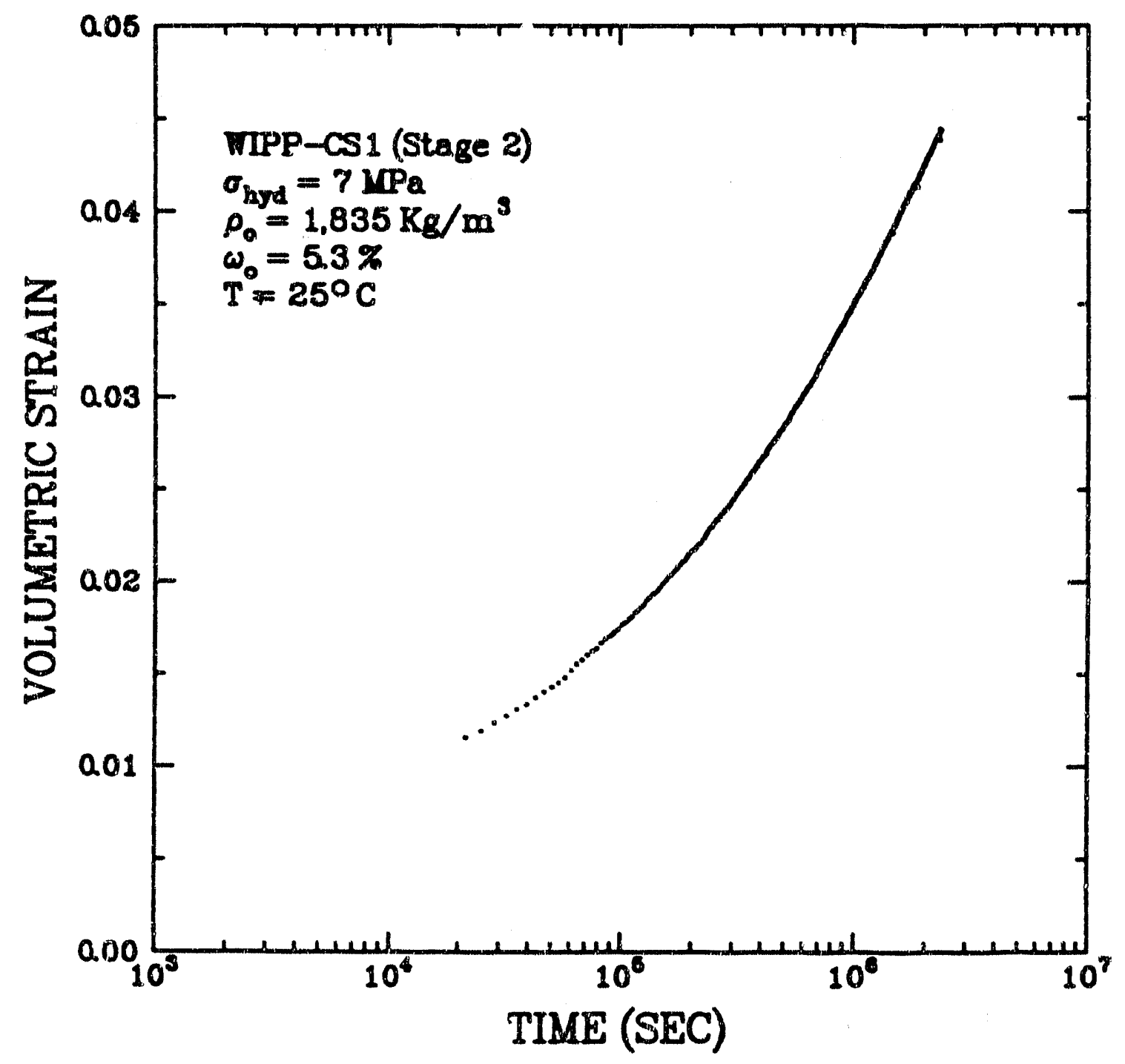

Figure A-5. Volumetric Strain as a Function of Log Time for CS1 Stage 2. 


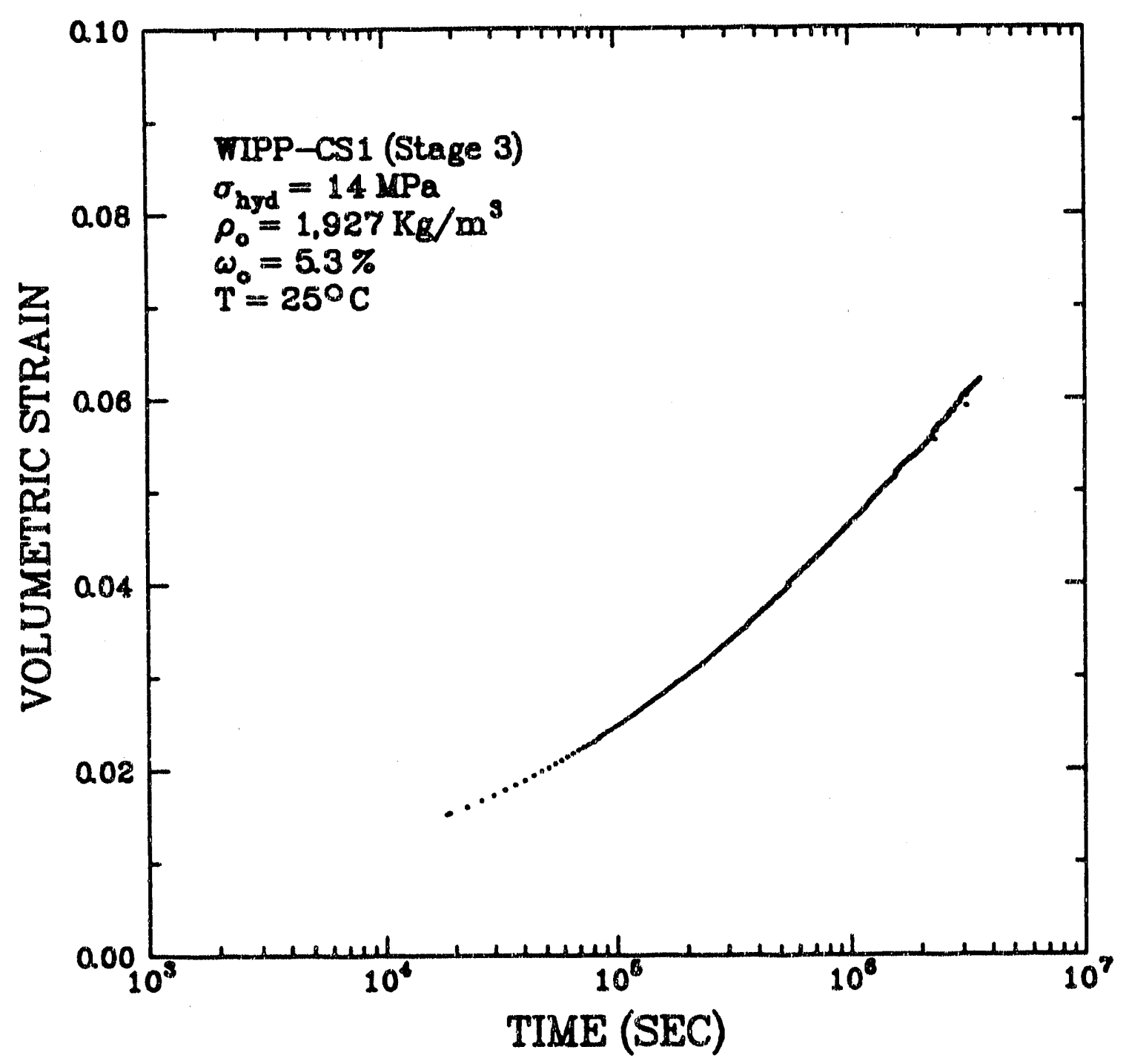

Figure A-6. Volumetric Strain as a Function of Log Time for CS1 Stage 3. 


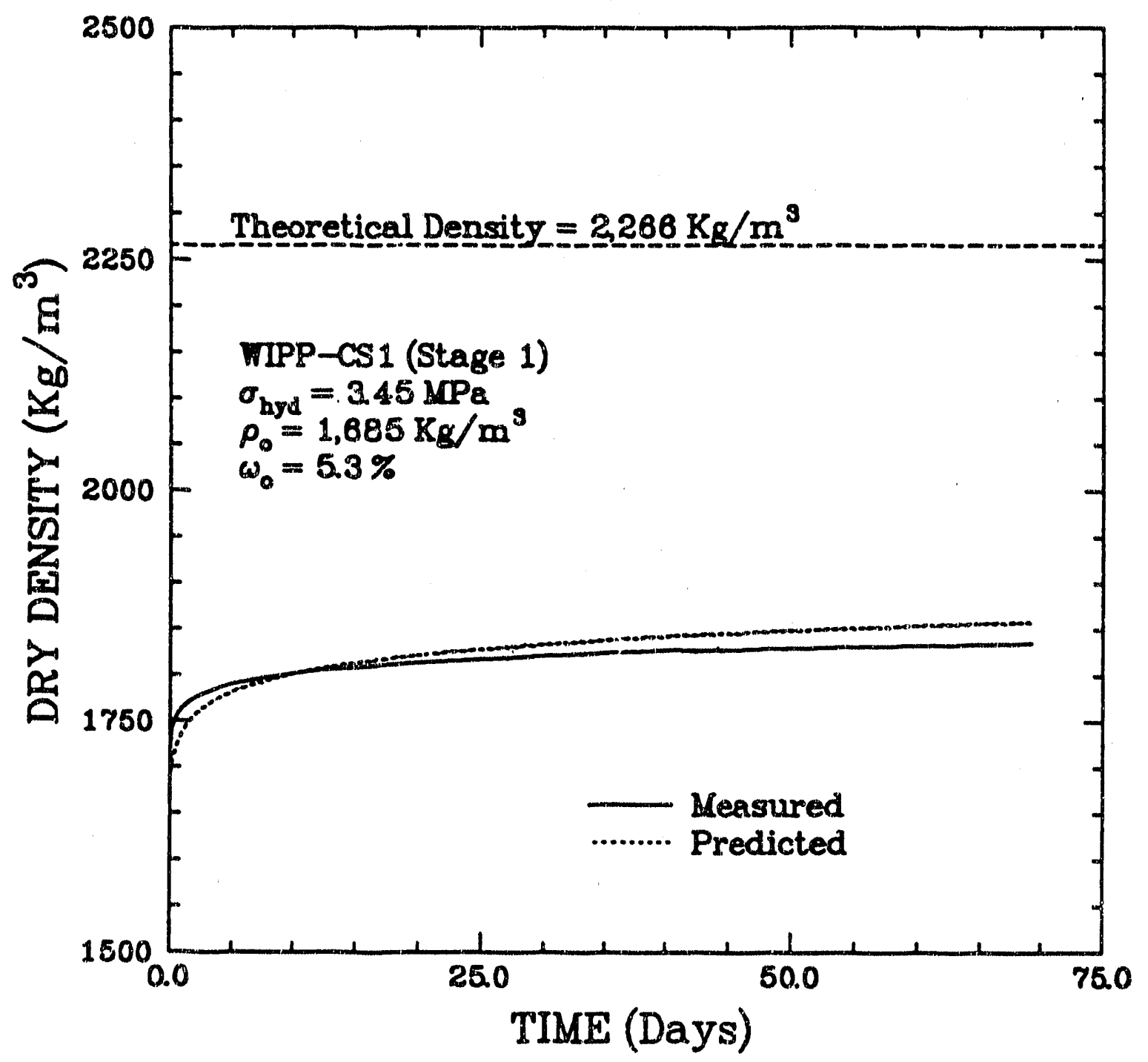

Figure A-7. Measured and Predicted Dry Densities as Functions of Time for CS1 Stage 1. 


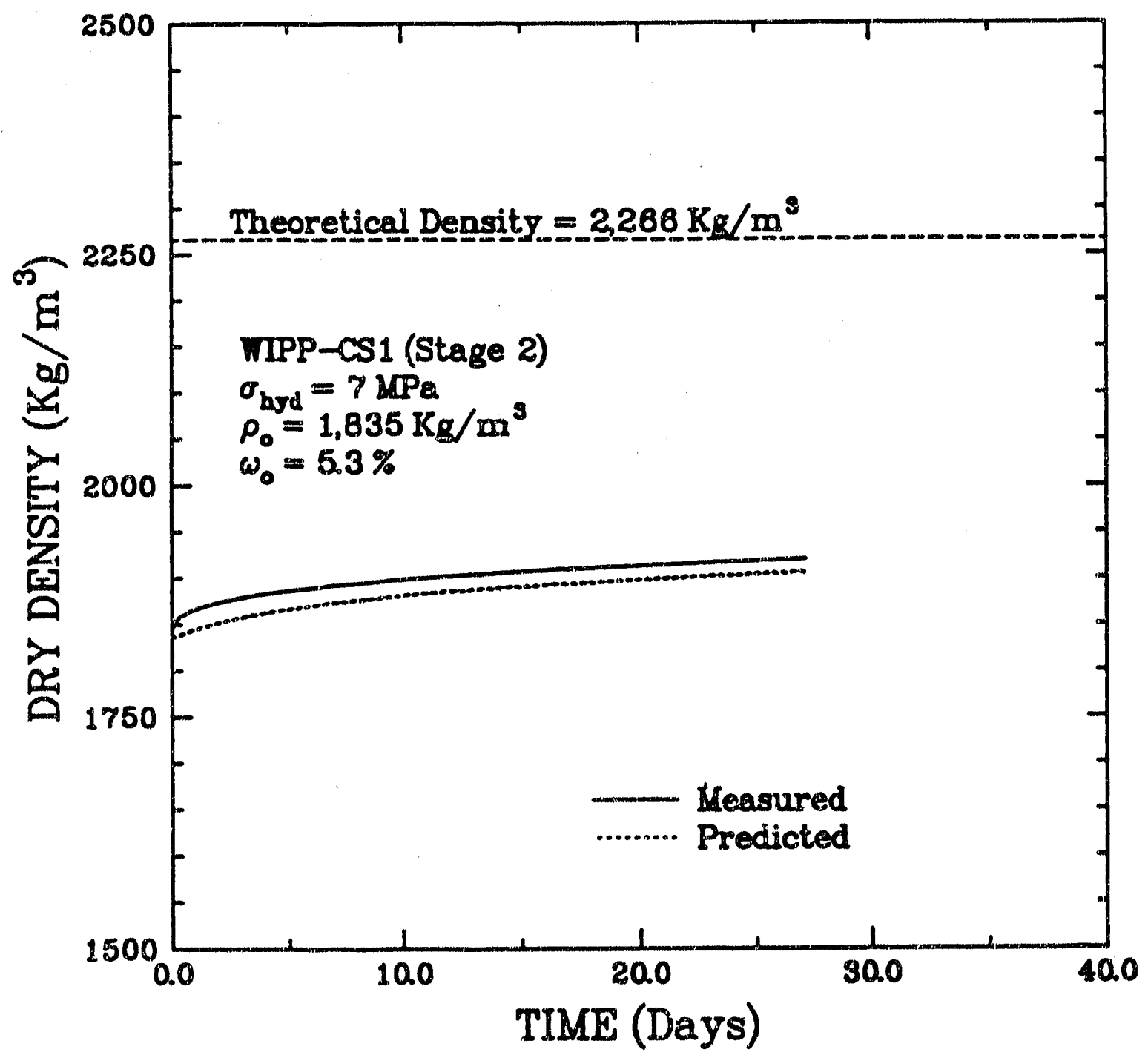

Figure A-8. Measured and Predicted Dry Densities as Functions of Time for CS1 Stage 2. 


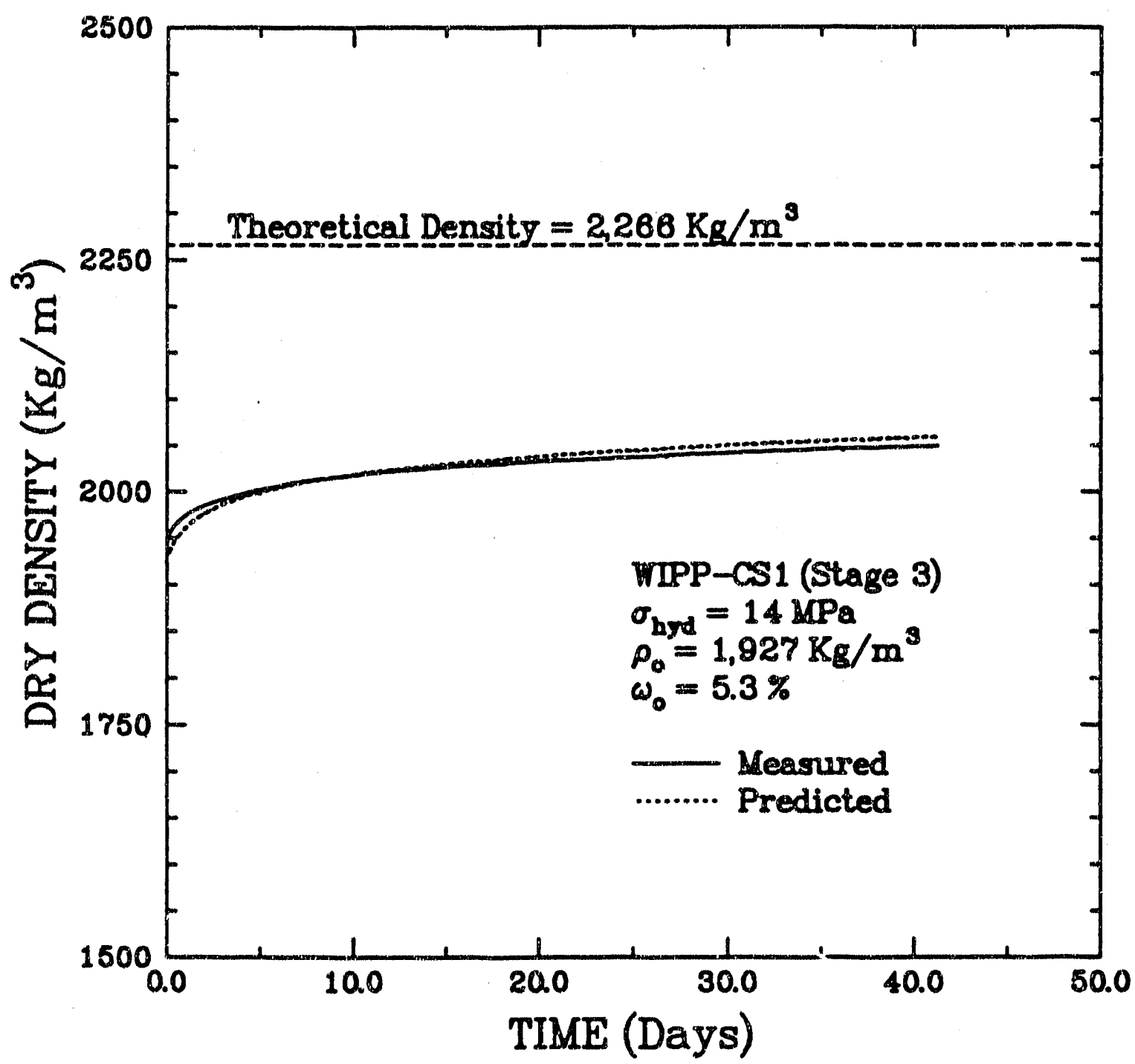

Figure A-9. Measured and Predicted Dry Densities as Functions of Time for CS1 Stage 3. 


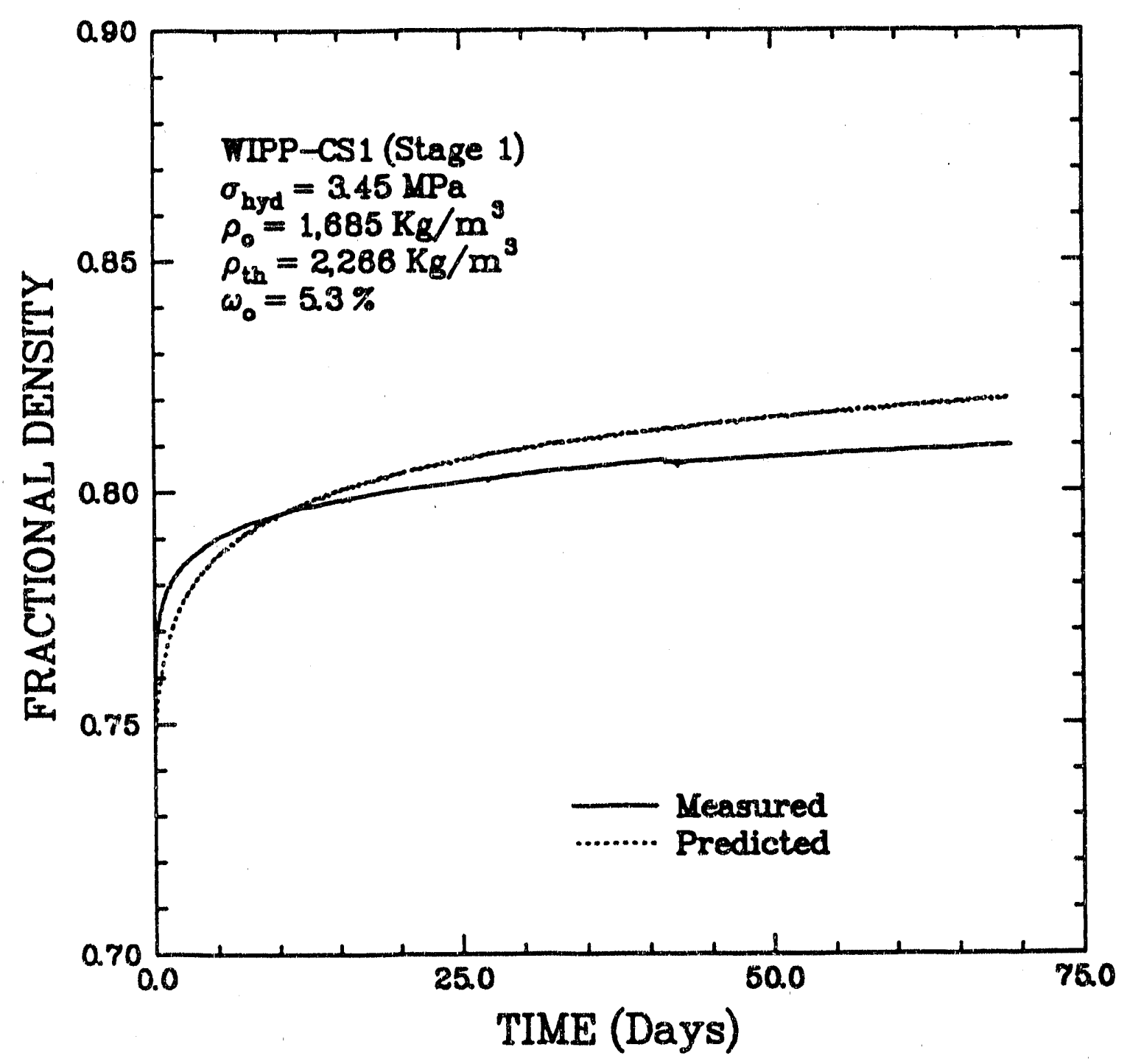

Figure A-10. Measured and Predicted Fractional Densities as Functions of Time for CS1 Stage 1. 


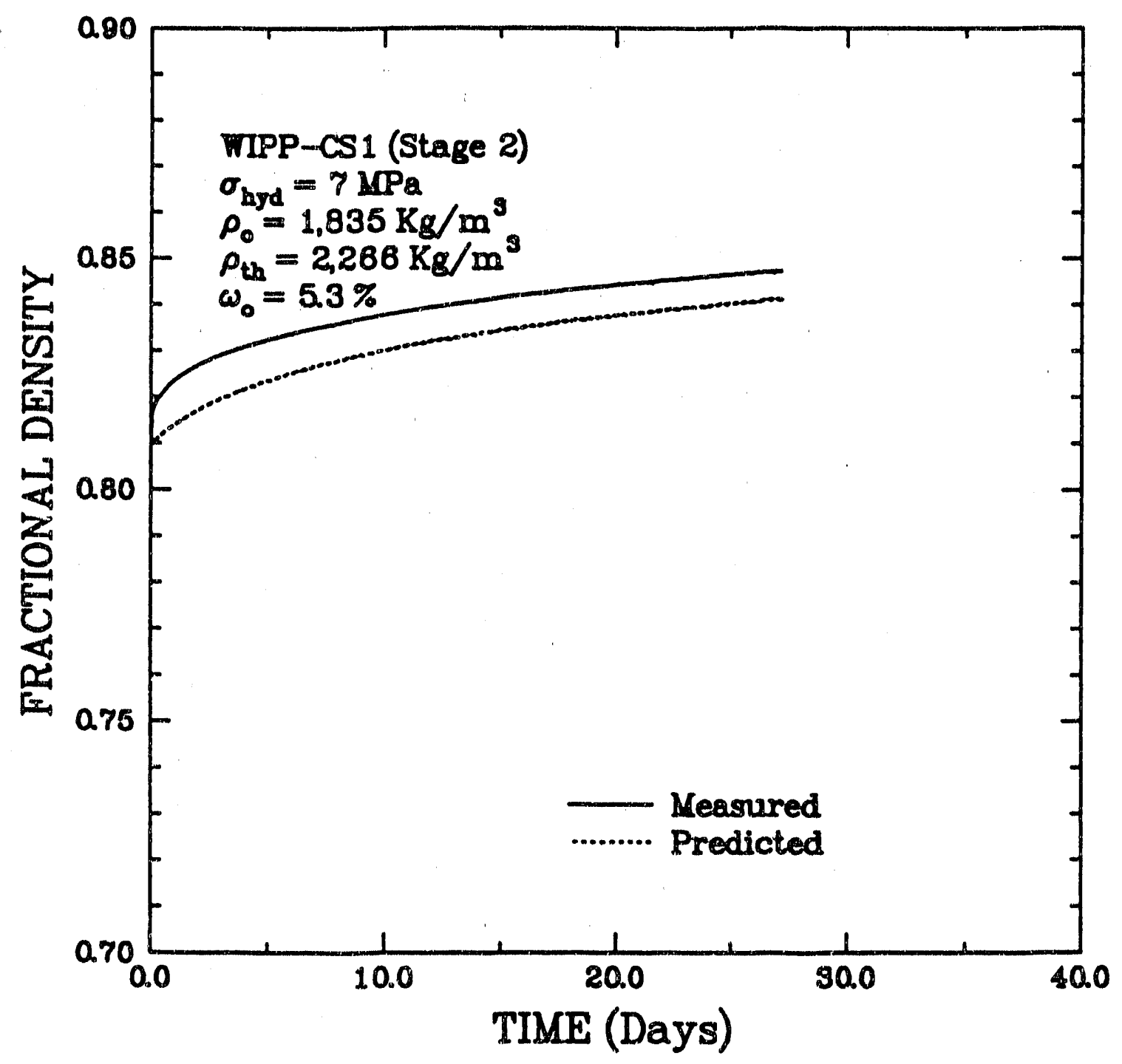

Figure A-11. Measured and Predicted Fractional Densities as Functions of Time for CS1 Stage 2. 


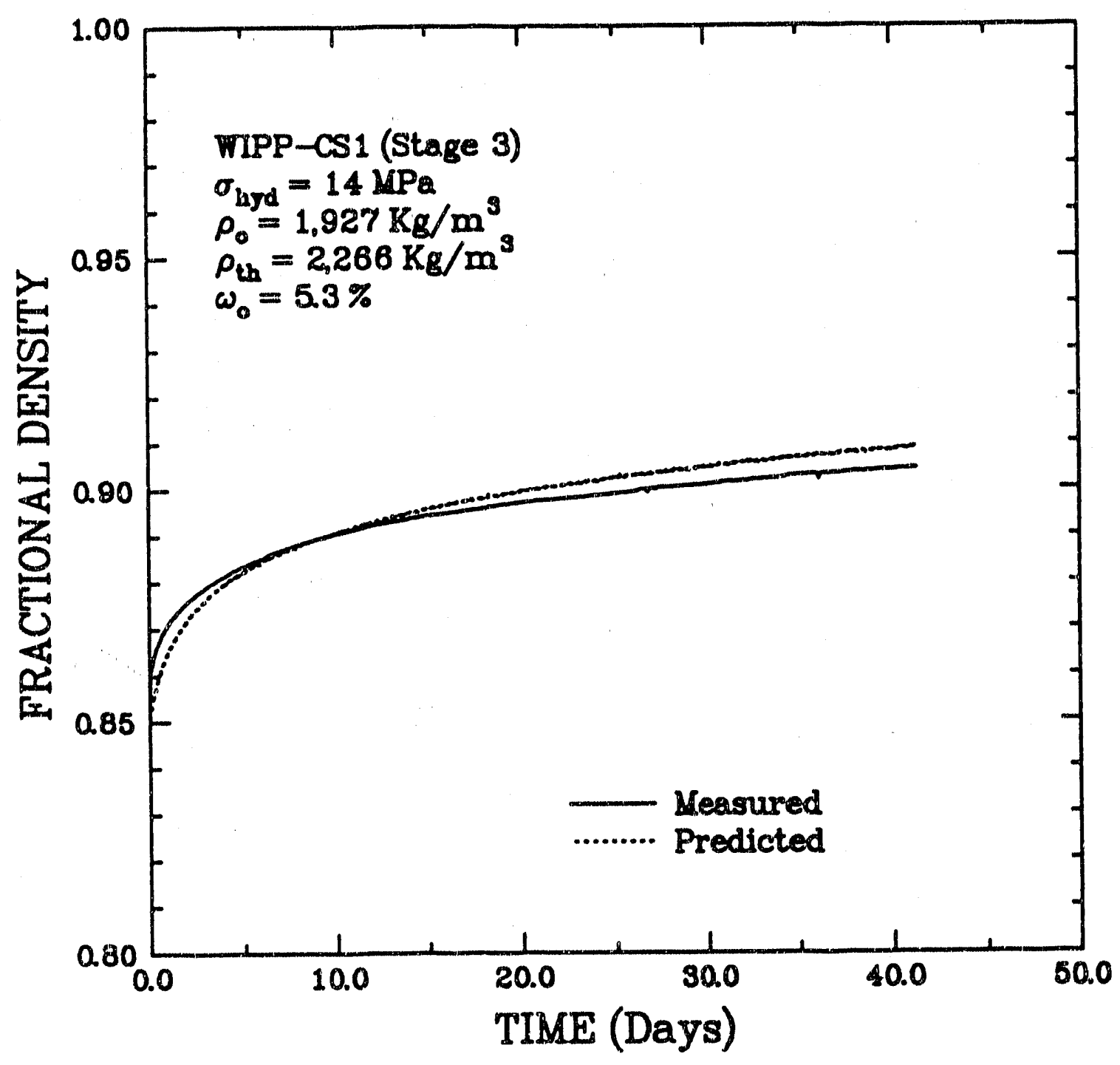

Figure A-12. Measured and Predicted Fractional Densities as Functions of Time for CS1 Stage 3. 


\section{APPENDIX B}

\section{SUPPORTING DATA FOR CS4}

$$
63 / 64
$$




\section{APPENDIX B LIST OF FIGURES}

B-1 Measured and Predicted Volumetric Strains as Functions of Time for CS4 Stage 1. . . . . . . . . . . . . . . . . . . . 67

B-2 Measured and Predicted Volumetric Strains as Functions of Time for CS4 Stage 2. . . . . . . . . . . . . . . . . . . . . 68

B-3 Volumetric Strain as a Function of Log Time for CS4 Stage 1. . . . 69

B-4 Volumetric Strain as a Function of Log Time for CS4 Stage 2. . . . 70

B-5 Measured and Predicted Dry Densities as Functions of Time for CS4 Stage 1. . . . . . . . . . . . . . . .

B-6 Measured and Predicted Dry Densities as Functions of Time for CS4 Stage 2. . . . . . . . . . . . . . . . . . . . .

B-7 Measured and Predicted Fractional Derisities as Functions of Time for CS4 Stage 1. . . . . . . . . . . . . . . . .

B-8 Measured and Predicted Fractional Densities as Functions of Time for CS4 Stage 2. . . . . . . . . . . . . . . . . 


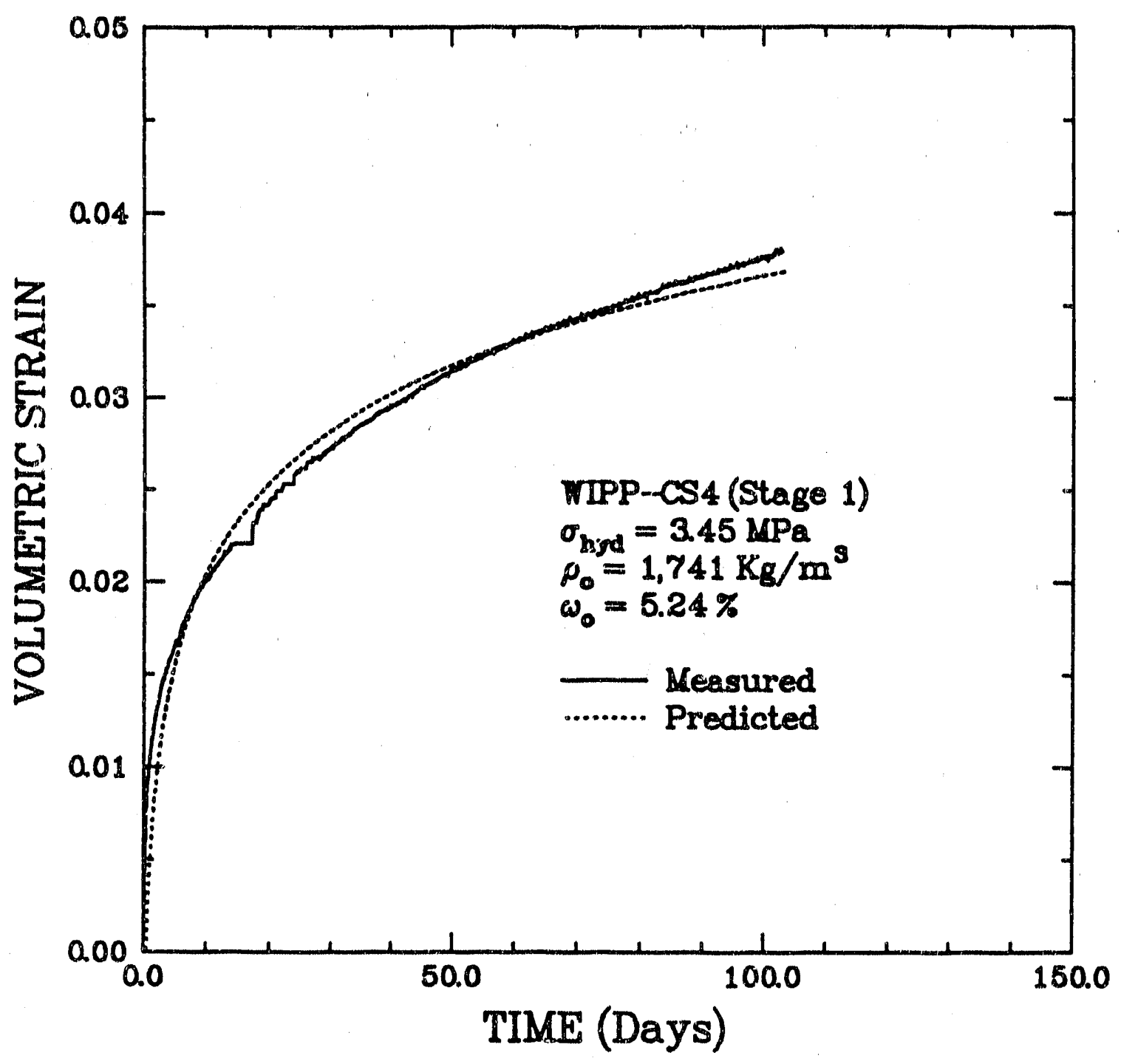

Figure B-1. Measured and Predicted Volumetric Strains as Functions of Time for CS4 Stage 1. 


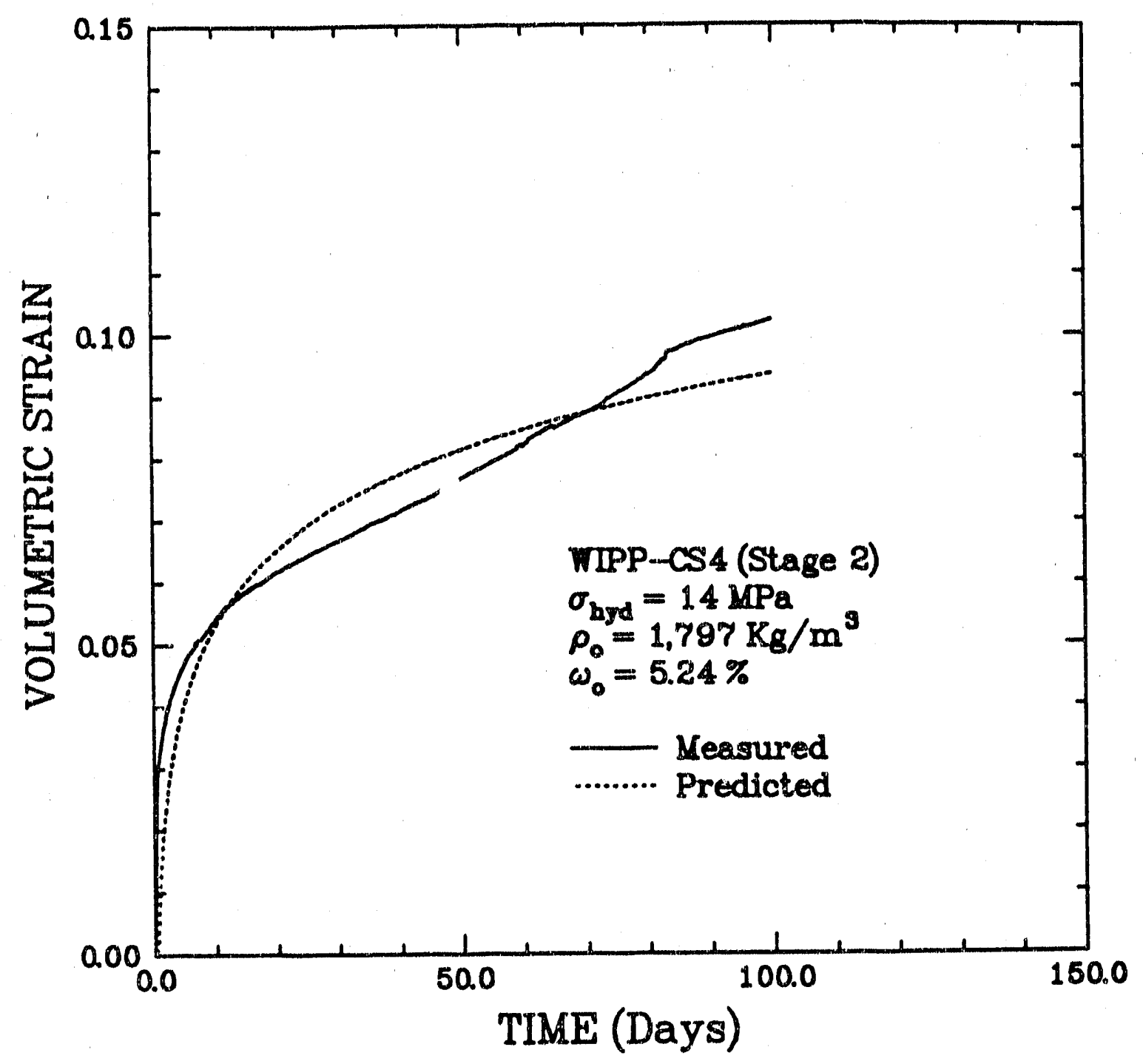

Figure B-2. Measured and Predicted Volumetric Strains as Functions of Time for CS4 Stage 2. 


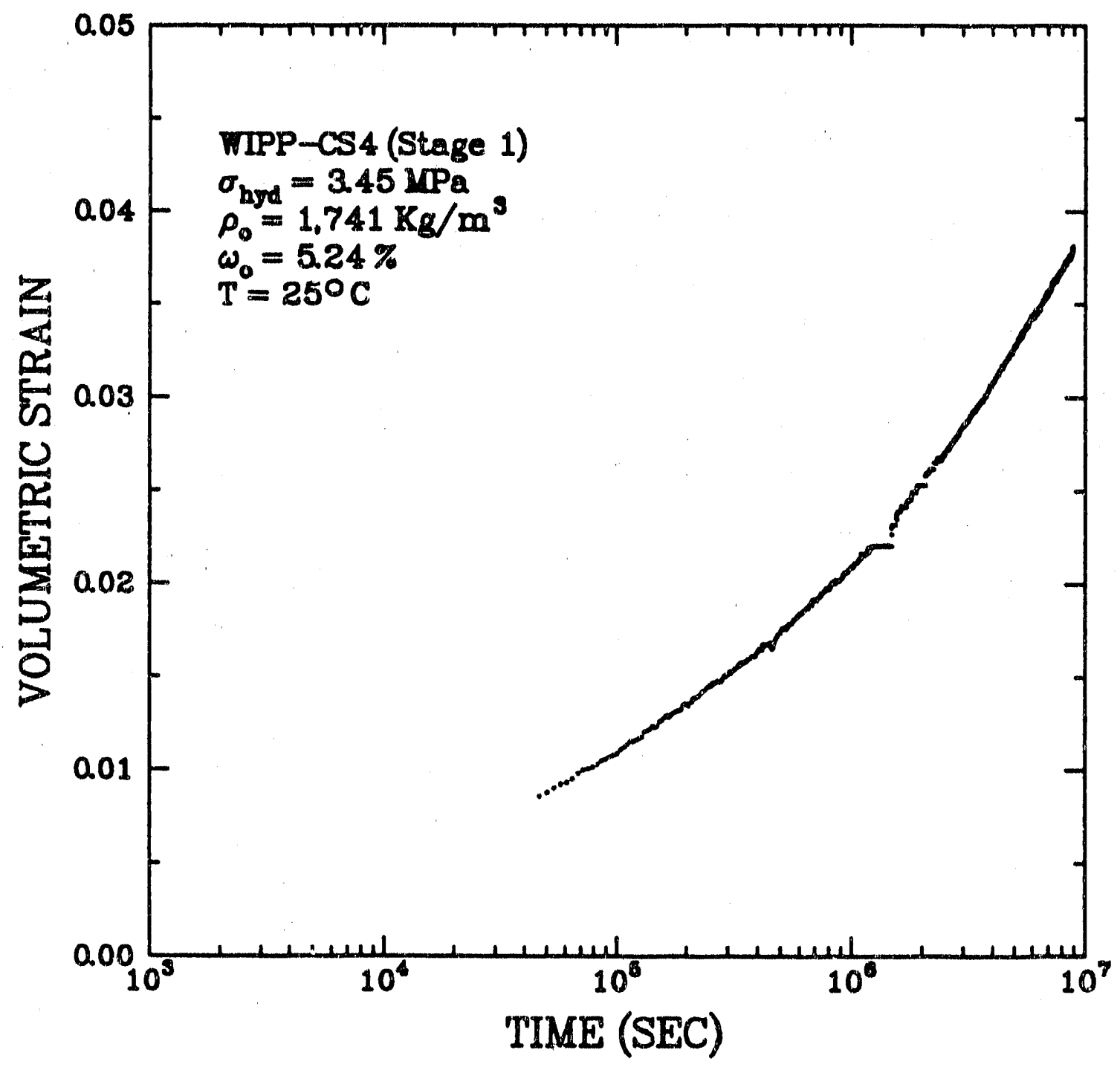

Figure B-3. Volumetric Strain as a Function of Log Time for CS4 Stage 1. 


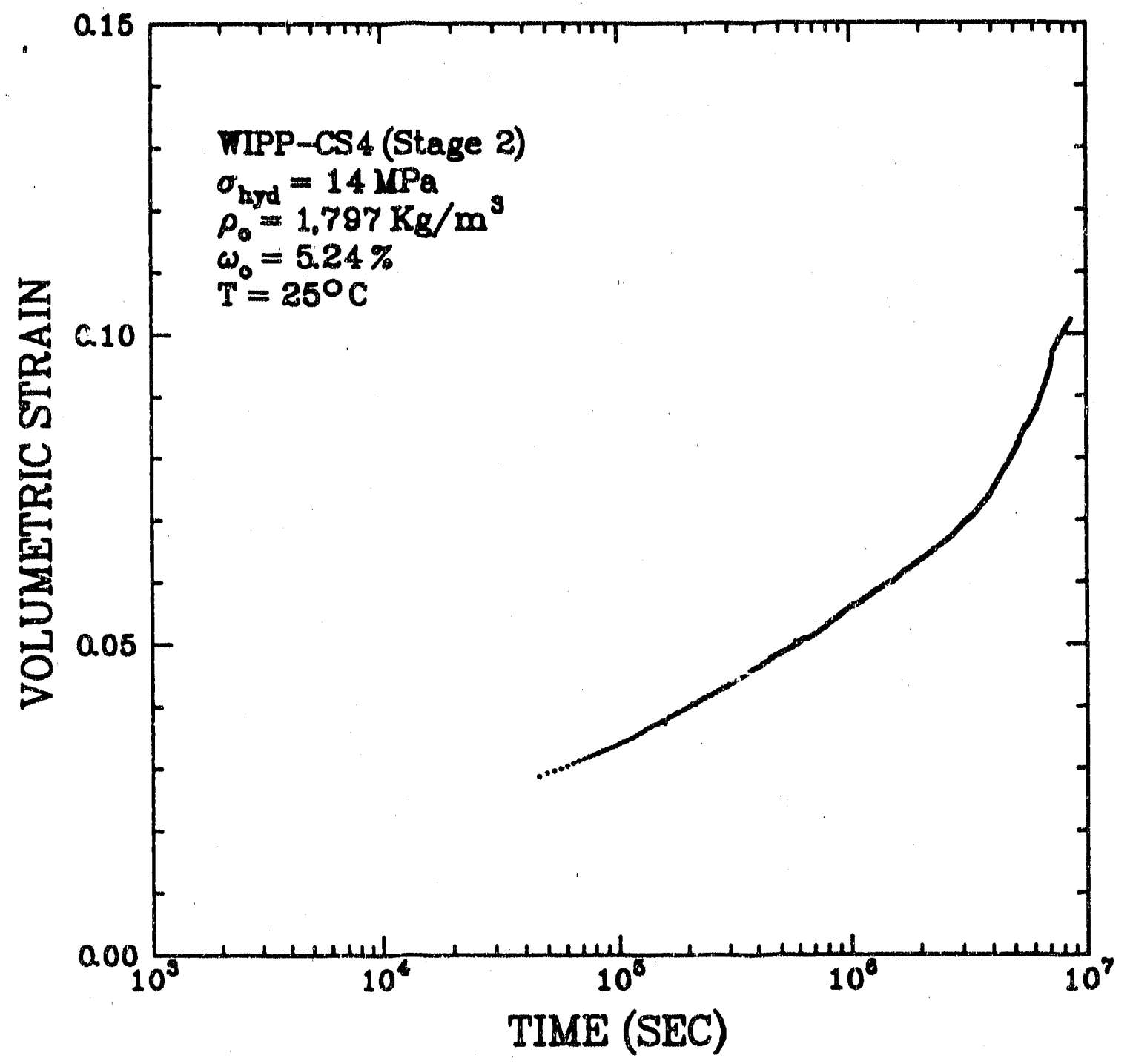

Figure B-4. Volumetric Strain as a Function of Log Time for CS4 Stage 2. 


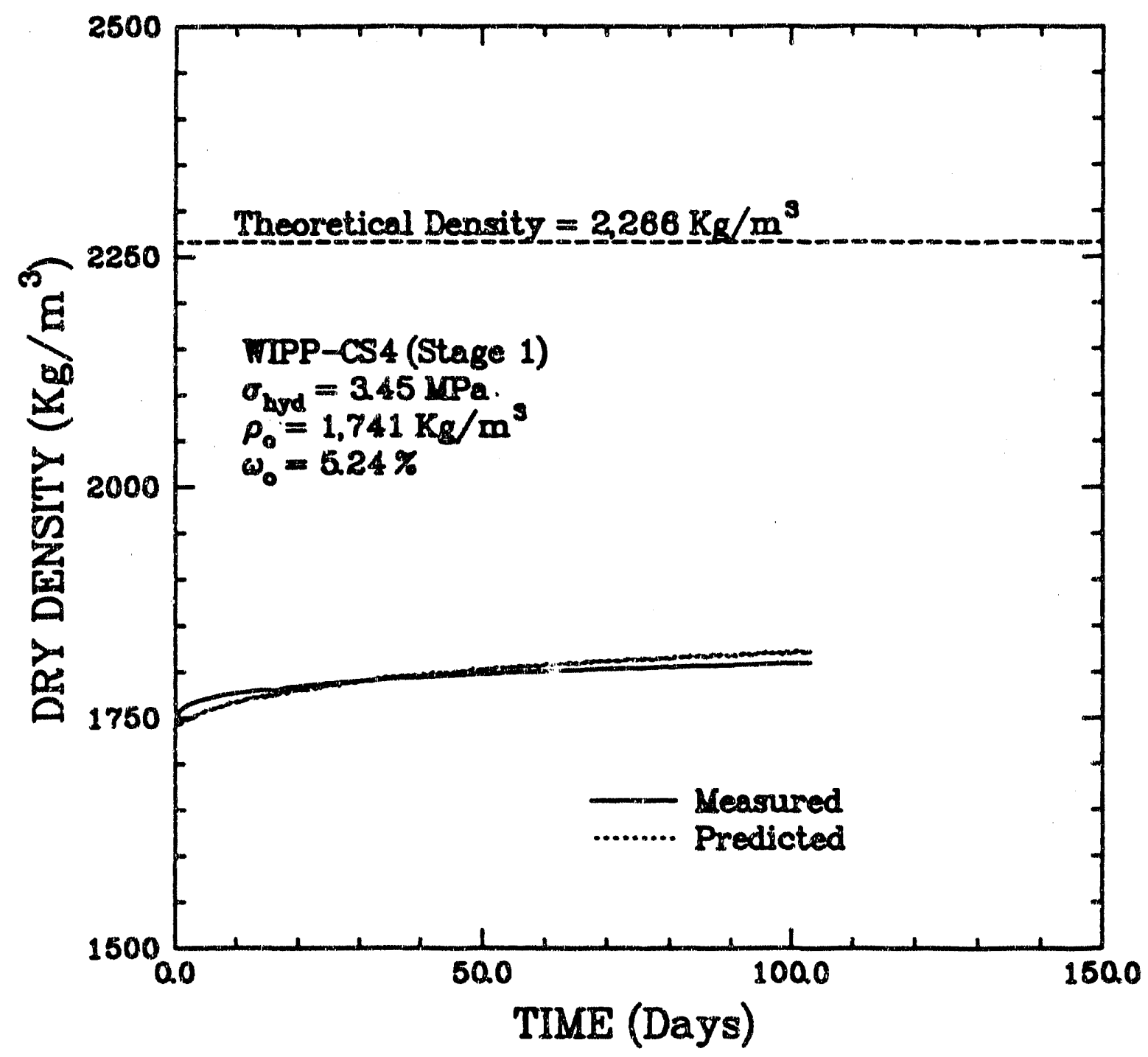

Figure B-5. Measured and Predicted Dry Densities as Functions of Time for CS4 Stage 1. 


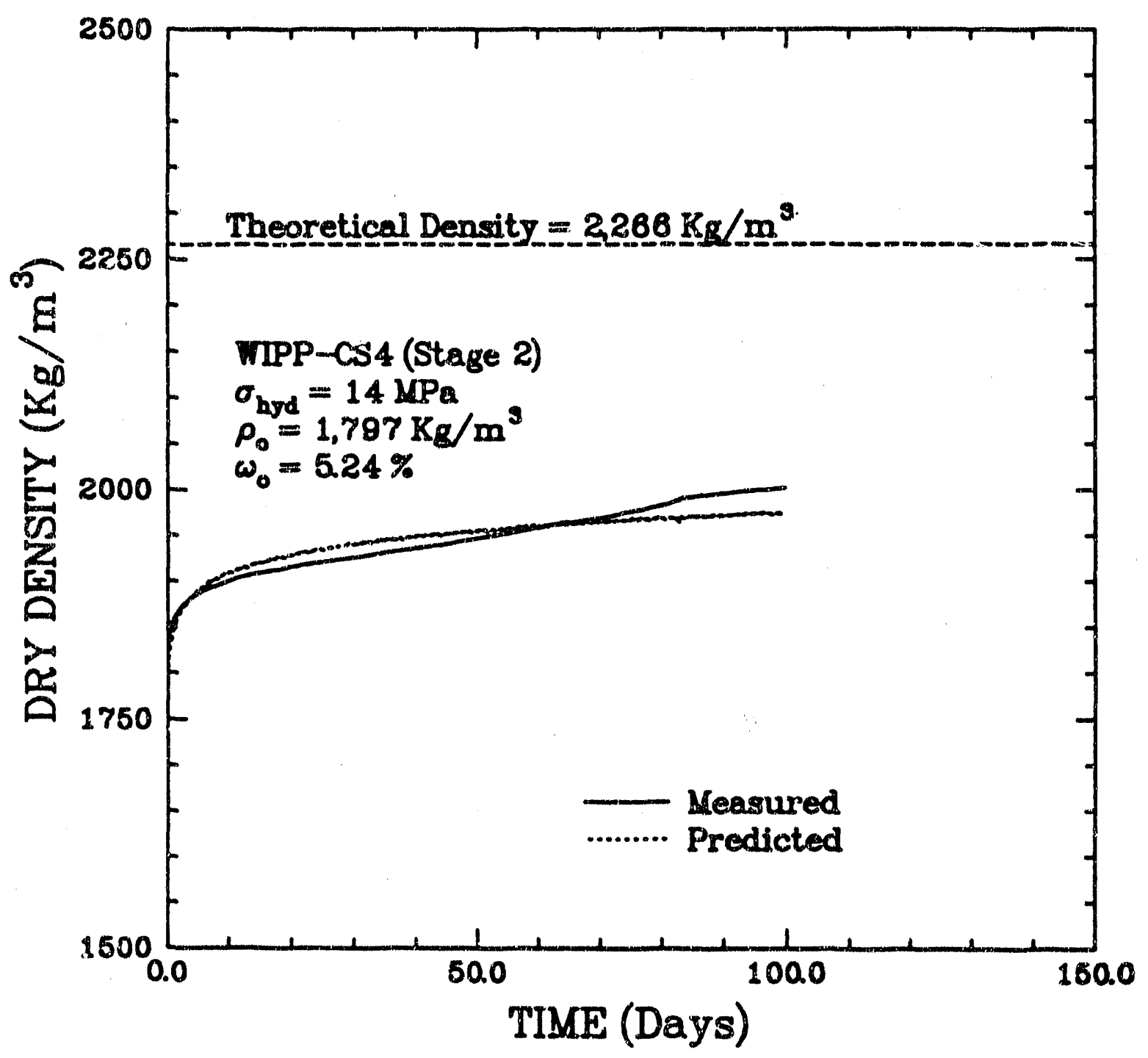

Figure B-6. Measured and Predicted Dry Densities as Functions of Time for CS4 Stage 2. 


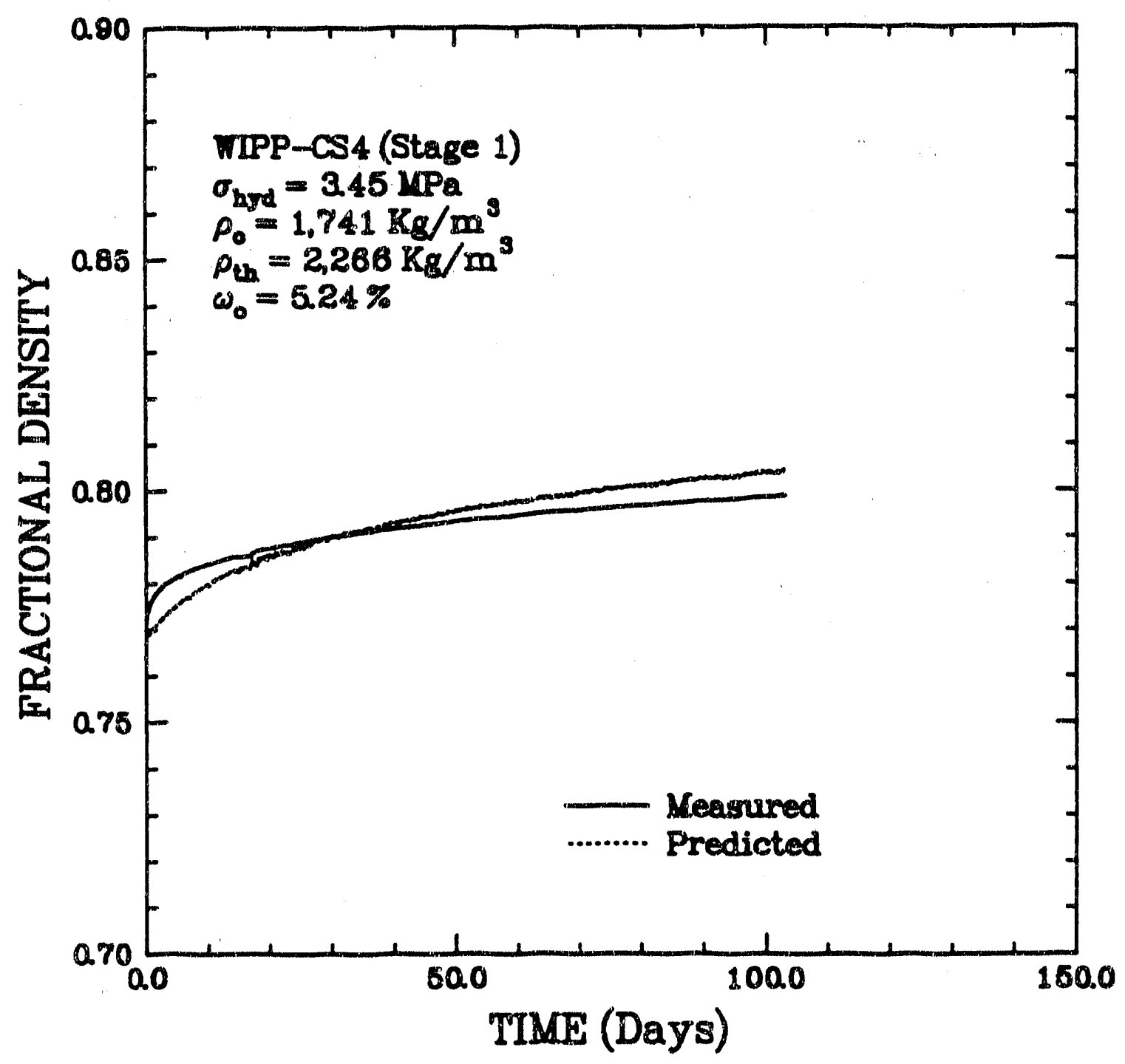

Figure B-7. Measured and Predicted Fractional Densities as Functions of Time for CS4 Stage 1. 


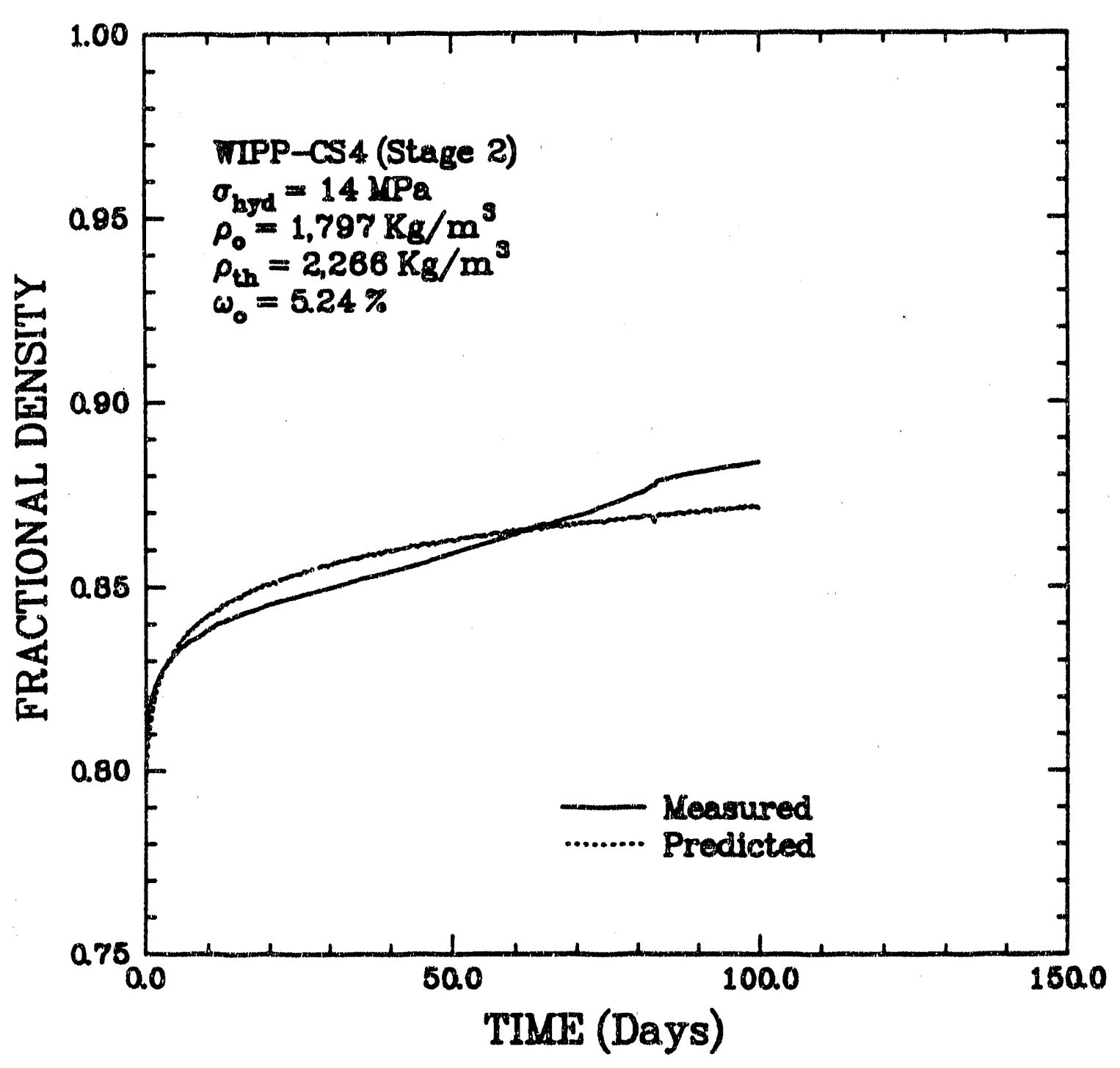

Figure B-8. Measured and Predicted Fractional Densities as Functions of Time for CS4 Stage 2. 


\section{APPENDIX C}

SUPPORTING DATA FOR CS3 


\section{APPENDIX C LIST OF FIGURES}

C-1 Measured and Predicted Volumetric Strains as Functions of Time for CS3 Stage 1. . . . . . . . . . . . . . .

C-2 Measured and Predicted Volumetric Strains as Functions of Time for CS3 Stage 2. . . . . . . . . . . . . . . . . . . . . . 80

C-3 Measured and Predicted Volumetric Strains as Functions of Tirne for CS3 Stage 3. . . . . . . . . . . . . . . . . . . . 81

C-4 Volumetric Strain as a Function of Log Time for CS3 Stage 1. . . . 82

C-5 Volumetric Strain as a Function of Log Time for CS3 Stage 2. . . . 83

C-6 Volumetric Strain as a Function of Log Time for CS3 Stage 3. . . . 84

C-7 Measured and Predicted Dry Densities as Functions of Time for CS3 Stage 1. . . . . . . . . . . . . . . . . . 85

C-8 Measured and Predicted Dry Densities as Functions of Time for CS3 Stage 2. . . . . . . . . . . . . . . . 86

C-9 Measured and Predicted Dry Densities as Functions of Time for CS3 Stage 3. . . . . . . . . . . . . . . . . . . . 87

C-10 Measured and Predicted Fractional Densities as Functions of Time for CS3 Stage 1. . . . . . . . . . . . . . . . . . . . 88

C-11 Measured and Predicted Fractional Densities as Functions of Time for CS3 Stage 2. . . . . . . . . . . . . . . . . . .

C-12 Measured and Predicted Fractional Densities as Functions of Time for CS3 Stage 3. . . . . . . . . . . . . . . . . . . . 


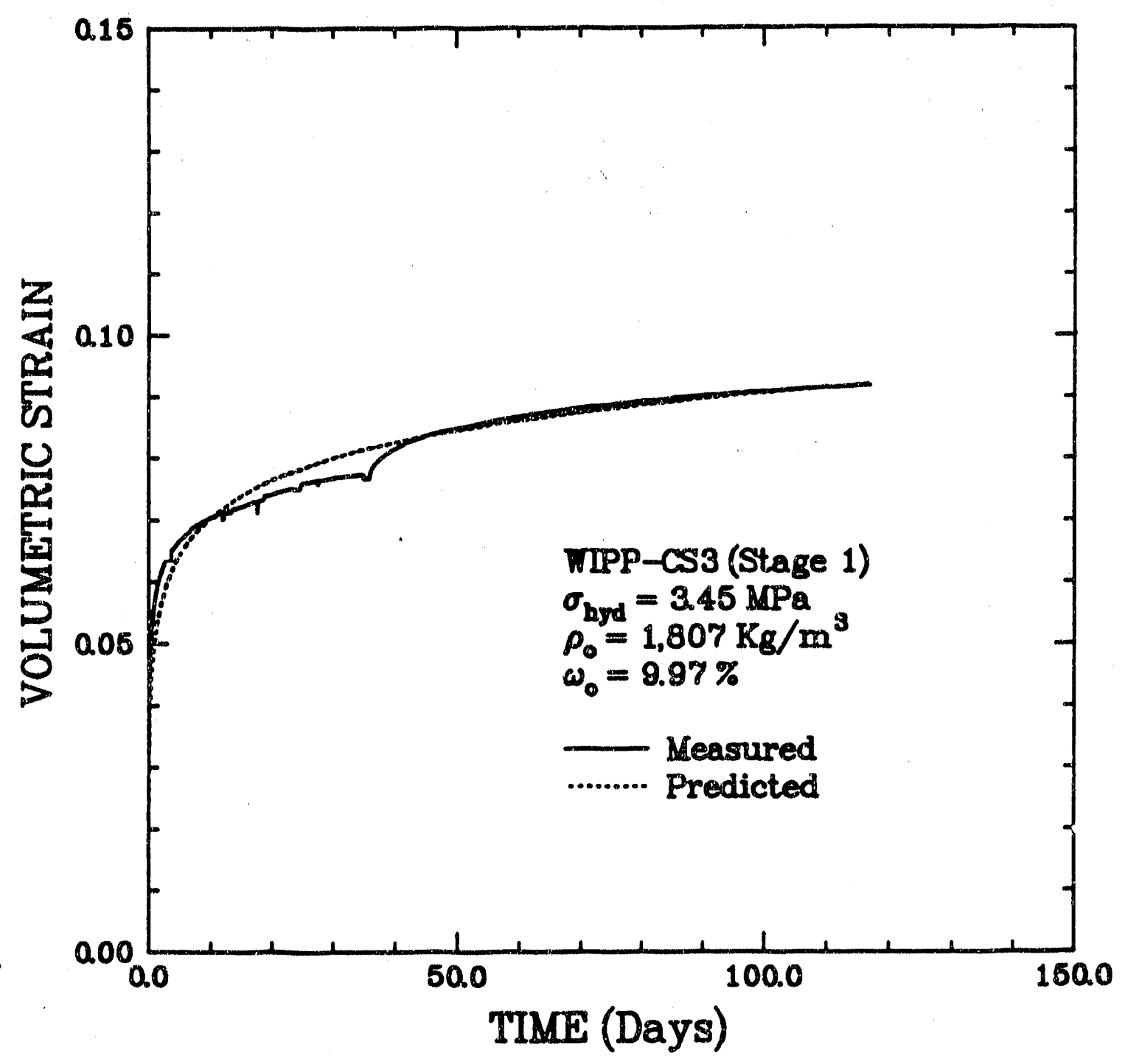

Figure C-1. Measured and Predicted Volumetric Strains as Functions of Time for CS3 Stage 1. 


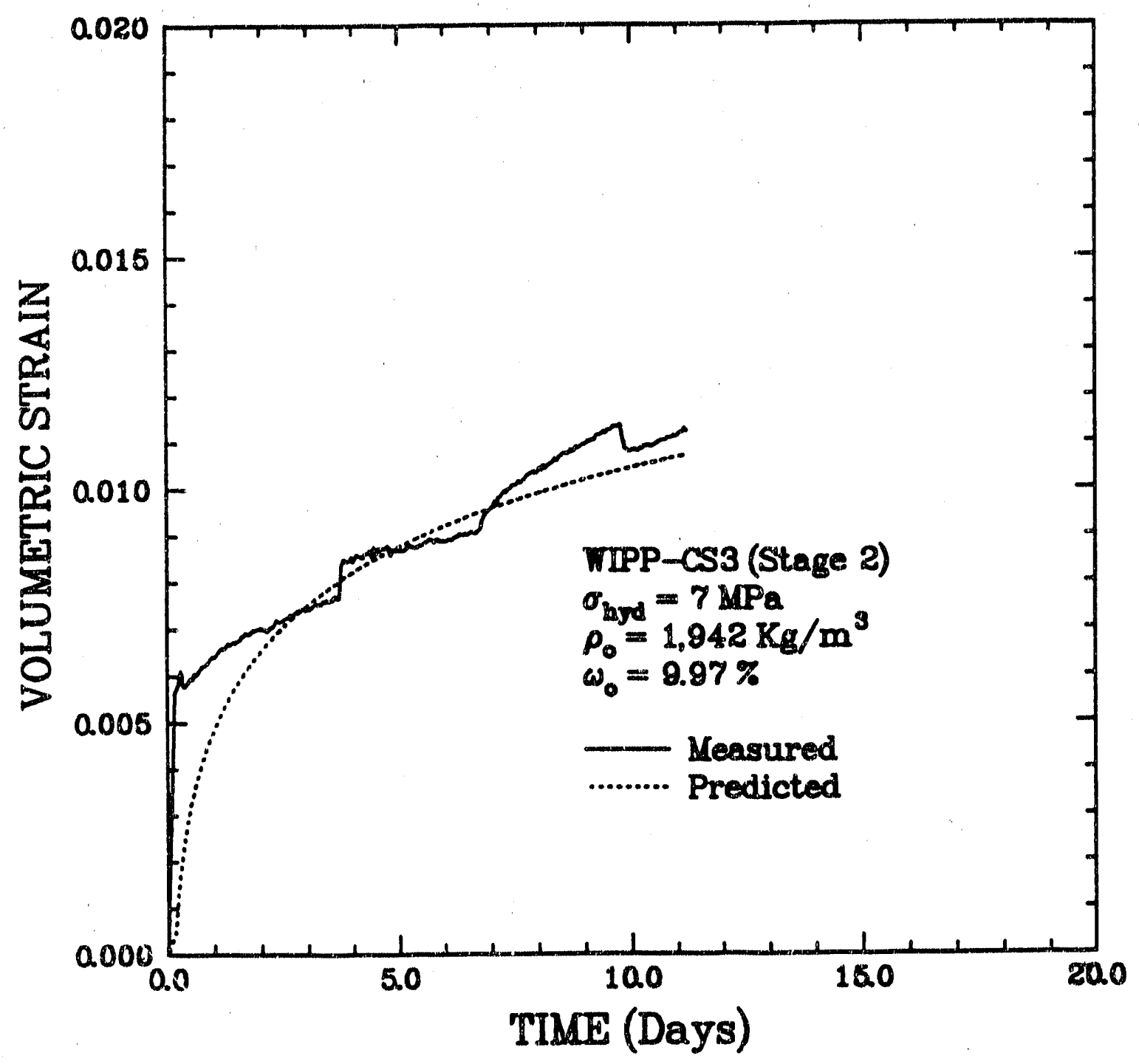

Figure C-2. Measured and Predicted Volumetric Strains as Functions of Time for CS3 Stage 2. 


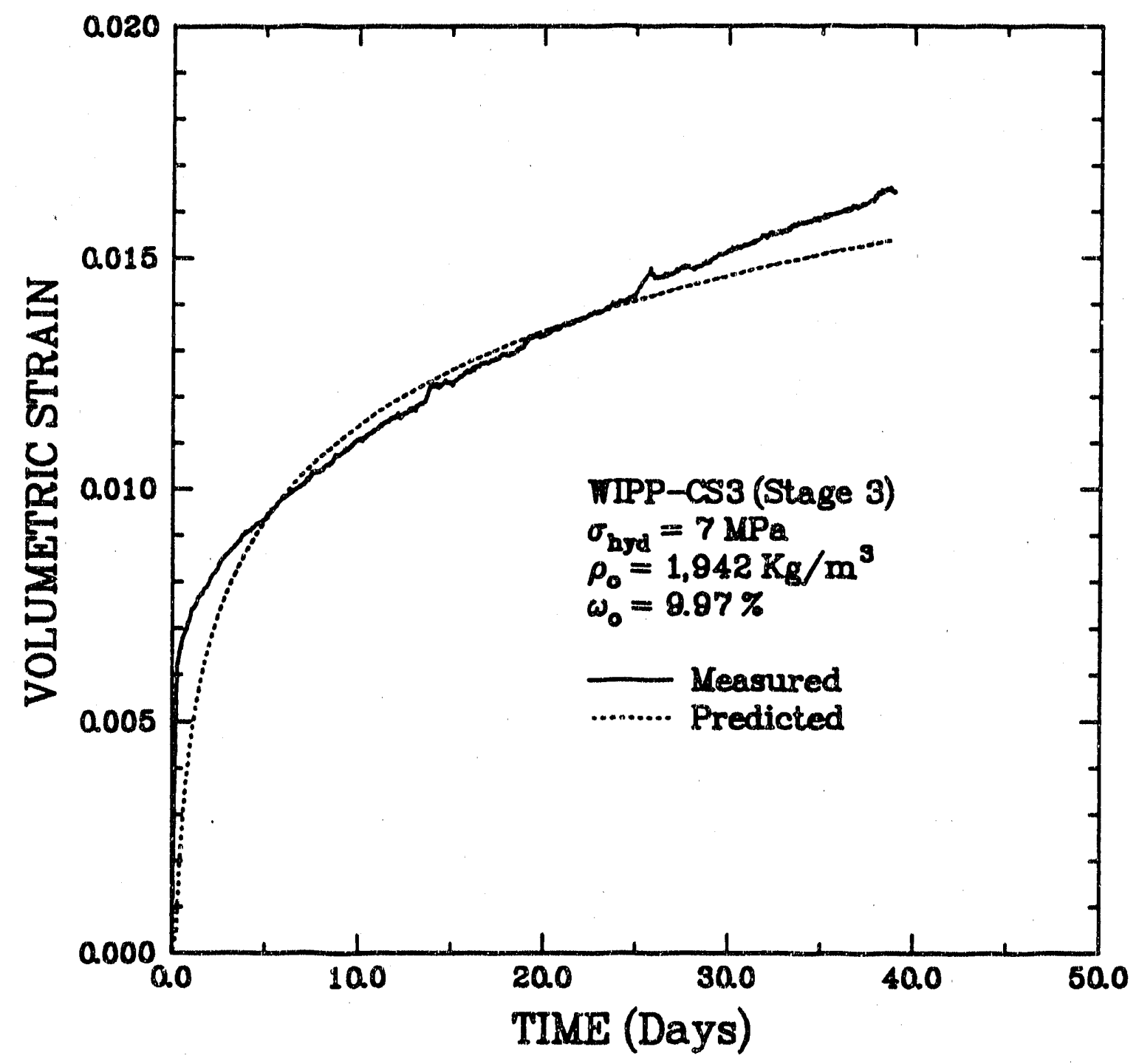

Figure C-3. Measured and Predicted Volumetric Strains as Functions of Time for CS3 Stage 3. 


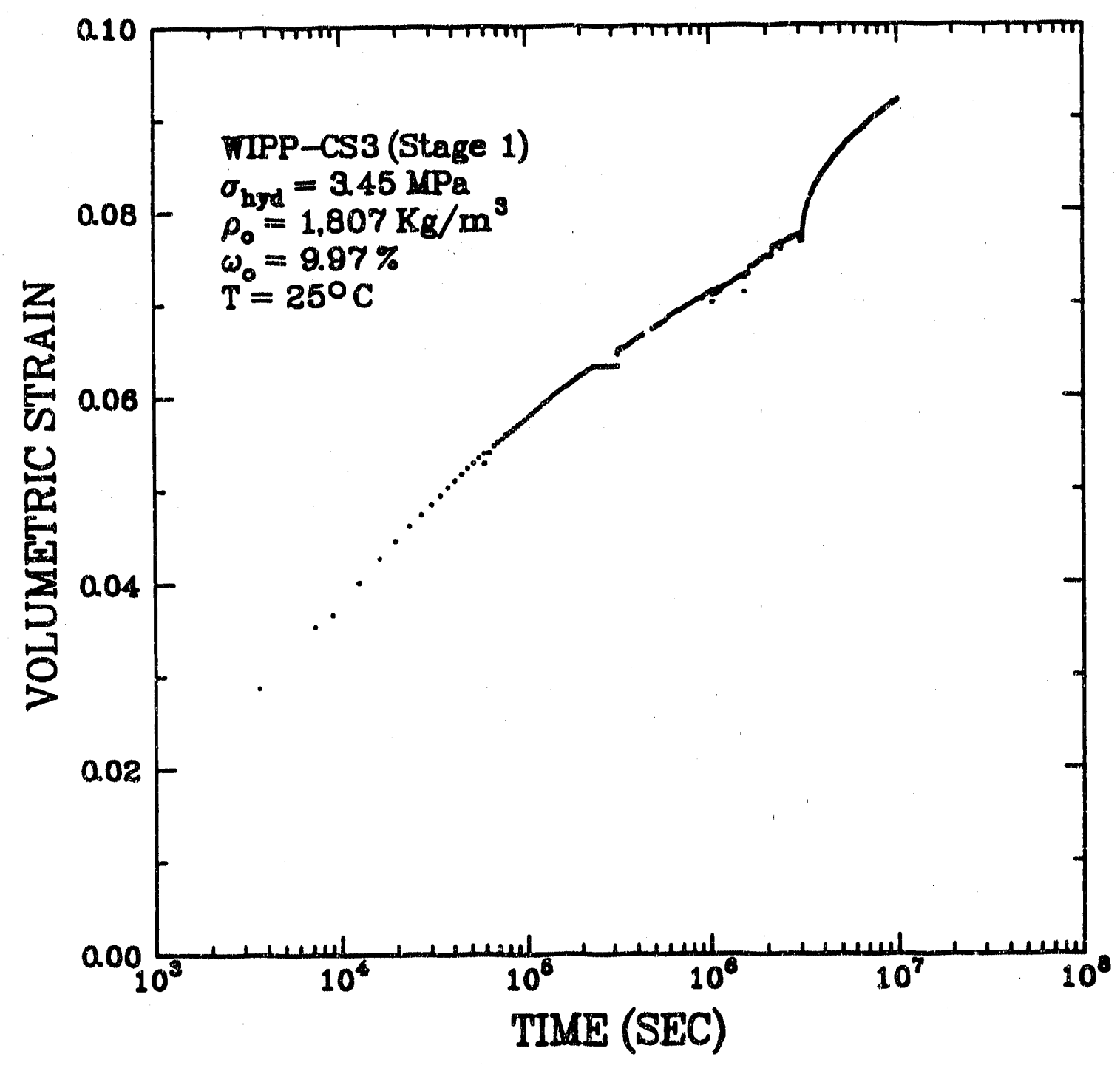

Figure C-4. Volumetric Strain as a Function of Log Time for CS3 Stage 1. 


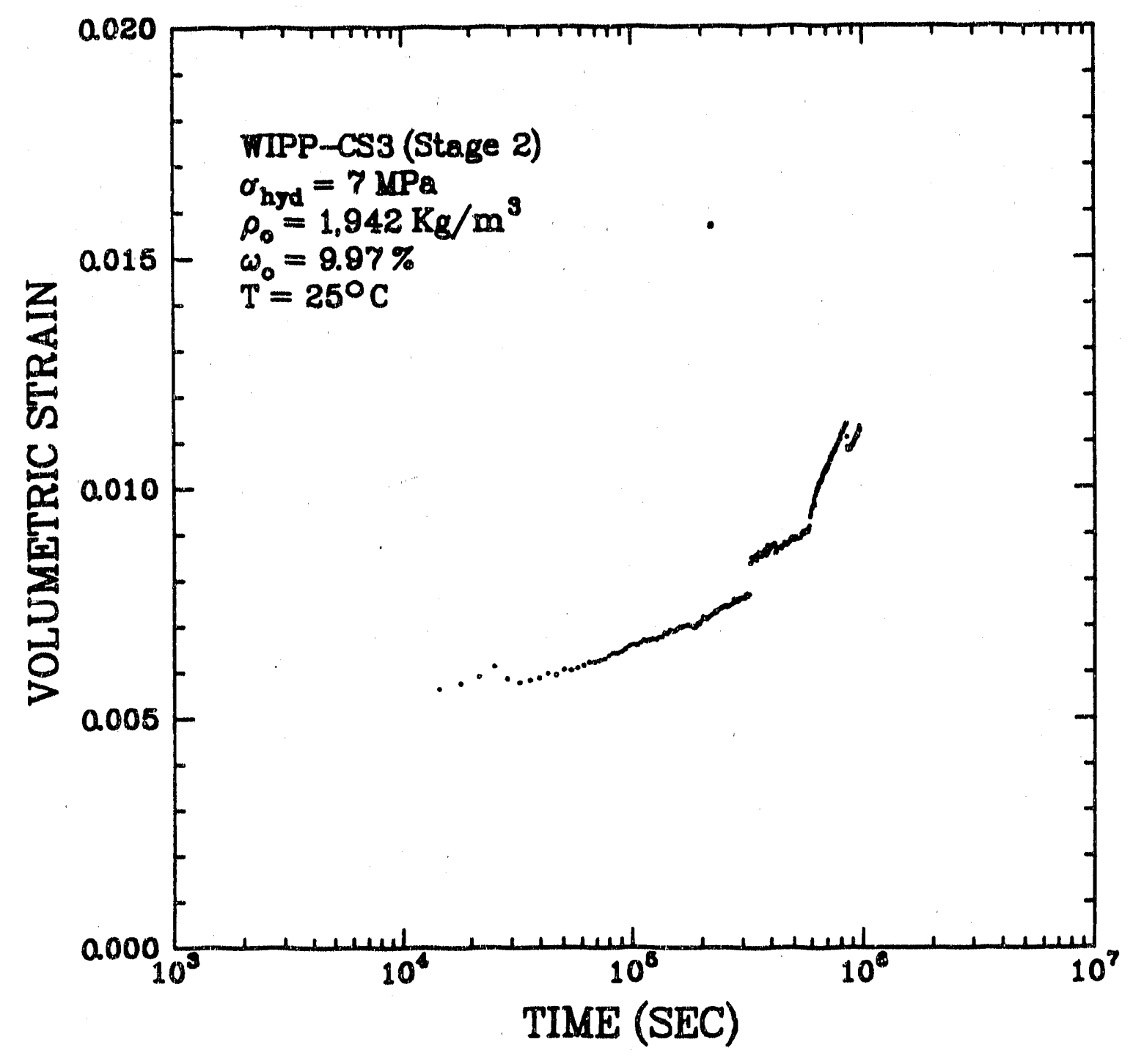

Figure C-5. Volumetric Strain as a Function of Log Time for CS3 Stage 2. 


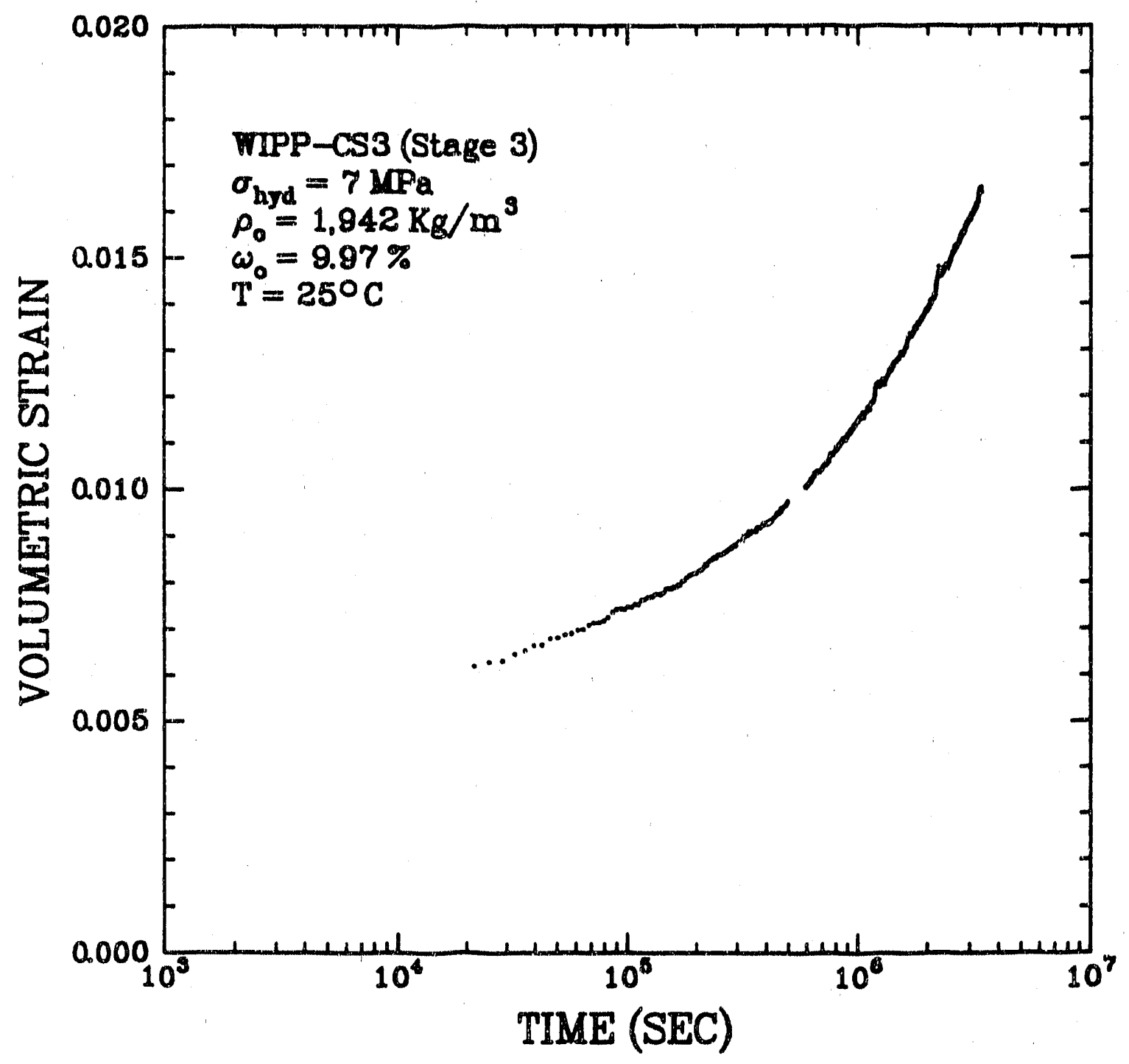

Figure C-6. Volumetric Strain as a Function of Log Time for CS3 Stage 3. 


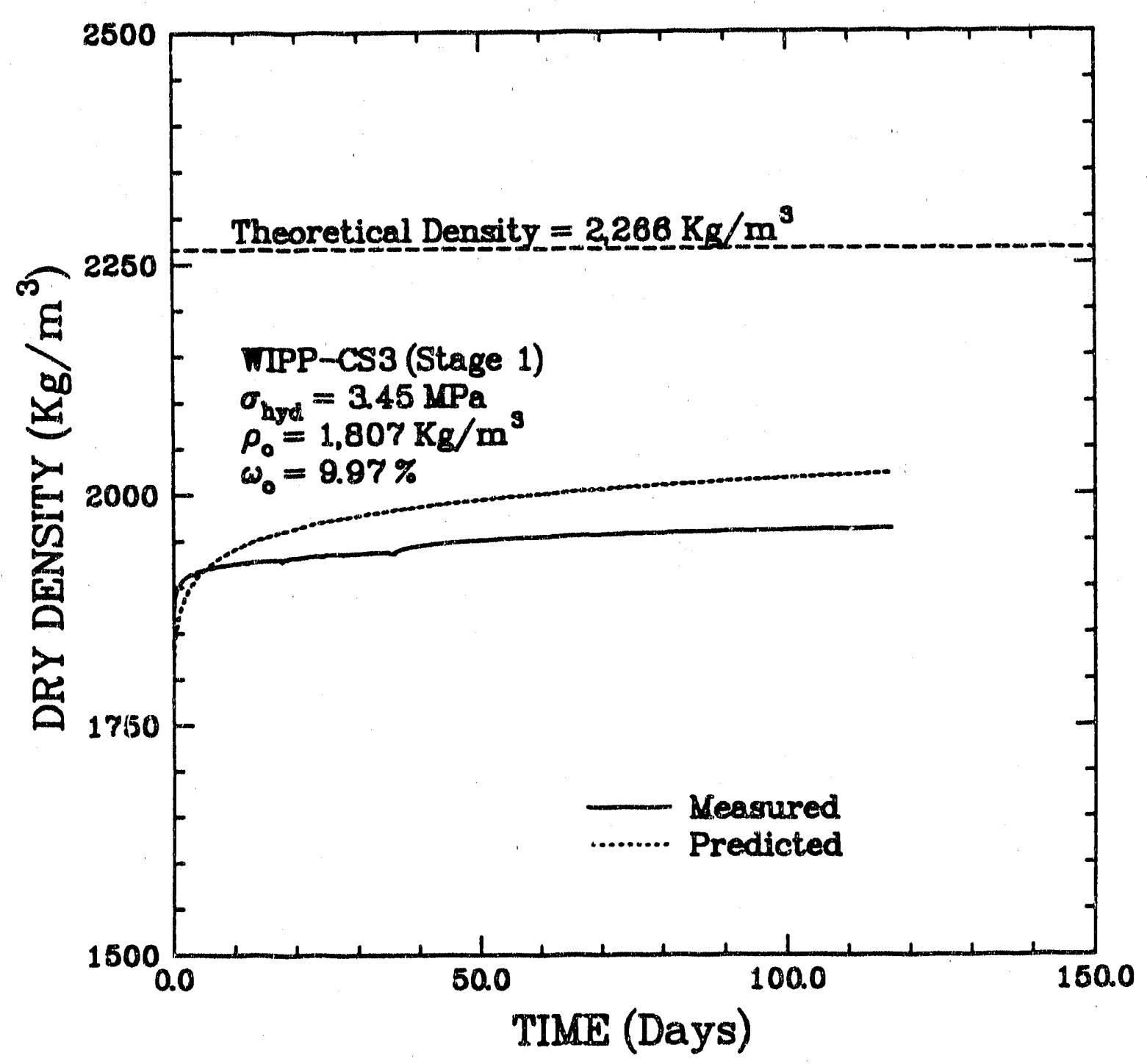

Figure C-7. Measured and Predicted Dry Densities as Functions of Time for CS3 Stage 1. 


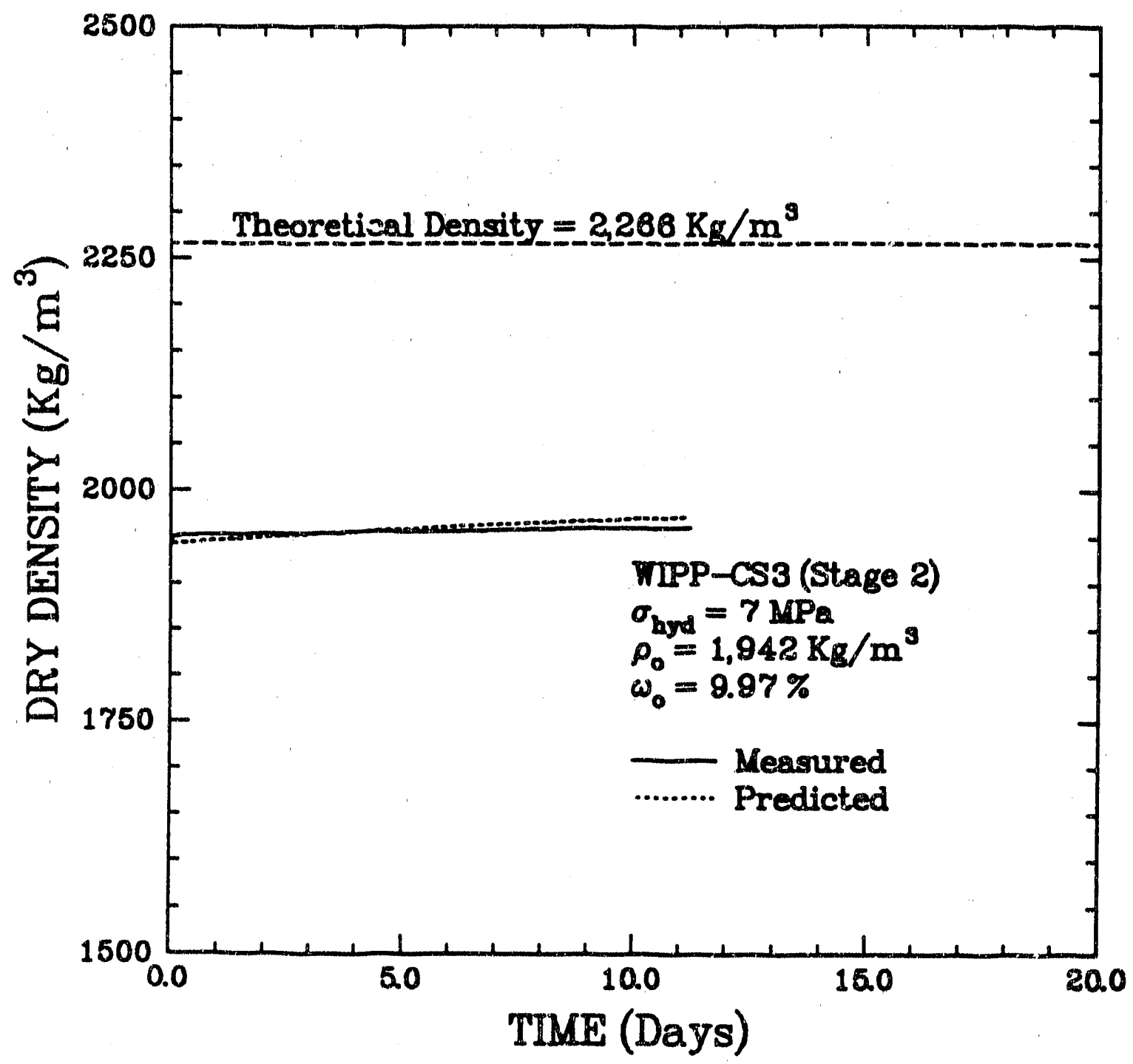

Figure C-8. Measured and Predicted Dry Densities as Functions of Time for CS3 Stage 2. 


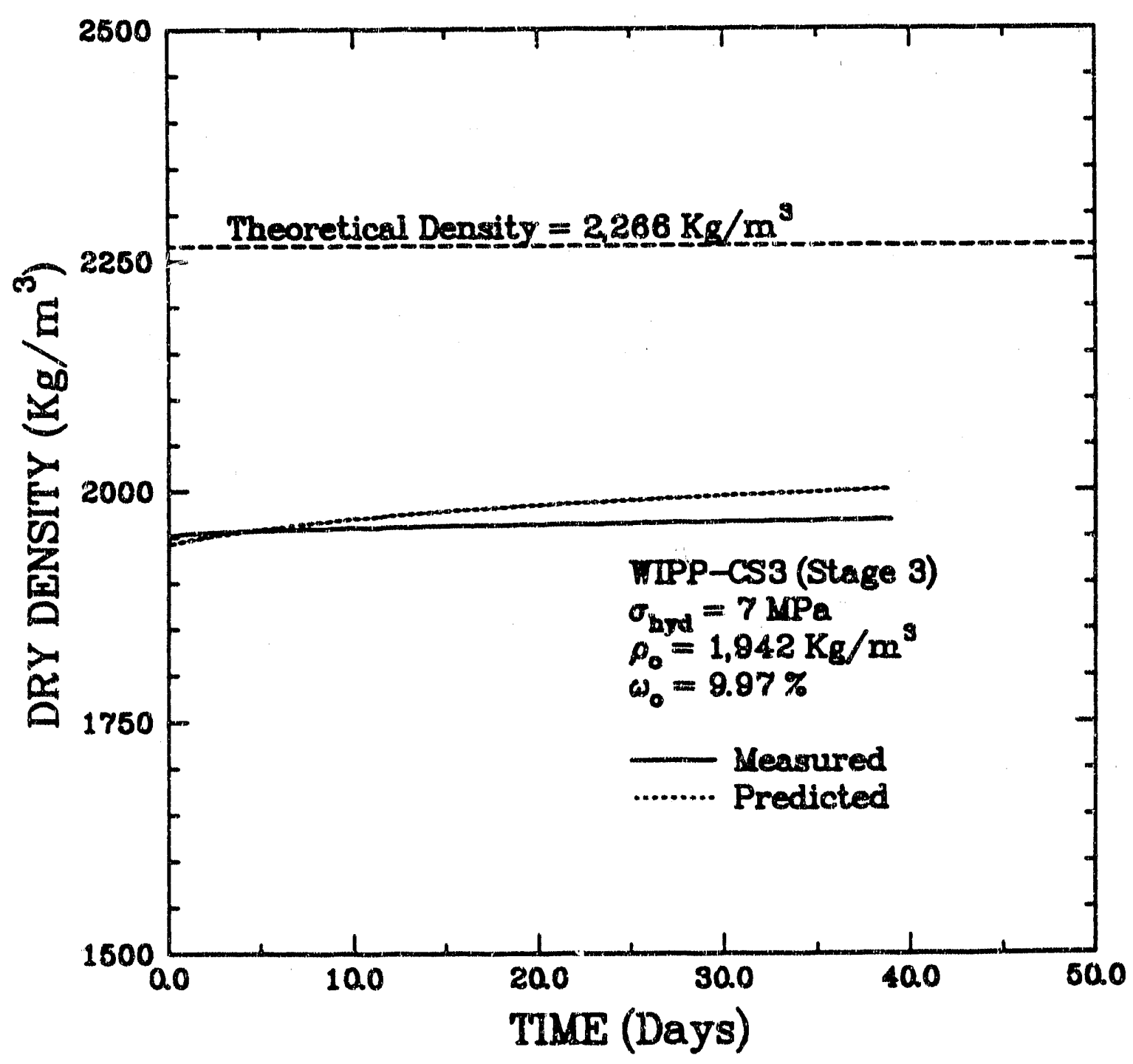

Figure C-9. Measured and Predicted Dry Densities as Functions of Time for CS3 Stage 3. 


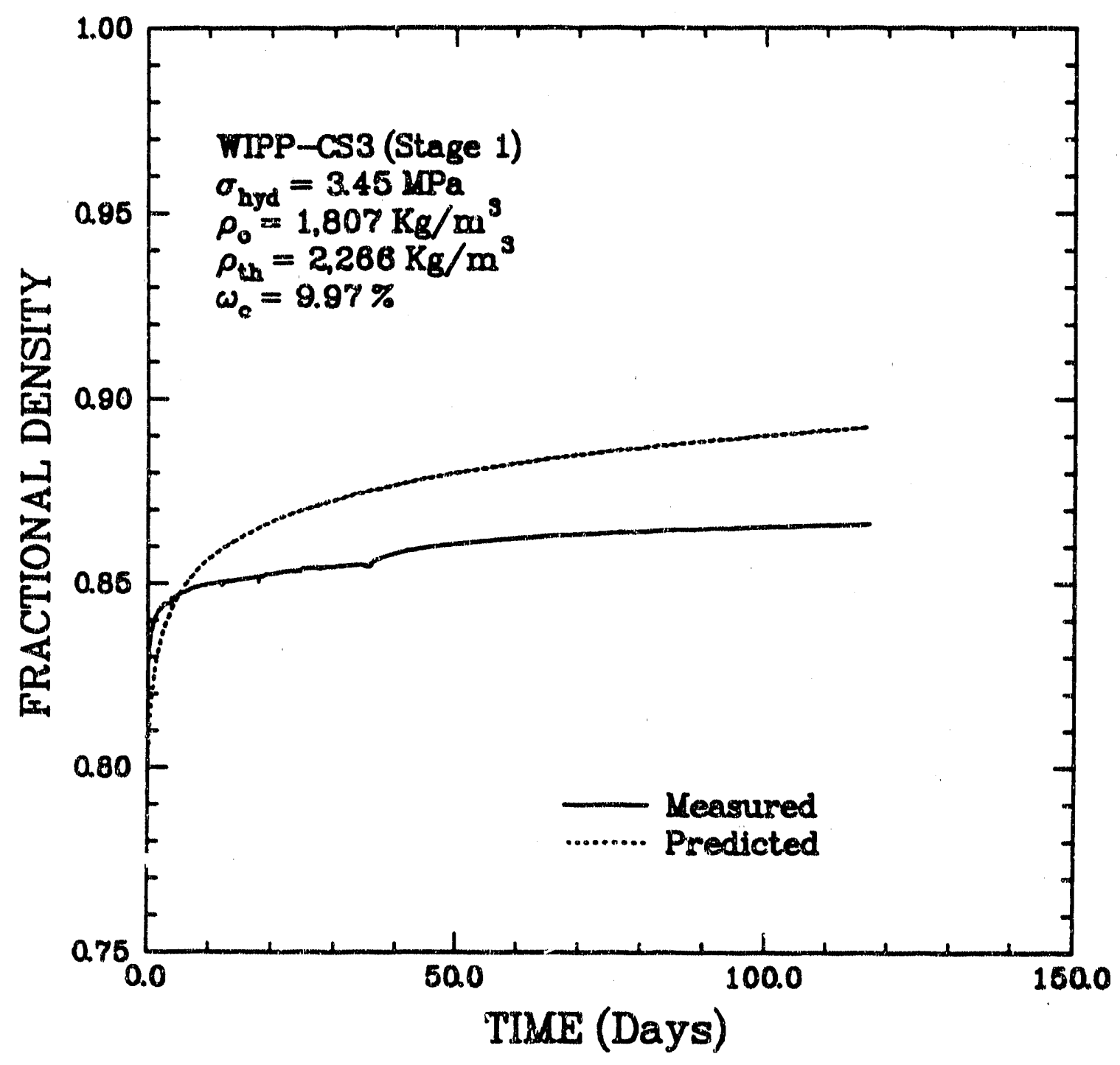

Figure C-10. Measured and Predicted Fractional Densities as Functions of Time for CSJ Stã̃e 1. 


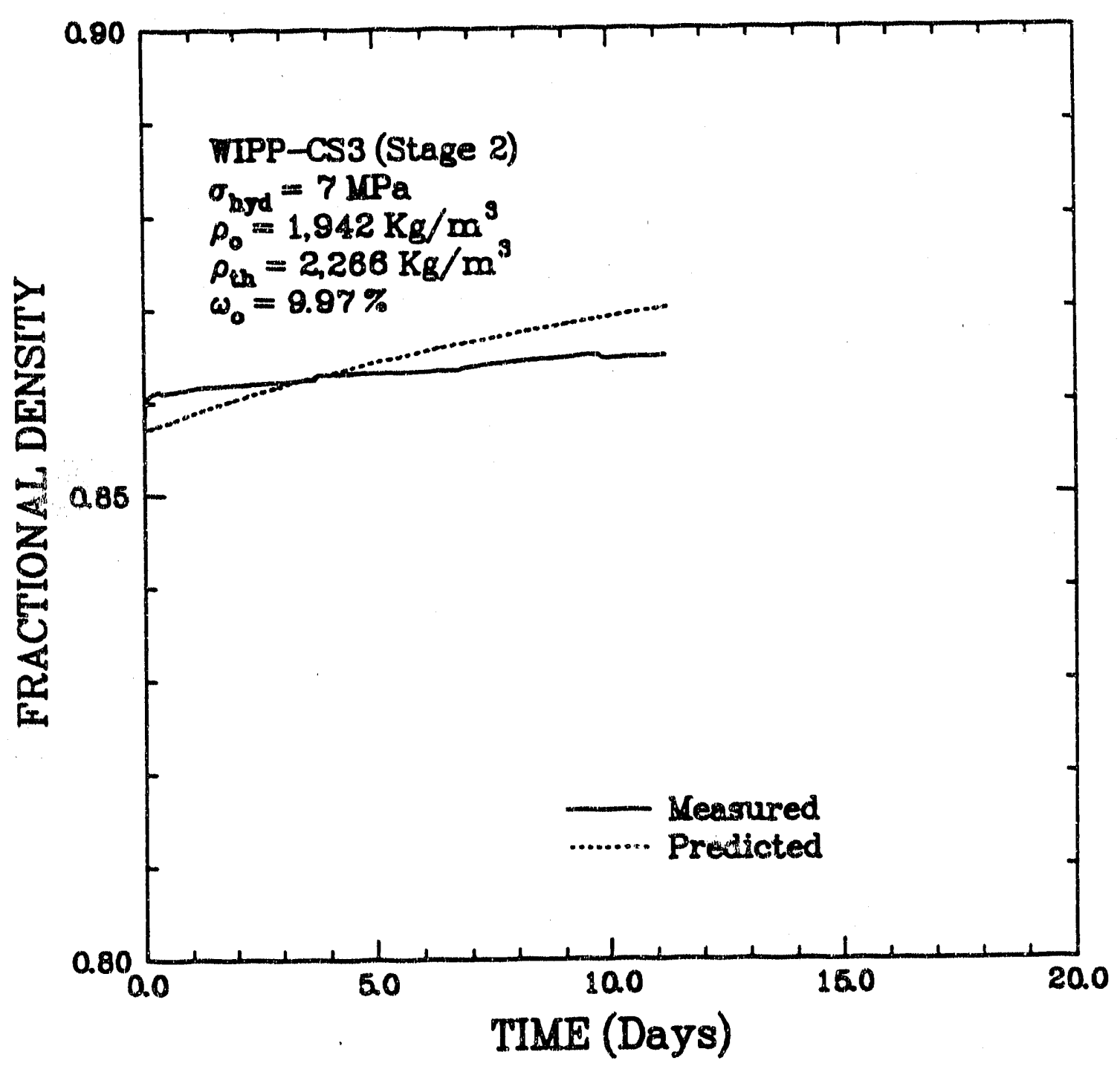

Figure C-11. Measured and Predicted Fractional Densities as Functions of Time for CS3 Stage 2. 


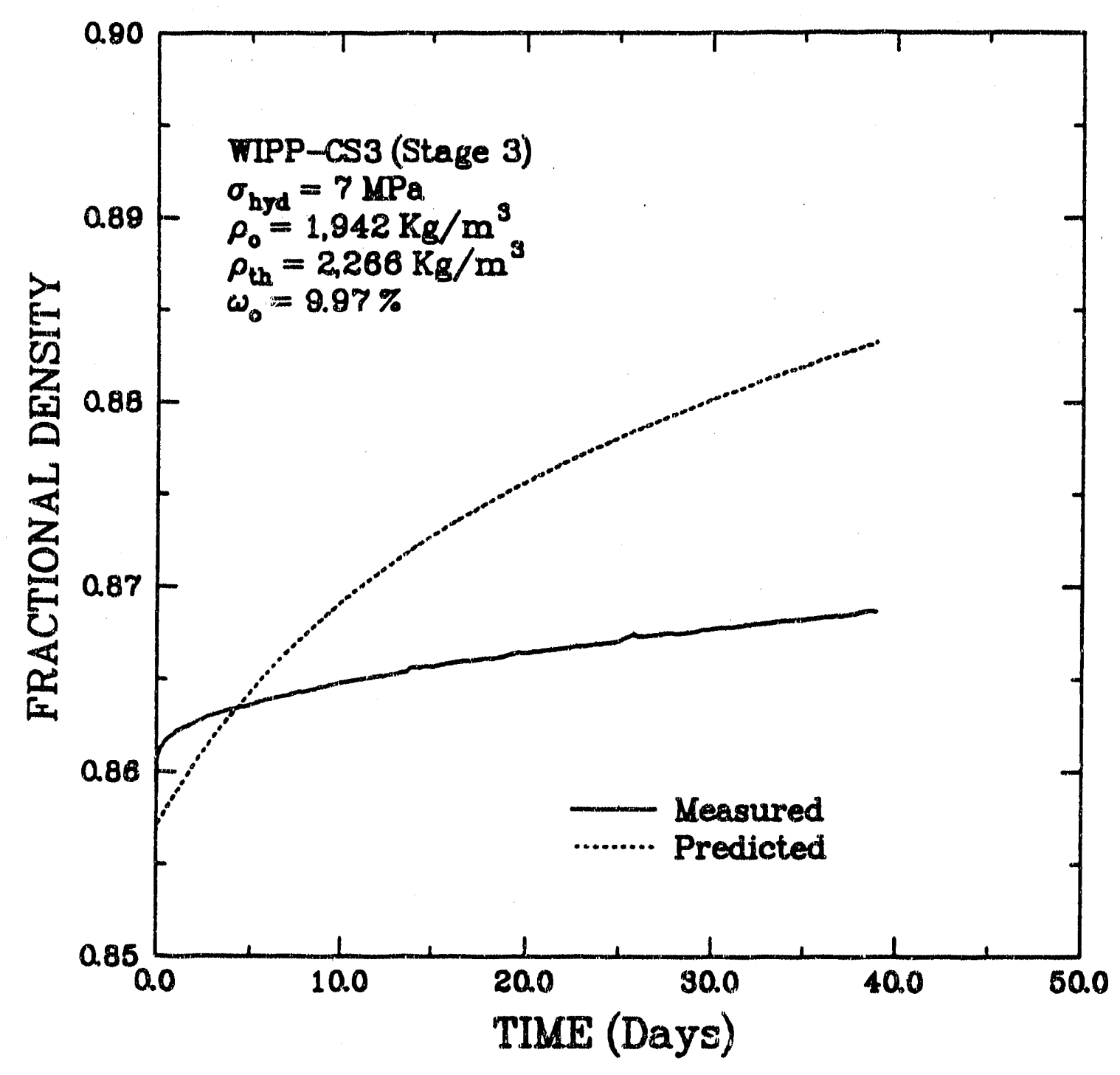

Figure C-12. Measured and Predicted Fractional Densities as Functions of Time for CS.3 Stage 3. 

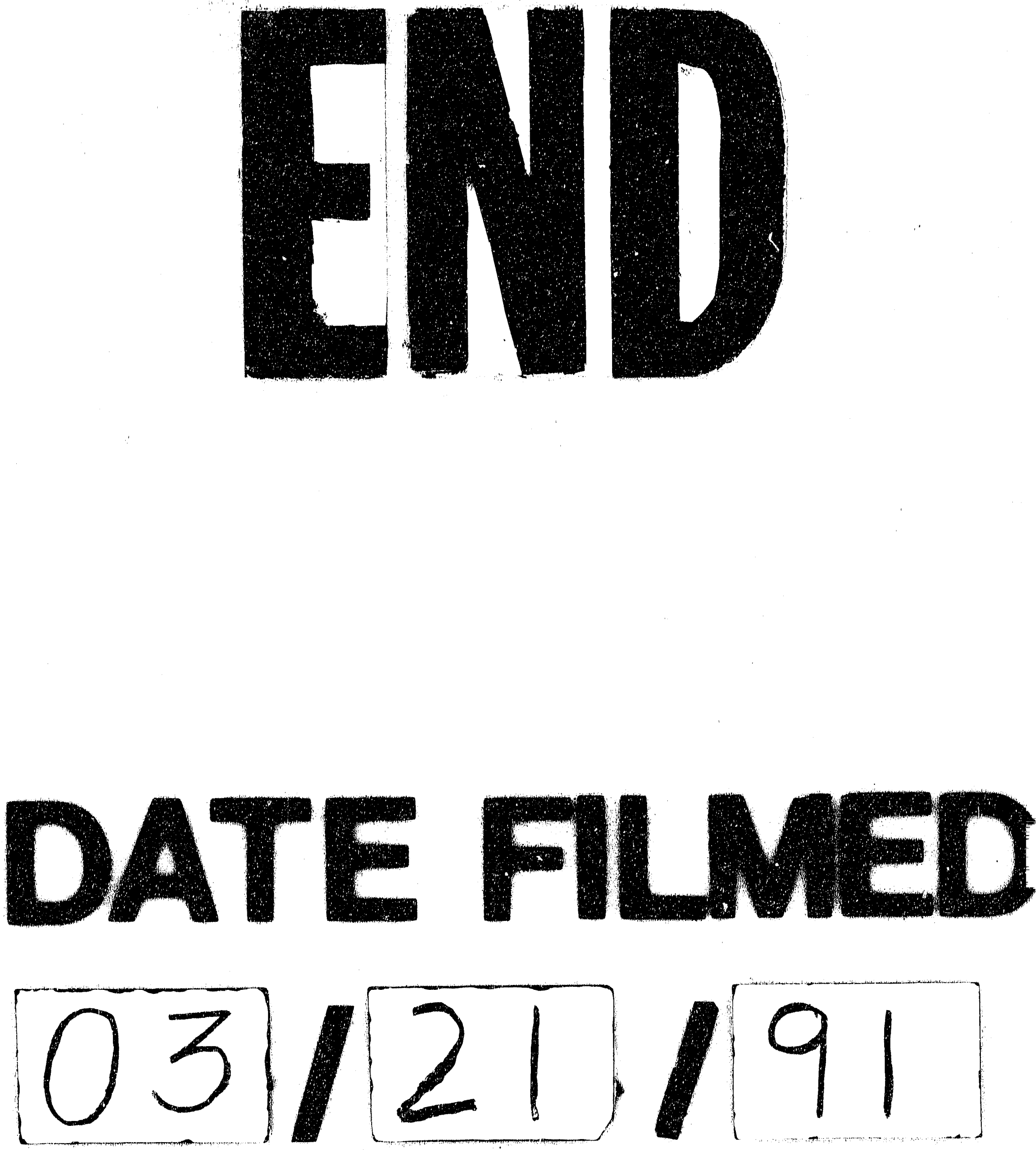


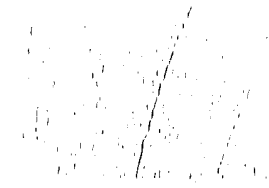

